
$\frac{2+10 / 3^{\prime}}{32} \quad I-2246$

\title{
Automobile Materials Competition: Energy Implications of Fiber-Reinforced Plastics
}

J. Cummings-Saxton

\section{Do wot Moromiln COVER}

\section{ARGONNE NATIONAL LABORATORY}




\section{DISCLAIMER}

This report was prepared as an account of work sponsored by an agency of the United States Government. Neither the United States Government nor any agency Thereof, nor any of their employees, makes any warranty, express or implied, or assumes any legal liability or responsibility for the accuracy, completeness, or usefulness of any information, apparatus, product, or process disclosed, or represents that its use would not infringe privately owned rights. Reference herein to any specific commercial product, process, or service by trade name, trademark, manufacturer, or otherwise does not necessarily constitute or imply its endorsement, recommendation, or favoring by the United States Government or any agency thereof. The views and opinions of authors expressed herein do not necessarily state or reflect those of the United States Government or any agency thereof. 


\section{DISCLAIMER}

Portions of this document may be illegible in electronic image products. Images are produced from the best available original document. 
The facilities of Argonne National Laboratory are owned by the United States Government. Under the terms of a contract (W-31-109-Eng-38) among the U. S. Department of Energy, Argonne Universities Association and The University of Chicago, the University employs the staff and operates the Laboratory in accordance with policies and programs formulated, approved and reviewed by the Association.

\section{MEMBERS OF ARGONNE UNIVERSITIES ASSOCIATION}

The University of Arizona

Carnegie-Mellon University

Case Western Reserve University

The University of Chicago

University of Cincinnati

Illinois Institute of Technology

University of Illinois

Indiana University

The University of Iowa

Iowa State University
The University of Kansas

Kansas State University

Loyola University of Chicago

Marquette University

The University of Michigan

Michigan State University

University of Minnesota

University of Missouri

Northwestern University

University of Notre Dame
The Ohio State University

Ohio University

The Pennsylvania State University

Purdue University

Saint Louis University

Southern Illinois University

The University of Texas at Austin

Washington University

Wayne State University

The University of Wisconsin-Madison

NOTICE

This report was prepared as an account of work sponsored by an agency of the United States Government. Neither the United States Government nor any agency thereof, nor any of their employees, makes any warranty, express or implied, or assumes any legal liability or responsibility for the accuracy, completeness, or usefulness of any information, apparatus, product, or process disclosed, or represents that its use would not infringe privately owned rights. Reference herein to any specific commercial product, process, or service by trade name, trademark, manufacturer, or otherwise, does not necessarily constitute or imply its endorsement, recommendation, or favoring by the United States Government or any agency thereof. The views and opinions of authors expressed herein do not necessarily state or reflect those of the United States Government or any agency thereof.

Printed in the United States of America

Available from

National Technical Information Service

U. S. Department of Commerce

5285 Port Royal Road

Springfield, VA 22161

NTIS price codes

Printed copy: A05

Microfiche copy: A01 
ANL/CNSV- -25

Distribution Category:

Energy Conservation - . Industry (UC-95f)

DE82 009488

\author{
ANL/CNSV-25 \\ ARGONNE NATIONAL LABORATORY \\ 9700 South Cass Avenue \\ Argonne, Illinois 60439
}

\begin{abstract}
AUTOMOBILE MATERIALS COMPETITION:
ENERGY IMPLICATIONS OF FIBER-REINFORCED PLASTICS

by

\author{
$J$. Cummings-Saxton \\ Energy and Environmental Systems Division \\ Special Projects Group
}

October 1981

work sponsored by
U.S. DEPARTMENT OF ENERGY

Assistant Secretary for Conservation and Renewable. Energy

Office of Industrial Programs

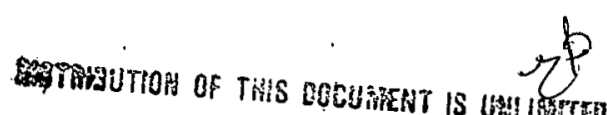


THIS PAGE

\section{WAS INTENTIONALLY \\ LEFT BLANK}


CONVERSION TO INTERNATIONAL (SI) UNITS. . . . . . . . . . . . . . vi vi

ACRONYMS .

viii

ABSTRACT .

EXECUTIVE SUMMARY

1 INTRODUCTION . . . . . . . . . . . . . . . . . . . 10

2 FIBER-REINFORCED PLASTIC SYSTEMS . . . . . . . . . . . . . . . 12

2.1 Plastic Resins. . . . . . . . . . . . . . . . . 13

2.1.1 Thermosetting Resins... . . . . . . . . . . . . . 13

2.1.2 Thermoplastic Resins................... 17

2.2 Reinforcement . . . . . . . . . . . . . . . . 18

2.3 Fillers......................... 23

2.4 Molding Compounds . . . . . . . . . . . . . . . . 25

2.5 Molding Processes .................... 28

3 ENERGY REQUIREMENTS. . . . . . . . . . . . . . . . . . . . 31

3.1 Plastic Resins... . . . . . . . . . . . . . . . 31

3.1.1 Chemical Process Sequences .. . . . . . . . . . . . . 31

3.1.2 Sequence Energy Computations . . . . . . . . . . . . 34

3.2 Reinforcements. . . . . . . . . . . . . . . . . 46

3.2.1 Glass Fibers...................... 46

3.2 .2 Graphite Fibers. . . . .............. 47

3.3 Fillers....................... 48

3.4 Fiber-Reinforced Plastic Products . . . . . . . . . . 48

4 AUTOMOBILE MATERTALS COMPETITION AMONG FIBER-REINFORCED PLASTICS,

STEEL, AND ALUMINUM. . . . . . . . . . . . . . . . . . . 50

4.1 Background. . .................... . . . 50

4.1 .1 Steel. .................... 52

4.1:2 Fiber-Reinforced Plastics. . . . . . . . . . 53

4.1.3 Aluminum .................. 54

4.2 Weight Reduction. . . . . . . . . . . . . . . . . . 55

4.3 Embodied Energy . . . . . . . . . . . . . . . . . . . 59

4.3.1 Fiber-Reinforced Plastics. . . . . . . . . . . . 59

4.3.2 Steel..................... 59

4.3.3 Aluminum.................... 61

4.4 Dependence of Fuel Savings on Vehicle Weight. . . . . . . . . 63.

4.5 Energy Implications of Materials Substitution . . . . . . . . . 65

4.6 Energy Resource Consumption . . . . . . . . . . . . . . . . . 67 
CONTENTS (Cont'd)

5 CONCLUSION . . . . . . . . . . . . . . . . . . . . . . . . 72

5.1 General Findings. . . . . . . . . . . . . . . . . . 72

5.2 Research and Development Needs. . . . . . . . . . . . 73

REFERENCES . . . . . . . . . . . . . . . . . . . . . . . . 77

\section{FIGURES}

2.1 Steps in the Production of Unsaturated Polyester Resin Products. . . 16

2.2 Tensile Stress-strain Curve. . . . . . . . . . . . . . . . 19

2.3 Flber-Keintorced Plastic Composite Tensile Strength as a .' Function of Fiberglass Quantity and Orientation. . . . . . . . . . 21

2.4 Whisker Tensile Strength as a Function of Diameter . . . . . . . . . 24

2.5 Tensile Strength of Whiskers and Carbon, Aramid, and Glass

Fibers . . . . . . . . . . . . . . . . . . . . . . . 25

2.6 Flexural Strength of Polypropylene as a Function of Total.

2.7 Sheet Molding Compound Process . . . . . . . . . . . . . . . 28

2.8 Compression and Injection Molding, the Two Most Important Automobile Molding Processes . . . . . . . . . . . . . . . 29

3.1 Chemical Process Sequences . . . . . . . . . . . . . . . 32

3.2 Interrelationships among Market-Competitive Plastic Resins . . . . . 33

3.3 Configuration and Parameters of a Generic Process Sequence . . . . . 34

3.4 Unsaturated Polyester Resin Process Sequence . . . . . . . . . . . . 37

3.5 Fiberglass Process Sequence. . . . . . . . . . . . . . . . . . 47

4.1 Materials Usage as a Function of Price . . . . . . . . . . . . . . . 50

4.2 Trend in Average Automobile Weight . . . . . . . . . . . . . . . . 52

4.3 Process Sequence for Cold-Rolled/Low-Carbon Steel Sheet. . . . . . 60

4.4 Aluminum Sheet Process Sequence. . . . . . . . . . . . . . . . . 62

4.5 Material Flows in Aluminum Sheet Manufacture . . . . . . . . . . . 64

\section{TABLES}

1.1 Automotive Materials Composition for Selected Car Model Years. . . . 11

2.1 Shipments of Fiber-Reinforced Plastics by Market . . . . . . . . . . 12

2.2 Total U.S. Plastics Production and Captive Use by Material, 1975-1980!. . . . . . . . . . . . . . . . . . . 14 
2.3 Relationship between Fiberglass Orientation, Form, and

Fabricating Process . . . . . . ............. 22

2.4 Component Weight Savings in the Ford Motor Company Lightweight

Vehicle Program . . . . . . . . . . . . . . . . . . . 23

2.5 Filler Consumption. . . . . . . . . . . . . . . . . . . 26

3.1 Utilities and Materials Participating in Plastics Manufacture . .. 38

3.2 Processes Participating in Plastics Manufacture . . . . . . . . . . 39

3.3 Input Coefficients and Process Energies for Selected Plastic

3.4 Process Splits. . . . . . . . . . . . . . . . . . . 43

3.5 Plastic Resin Sequence Energies . . . . . . . . . . . . . . . 46

3.6 Energy Requirements for Fiber-Reinforced Plastics . . . . . . . . 49

4.1 Adjustments in U.S. Automobile Materials Usage Motivated by

Efforts to Improve Fuel Economy . . . . . . . . . . . . . . . 51

4.2 Comparative Mechanical Properties . . . . . . . . . . . . . . 56

4.3 Weight Comparisons for Alternative Materials by Component Shape . . . . . . . . . . . . . . . . . . . . . . 57

4.4 Representative Weight Savings.................. . 58

4.5 Cold-Rolled/Low-Carbon Steel Sheet Production Processes . . . . . . 61

4.6. Energy Consumption in Cold-Rolied/Low-Carbon Steel Sheet. Manufacture, 1975 . . . . . . . . . . . . . . . . . . . . 62

4.7 Aluminum Sheet Production Processes . . . . . . . . . . . . . . . 63

4.8 Energy Consumption in Aluminum Sheet Manufacture, 1980. . . . . . . 64

4:9 Embodied Energies of Steel, Fiber-Reinforced Plastics, and Aluminum Sheet. . . . ... . . . . . . . . . . . . . 65

4.10 Energy Reduction Potential of Fiber-Keinforced Plastics and

4.11 Fuel Participation by Industry, 1978. . . . . . . . . . . . . . 68

4.12 Fuel Participation in Embodied Energy of Steel, FiberReinforced Plastics, and Aluminum Components. . . . . . . . . 69

4.13 Life Cycle Fuels Participation in Structurally Equivalent Steel, Fiber-Reinforced.Plastics, and Aluminum Automobile Components. , . . . . . . . , . . . . . . . . . .

5.1 Energy Requirements of Structurally Equivalent Automotive Body Panels, Including Associated Secondary Weights. . . . . . . . . .

5.2 Summary of Fuel Requirements of Steel, Fiber-Reinforced Plastics, and Aluminum Components ... . . . . . . . . . .. . .

5.3 Objectives for Fiber-Reinforced Plastics'Research and Development .......................... 
CONVERSION TO INTERNATIONAL（SI） UNITS

\begin{tabular}{lll}
\hline \multicolumn{1}{c}{ Multiply } & \multicolumn{1}{c}{ By } & To Obtain \\
\hline Btu & $1.055 \times 10^{3}$ & $\mathrm{~J}$ \\
$\mathrm{Btu} / 1 \mathrm{~b}$ & $2.33 \times 10^{3}$ & $\mathrm{~J} / \mathrm{kg}$ \\
${ }^{\circ} \mathrm{F} 32$ & 0.556 & ${ }^{\circ} \mathrm{C}$ \\
gal (U.S. liquid) & 3.785 & $\mathrm{~L}$ \\
in. & 2.54 & $\mathrm{~cm}$ \\
$\mathrm{kWh}$ & $3.6 \times 10^{6}$ & $\mathrm{~J}$ \\
$\mathrm{lb}$ & 0.454 & $\mathrm{~kg}$ \\
$\mathrm{mi}$ & 1.609 & $\mathrm{~km}$ \\
\hline
\end{tabular}


vii

ACRONYMS 
ABS acrylonitrile butadienestyrene

ACM advanced composite materials

BMC bulk molding compound

BOF basic oxygen furnace

CAFE corporate average fuel economy

CRLC cold-rolled, low-carbon

DAP diallyl phthalate

DOE U.S. Department of Energy

DOT '. U,S, Department of Transportation

EAF electric-arc furnace

EG. epoxy graphite

FRP fiber-reinforced plastic(s)

HDPE high-density polyethylene

HHV higher heating value

HSLA high-strength/low-alloy

HSS high-strength steel(s)

LDPE . low-density polyethylene

LHV lower heating value
LLDPE linear low-density polyethylene

LPG liquid petroleum gas

MDPE . medium-density polyethylene

NASA National Aeronautic.s and

Space Administration

NBS National Bureau of Standards

OHF open-hearth furnace

PAN - polyacrylonitrile

PP. polypropylene

$\mathrm{P}$

PVC

polystyrene

polyvinyl chloride

RRIM reinforced reaction-injected molded (plastics)

RTP reinforced thermoplastics

SAN styrene-acrylonitrile.

SMC : sheet molding compound

TMic thick molding compound

TP thermoplastic(s)

TS "thermosetting

UPE unsaturated polyester 
AUTOMOBILE MATERIALS COMPETITION:

ENERGY IMPLICATIONS OF FIBER-REINFORCED. PLASTICS

by

J. Cummings-Saxton

ABSTRACT

The embodied energy, structural weight, and transportation energy (fuel requirement) characteristics of steel, fiber-reinforced plastics, and aluminum were assessed to determine the overall energy savings of materials substitution in automobiles. In body panels, a 1.0-1b steel component with an associated $0.51 \mathrm{~b}$ in secondary weight is structurally equivalent: to a 0.6-1b fiber-reinforced plastic component with $0.31 \mathrm{~b}$ in associated secondary weight or a $0.5-1 b$ aluminum component with $0.251 \mathrm{~b}$ of secondary weight. (Secondary weight refers to the combined weight of the vehicle's support structure, engine, braking system, and drive train, all of which can be reduced in response to a decrease in total vehicle weight.) The life cycle transportation energy requirements of structurally equivalent: body panels (including their associated secondary weights) are $174.4 \times 10^{3}$ Btu for steel, $104.6 \times 10^{3}$ Btu for fiber-reinforced plastics, and $87.2 \times 10^{3}$ Btu for aluminum. The embodied energy requirements are $37.2 \times 10^{3}$ Btu for steel, 22.1 $\times 10^{3}$. Btu for fiber-reinforced plastics, and $87.1 \times 10^{3}$ Btu for aluminum. These results can be combined to yield total energy requirements of $211.6 \times 10^{3}$ Btu for steel, $126.7 \times 10^{3}$ Btu for fiberreinforced plastics, and $174.3 \times 10^{3}$ Btu for aluminum. Fiberreinforced plastics offer the greatest improvements over steel in both embodied and total energy requirements. Aluminum achieves the greatest savings in transportation energy.

EXECUTIVE SUMMARY

\section{AUTOMOBILE MATERIALS COMPETITION}

Concern about the availability and cost of petroleum has resulted in steadily improving vehicle fuel efficiencies. Although the improved efficiencies have been achieved by automobile manufacturers to help maintain their market competitiveness, an important initial factor was the Encrgy Policy and Conservation $\Lambda$ ct of 1975. This act establishes corporate average fuel economy (CAFE) standards for automobile manufacturers, which are scheduled to increase from $18 \mathrm{mpg}$ in 1978 to $27.5 \mathrm{mpg}$ in 1985.

Reducing vehicle weight has been the dominant strategy for improving fuel economy. (Other means have included reduced parts friction and improved engine performance, aerodynamic design, tire design, and drive train performance.) Average vehicle dry weight is projected to decline $30 \%$, from $3750 \mathrm{lb}$ in 1977 to $2600 \mathrm{lb}$ in 1985. This is being accomplished mostly by 
downsizing, conversion to front wheel drive, and engine modifications. Only about $18 \%$ of this reduction is expected to be achieved by materials substitution. Further decreases in vehicle weight, however, will have to depend mainly on materials substitution.

Materials substitution in automobiles has been relatively minor. Plastics usage increased from $104 \mathrm{lb}$ in 1971 to $2001 \mathrm{~b}$ in 1980 , and is projected to increase to $260 \mathrm{lb}$ in 1985. Aluminum usage has increased more gradually, from $76 \mathrm{lb}$ in 1971 to $132 \mathrm{lb}$ in 1980 and to a projected $210 \mathrm{lb}$ in 1985. These increases, though modest, are taking place within the context of significant decreases in total vehicle weight.' By 1985 plastics and aluminum will represent $10.0 \%$ and $8.1 \%$, respectively, of vehicle weight. Use of conventional steel decreased from $2400 \mathrm{lb}$ in 1971 to $1900 \mathrm{lb}$ in 1980 , and will likely fall to $1270 \mathrm{lb}$ in 1985. Cast iron, which decreased slightly from 572 $1 \mathrm{~b}$ in 1971 to $515 \mathrm{lb}$ in 1980, is expected to decrease to $260 \mathrm{lb}$ in 1985 . Use of the recently introduced high-strength steels (HSS) is rapidly growing. ihey are expected to triple their market share between 1977 and 1985, but this will not be enough to counter the overall decline in steel usage.

Plastics have been used almost exclusively in cosmetic applications or where parts consolidation is possible, such as in integral front ends. To achieve wider application, plastics must be used for structural components. Fiber-reinforced plastics (FRP), which have structural properties rivaling those of steels, are the leading candidates for increased plastics use in automobiles. One Detroit designer estimates that automobile weight $c$ an be reduced to $20001 \mathrm{~b}$ during the li990s through the use of up to $45 \%$ plastics if FRP successfully displace steel in body panels.*

FIBER-REIRFORCED PLASTICD

Plestic Resins

The mechanical strength of plastic resins can be increased by fiber reinforcement. Unsaturated polyester (UPE) resins form a particularly synergistic combination with reinforcing fibers. These thermosetting (TS) resins tend to be brittle when not reinforced, Reinforcement provides the neressary structural stability, so that their low cost, dimensional stability, and excellent chemical and electrical prnpertips ran he fully exploitod. Unsaturated polyester resins account for nearly $80 \%$ of FRP usage. Other TS resins account for an additional $10 \%$ and thermoplastic (TP) resins for slightly over $10 \%$.

Production of UPE resins proceeds in two steps. First, a set of dibasic acids (or anhydrides) are combined with a polyhydric alcohol to produce the basic UPE polymer. This is a condensation reaction involving both saturated and unsaturated dibasic acids, the relative amounts of which

* Reinforced reaction-injected molded (RRIM) plastic components are also being introduced into some automobile body component applications. This report restricts its attention to. FRP components as representative of the type of market competition and resulting energy adjustments taking place. 
determine the extent of cross linking in the polymer. As more unsaturated acid is used, a more rigid final product is produced due to greater cross linking. Most commonly, maleic anhydride is the unsaturated anhydride, phthalic anhydride is the saturated anhydride, and propylene glycol is the dihydric alcohol. In the second step of the production sequence, these constituents are combined with a reactive monomer, usually sytrene. This monomer eventually reacts with the resin in the curing, or molding, process. Its addition at this stage transforms the resin paste into a liquid that can be handled easily during intermediate processing steps, such as molding compound formulation. A typical resin composition is $16 \%$ maleic anhydride, $21 \%$ phthalic anhydride, $28 \%$ propylene glycol, and $35 \%$ styrene.

Once the basic resin. mix has been established, a number of additives may be introduced to achieve desired properties, e.g., an inhibitor to retard curing of the resin prior to the molding process, a thickener to impart desired handling properties, a pigment or dye to achieve desired color, a $\mathrm{TP}$ additive to improve surface properties, and/or a stabilizer to improve product resistance to light and heat. Additives can be mixed with the resin by the plastic resin manufacturer or by a different type of processor known as a compounder.

The embodied energy of the plastic resin is of particular interest because hydrocarbon feedstocks are consumed in the production of each of the four major constituents. For example, styrene is made from ethylbenzene; ethylbenzene is made from ethylene and benzene; benzene is obtained from petroleum reformate; and ethylene is made from ethane, gas oil, or naphtha. To estimate the embodied energy of styrene, both the participation level of each process step and the process and feedstock energy requirements of each step have to be determined. The same inputs are required for maleic anhydride, phthalic anhydride, and propylene glycol. The feedstock energy requirements of UPE resins were calculated to be $22.16 \times 10^{3} \mathrm{Btu} / 1 \mathrm{~b}$ and the process energy requirements to be $12.47 \times 10^{3} \mathrm{Btu} / 1 \mathrm{~b}$. Thus, the total embodied energy for UPE resins is $34.63 \times 10^{3} \mathrm{Btu} / 1 \mathrm{~b}$.

\section{Reinforcements}

A variety of reinforcing materials have been used: glass, asbestos, cotton, nylon, sisal, and cellulose. Type-E fiberglass is the reinforcement currently used in nearly all automotive applications. The tensile strength of fiberglass $\left(500 \times 10^{3} \mathrm{psi}\right.$ ) is 10 times that of steel, while its tensile modulus ( $10.5 \times 10^{6} \mathrm{psi}$ ) is three-eighths that of steel.* Advanced composite materials ( $A C M$ ) have been developed that have better mechanical properties than those of fiberglass. These materials use more expensive reinforcements, such as carbon/graphite fibers, aramids, and metal whiskers. Their substantially greater cost -- $\$ 20 / 1 b$ or more as compared with $\$ 0.60-70 /$ $1 \mathrm{~b}$ for fiberglass -- has severely restricted their use:

Reinforcing materials perform their function by absorbing essentially the entire mechanical stress as it is applied to the composite. The

*Tensile strength is the tensile stress required to achieve material rupture. Tensile modulus is the slope of the stress-strain curve in the elastic region and provides a measure of material stiffness. 
reinforcing fibers can be thought of as a set of "ropes" scattered throughout the resin matrix. Their strength can be exerted only when they are stretched taut by tension along their axes. Therefore, fiber orientation relative to the applied stress determines the strength of the composite. For example, if all of the fibers are aligned in a single direction, stress applied in that direction will be resisted by all fibers, providing maximum strength; however, stress applied in a different direction will encounter little resistance. Thus, fiber orientation must be carefully tailored to the anticipated stress environment. Maximum strength must frequently be sacrificed to achieve good multidirectional strength through use of random fiber orientation.

A second critical parameter is the quantity of reinforcing fibers. Composite strength is proportional to the amount of reinforcement, i.e., two times the amount of reinforcing fibers generally leads to two times the composite strength. A third important parameter is fiber length. The longer the fiber in a given direction, the greater is the continuity of stress transfer in that direction. Extremely strong FRP have been achieved by using long, unidirectionally. oriented fibers in quantities up to $80 \%$. For these materials, the primary purpose of the resin is to lock the fibers in p1ace.

Fiberglass manufacture involves three process steps: (1) mixing the mainly inorganic raw materials to form the glass batch, (2) heating the batch to approximately $2700^{\circ} \mathrm{F}$ to melt and refine the mixture, and (3) drawing the glass through platinum bushings to form the $0.1-0.75 \mathrm{mil}$ glass fibers. The energy required for these steps is $21.80 \times 10^{3} \mathrm{Btu} / \mathrm{lb}$. When this is added to the $0.3 \times 10^{3} \mathrm{Btu} / 1 \mathrm{~b}$ to mine the raw materials; the total embodied energy becomes $22.10 \times 10^{3} \mathrm{Btu} / \mathrm{lb}$.

Although carbon/graphite fibers have been proposed for future use in automotive applications, their continued high cost, even when projected future economles of scale are taken into consideration, will probably limit their use to hybrid composites that also contain fiberglass. Carbon/graphite fibers are manufactured in a two-step sequence. A precursor material, such as polyacrylonitrile fiber, is held under tension as it is heated to $480-750^{\circ} \mathrm{F}$. Once the precursor material has been fully oxidized, the temperature is increased to $2730-4530^{\circ} \mathrm{F}$. Al1 of the atoms except the carbon ladder backbone are pyrolyzed at this higher temperature. Total energy requirements of the two steps are estimated at $88.8 \times 10^{3} \mathrm{Btu} / 1 \mathrm{~b}$, an amount four times higher than that for fiberglass manufacture.

\section{Fillers}

The fillers added to FRP reduce cost, help to achieve desired flow properties, and provide a smoother surface. Fillers usually cost less than $\$ 0.20 / 1 b$ compared to the $\$ 0.60-0.70 / 1 b$ cost for the fiberglass and resin they displace. Their granular or platelet shapes enable them to flow more easily than the fiberglass filaments, thereby decreasing the pressure necessary for molding and permitting more complex shapes. Calcium carbonate is by far the most widely used filler, both in automotive and other applications.

The energy requirements to produce fillers are related to mining and beneficiating the inorganic materials. For calcium carbonate, the total 
energy required is only $0.35 \times 10^{3} \mathrm{Bt} / \mathrm{lb}$. Therefore, using large quantities of filler - $40 \%$ is typical - greatly reduces the total embodied energy of FRP.

\section{Sheet Molding Compound}

The resin, filler, and reinforcement can be joined together during the molding operation, as is done in the hand lay-up of boats. In nearly all high-volume operations, however, an intermediate molding compound is formulated. The kind most frequently employed in automotive applications is sheet molding compound (SMC). As its name indicates, the mixture is assembled in sheet form. A thickening agent is used to impart rigidity so that the SMC can be easily handled and stored. In many respects, it can be treated like metal sheet products.

To initiate the product manufacturing sequence, SMC is cut to size and manually placed in a compression mold. The mold then closes, forcing the SMC into the desired product configuration. A small amount of heat usually is added to initiate the reaction, and a catalyst insures that the curing reaction proceeds rapidly. Although. the actual molding operation is complete in about $20 \mathrm{~s}$, the part has to remain in the mold for nearly 2 min. until curing is complete. This time requirement compares unfavorably with the few seconds required for a steel or aluminum stamping operation. Manufacturers of FRP attempt to counter this disadvantage by parts consolidation, whereby a single molding operation achieves the same result as several stamping and joining operations.

Sheet molding compound with $30 \%$ fiberglass is the most widely used type in the automotive industry. The energy required for SMC formulation and molding is $4.30 \times 10^{3} \mathrm{Btu} / \mathrm{b}$. The aggregate energy for manufacturing the FRP product comprises the energies needed to produce the resin, fiberglass, and filler, plus the energy for SMC formulation and molding. For SMC-30, which contains $30 \%$ fiberglass, $30 \%$ resin, and $40 \%$ calcium carbonate, the total energy is $24.4 \times 10^{3} \mathrm{Btu} / \mathrm{lb}$. This value includes materials losses ( $4 \%$ ) during SMC manufacture, scrappage losses (10\%) during product manufacture, and $0.22 \mathrm{x}$ $1 \mathrm{n}^{3} \mathrm{Btw} / \mathrm{lh}$ transportation energy.

\section{STEEL}

The use of steel in automobiles is projected to decrease $34 \%$, from 2320 1b per vehicle in 1977 to 1530 1b in 1985. Nevertheless, steel will remain the predominant automobile material in 1985, accounting for $58.8 \%$ of total vehicle dry weight. New varieties of HSS are being introduced in an attempt to. maintain steel's market share as vehicle weight. is reduced. Dual-phase steels appear to be the most promising of the HSS. They provide good ductility during stamping operations but then set into crystalline structures that provide ultimate strengths of $60-145 \times 10^{3} \mathrm{psi}$. The chief impediment to their increased use is the need for the industry to invest in continuous annealing furnaces; which are highly capital intensive.

Steel production involves 14 separate processes. The most energy intensive of these are the production of hot metal by blast furnaces; molten 
steel by open-hearth, basic oxygen, or electric-arc furnaces; and slabs by the casting of ingots or by energy-conserving continuous casting. Approximately three-fourths of automotive steel is produced via the blast-furnace/basicoxygen-furnace route and one-fourth via the blast-furnace/open-hearth-furnace route. Essentially none is produced via the scrap-fired electric-arc furnace, which is less energy intensive. Continuous casting now accounts for $17 \%$ of slab production, and further growth is anticipated. The production-weighted energy requirements from all participating processes are $18.1 \times 10^{3} \mathrm{Btu} / 1 \mathrm{~b}$. An additional $0.4 \times 10^{3} \mathrm{Btu} / \mathrm{lb}$ is required for transport to Detroit, and product fabrication energy is approximately $0.13 \times 10^{3}$ Btu/lb. The offal rate for production of steel automotive parts averages $25 \%$. The resulting total embodied energy for steel is $24.8 \times 10^{3} \mathrm{Btu} / 1 \mathrm{~b}$.

\section{ALUMINUM}

Aluminum is a lightweight alcernative to steel for many automotive applications. This material, which is three times lighter than steel, can be handled on the same types of equipment as steel, and its assembly techniques are well established. However, the weight advantage of aluminum relative to steel is offset both by its cost, which is three times higher, and by a tensile modulus that is only one-third that of steel. A low tensile modulus reduces aluminum's weight advantage in applications where stiffness is important. Primarily because of its cost, aluminum sheet has been used mostly in short-term applications to achieve specific weight reduction goals. Many of these aluminum parts are replaced subsequently by improved steel components.

Aluminum production is extremely energy intensive. The alumina electrolysis step accounts for three-fourths of the energy needed to produce aluminum sheet from bauxite. This step can be bypassed, when scrap is available, by using a reverbatory furnace. Producing aluminum ingots using this furnace requires only $10 \%$ of the energy needed to proceed to that point from bauxite ore. Ten percent of aluminum sheet output is produced from recycled post-consumer scrap. In addition, the reverbatory furnace processes the large quantities ( $35 \%$ of the aluminum ingots) of mill scrap generated during aluminum sheet fabrication. The production-weighted average energy of aluminum sheet manufacture via the two furnaces is $120.9 \times 10^{3} \mathrm{Btu} / 1 \mathrm{~b}$. An additional $400 \mathrm{Btu} / \mathrm{lb}$ is needed for transport to Detroit and $130 \mathrm{Btu} / 1 \mathrm{~b}$ for product fabrication. An offal rate of $25 \%$ is sustained during product fabrication. Thus, total embodied energy is $161.9 \times 10^{3} \mathrm{Btu} / 1 \mathrm{~b}$, more than six times that for steel or FRP.

ENERGY IMPLICATIONS OF AUTOMOBILE MATERIALS SUBSTITUTION

\section{Weight Reduction}

Fiberglass and carbon/graphite fibers have, respectively, five to ten times the tensile strength of steel. Carbon/graphite fibers have a tensile modulus equal to that of steel, while the modulus for fiberglass is only three-eighths as great. In addition, fiberglass is three times lighter and carbon/graphite is four times 1 ighter than steel. As a result of these properties, fiberglass and carbon/graphite fibers are used in composite 
materials to achieve overall mechanical properties comparable to those of steel, but at significantly lower weights. Aluminum achieves specific properties comparable to those of steel by offsetting. lower mechanical properties with a density that is three times lower than that of steel. Aluminum components have achieved, on average, weight reductions of $50 \%$ relative to steel, while SMC and epoxy/graphite (EG) components have achieved $40 \%$ and $50 \%$ reductions; respectively. The high cost of carbon/graphite fibers precludes their extensive use in automotive applications within the foreseeable fut ure.

If materials substitution takes place within the context of an overall weight reduction effort, a number of secondary weight reductions are possible. These consist of opportunities to reduce the weights of the support structure, engine, braking system, and drive train. Values for the ratio of secondary to primary weight savings range from 0.4 to 1.6 . Ford Motor Company recently achieved a 0.76 secondary weight reduction ratio in an advanced concept lightweight vehicle. This report uses 0.5 as being representative of the general potential for secondary weight reduction in present-day vehicles.

\section{Transportation Energy}

Automobile weight reduction through materials substitution translates directly into savings in vehicle fuel (transportation energy). The U.S. Department of Transportation (DOT) has correlated fuel economy with vehicle weight for all models over a period of years. Theirr correlations include the effects of both reduced weight and improved aerodynamics. For a 3000-1b gasoline vehicle with a performance parameter equaling $0.03 \mathrm{hp} / 1 \mathrm{~b}$, the effect of weight reduction, corrected for aerodynàmic drag, is $0.93 \times 10^{-5}$ $\mathrm{gal} / \mathrm{mi} / 1 \mathrm{~b}$. Thus, assuming a vehicle 1 ifetime of $100,000 \mathrm{mi}$, each pound of weight reduction saves $0.93 \mathrm{gal}$ of gasoline. In energy terms, this is a $116 \mathrm{x}$ $10^{3}$ Btu savings per pound of weight reduction.

\section{Overall Savings}

The embodied energy, weight reduction, and transportation energy data together yield the overall energy savings achievable by materials substitution. In body panels, a 1.0-1b steel component with an associated $0.5-1 b$ in secondary weight is structurally equivalent to a $0.6-1 \mathrm{~b}$ FRP component with a $0.3-1 b$ secondary weight or a 0.5-1b aluminum component with a 0.25-1b secondary weight. (Because of its predominant usage, steel is assumed to be the secondary material in each case.) The transportation energy requirements of the steel, FRP, and aluminum components are $174.4 \times 10^{3} \mathrm{Btu}, 104.6 \times 10^{3}$ $B t u$, and $87.2 \times 10^{3} \mathrm{Btu}$, respectively. The embodied energy requirements are $37.2 \times 10^{3} \mathrm{Btu}, 22.1 \times 10^{3} \mathrm{Btu}$, and $87.2 \times 10^{3} \mathrm{Btu}$, respectively. Total energy requirements are $211.6 \times 10^{3} \mathrm{Btu}, 126.7 \times 10^{3} \mathrm{Btu}$, and $174.3 \times 10^{3} \mathrm{Btu}$, respectively. Thus, FRP offer the greatest improvements in both embodied and total energy. Aluminum, on the other hand, achieves the greatest savings in transportation energy, but this does not fully compensate for its large embodied energy requirements.

The type of energy resources consumed is also important. For example, the irou and steel industry depends on coal and coke (63\%), the aluminum industry on electricity $(68 \%)$, and the fiberglass industry on natural gas 
(75\%). The amount of petroleum (oil) consumed is of particular interest because that energy resource is currently of great concern. Electricity consumption also is important because its use translates into higher fuel consumption when the thermal losses of electricity generation are taken into account. Based on the average fuel usage of each industry and on the fuel requirements of current patterns of electricity generation: (1) direct energy requirements of steel, FRP, and aluminum are, respectively, $22.6 \times 10^{3} \mathrm{Btu} / \mathrm{lb}$, $18.3 \times 10^{3} \mathrm{Btu} / 1 \mathrm{~b}$, and $70.3 \times 10^{3} \mathrm{Btu} / 1 \mathrm{~b}$, and (2) assuming $34.12 \%$ thermal efficiency in electricity generation, total fuel requirements are, respectively, $24.8 \times 10^{3} \mathrm{Btu} / 1 \mathrm{~b}, 24.4 \times 10^{3} \mathrm{Btu} / 1 \mathrm{~b}$, and $161.9 \mathrm{Btu} / \mathrm{lb}$. Petroleum (oil) requirements are $3.5 \times 10^{3} \mathrm{Btu} / 1 \mathrm{~b}, 9.6 \times 10^{3} \mathrm{Btu} / 1 \mathrm{~b}$, and $27.7 \times 10^{3}$ $\mathrm{Btu} / \mathrm{lb}$, respectively. If all new aluminum production were supplied by dedicated, base-load, coal-fired electricity, aluminum's petroleum consumption would fall to $4.0 \times 10^{3} \mathrm{Btu} / \mathrm{lb}$, while its coal consumption would rise to 143.9 $x 10^{3} \mathrm{Btu} / \mathrm{lb}$. The comparisnns for petroleum consumption in an autumobilc materials context (structurally equivalent body panels -- 1.0 lb steel, $0.61 \mathrm{~b}$ FRP, and $0.31 \mathrm{~b} \cdot \mathrm{aluminum}$, with associated secondary weights -- over a vehicle lifetime of $100,000 \mathrm{mi}$ ) are $179.7 \times 10^{3}$ Btu for steel, $111.4 \times 10^{3}$ Btu for FRP, and $101.9 \times 10^{3}$ Btu for aluminum. Fiber-reinforced plastics compete favorably against steel in all respects. The desirability of aluminum in energy terms depends on the fuels used to generate electricity for al uminum produc$t$ ion. If fossil fuels alone were used, aluminum would require $38 \%$ more total energy than that required by FRP but $18 \%$ less.energy than that needed for steel. If large amounts of hydropower were employed in aluminum manufacture, however, the total energy requirements would be reduced accordingly. For example, $40 \%$ hydropower usage would reduce aluminum's total energy requirements to $118.6 \times 10^{3} \mathrm{Btu} / 1 \mathrm{~b}, 6 \%$ less than those for FRP.

\section{FIBER-REINFORCED PLASTICS RESEARCH AND DEVELOPMENT NEEDS}

Both a lack ot knowledge of the material characteristics of FRP and inadequate production techniques constrain the use of FRP for automobile components. Inadequacies include surface quality deficiencies, low production rates, undeveloped assembly techniques, uncertain energy absorption characteristics, inadequate knowledge of material properties, and lack of recyclability. To respond to these needs, research and development is.required to develop improved processing techniques and to assemble a product characterization data base. Although some research and development effort is underway in each of these areas, it is generally at a low level because of the ongoing cash flow problems in Detroit and the emphasis being given to vehicle downsizing as the primary method for achieving improved fupl efficienry. Extensive materials substitutions are likely to be delayed for several years until the more cost effective downsizing opportunities are fully exploited. At present rates of investigation, however, the necessary FRP data will not be developed in time for the next round of decision making concerning desirable strategies for achieving the improved fuel efficiencies that have been discussed for the mid-1990s. Therefore, industry representatives are indicating that support for research and development by a government agency, such as the U.S. Department of Energy (DOE), would be helpful. The potential savings in total energy and petroleum consumption through use of FRP automobile components might justify such support. 
The governmental role could take two forms: (1) financial support for research and development in the use of FRP for automotive applications, and (2) in-house development of basic FRP engineering data. The National Aeronautics and Space Administration (NASA) already performs such a role in support of FRP research and development related to aerospace applications. Since the NASA effort is focused on low-volume applications where cost is a secondary consideration, results generally are not applicable to the highvolume automotive. industry. Projects conducted by industry might focus on development of improved FRP processing techniques for automotive applications, while programs at universities and/or government laboratories might emphasize exploratory engineering design. 


\section{INTRODUCTION}

The use of plastics in automobiles has been steadily increasing over the last $15 \mathrm{yr}$, both in total quantity and in relative market share. Overall, the trend has been for plastics and aluminum to increase their market penetration at the expense of iron and steel. The national emphasis on improved transportation efficiency since the oil embargo of 1973-1974 has tended to reinforce the penetration of plastics and aluminum, because they are lighter in weight than iron and steel in most automotive applications.

As the role of plastics has grown, concern has been expressed as to their dependence on crude oil. Because plastics are composed primarily of hydrocarbons obtained from natural gas and crude oil, these resources are required both as an energy input during fabrication and for the plastics molecules themselves. It is generally easier to use alternative energy sources for processing than for feedstocks.* Therefore, concern about the displacement of iron and steel or aluminum by plastics largely stems from the. crude oil requirements for plastics feedstocks.

The effect of increased emphasis on transportation efficiency can be seen in recent trends of automobile weights. Table 1.1 gives the materials used in automobiles from 1965 to 1980 . Since the values are productionweighted averages, they reflect both the weight of the vehicles manufactured in each size range (e.g., compact) and the number of vehicles purchased from each group. From 1965 to 1971 , consumers purchased more spacious, luxurious, and heavier cars. Even though manufacturers could not immediately change basic vehicle characteristics after the 1973-1974 oil embargo, consumer purchases reduced the average weight of vehicles sold in 1974 by $4 \%$ compared to 1971 . Subsequent manufacturer adaptations to changed demand reduced average vehicle weight by $17 \%$ in 1980 compared to 1971 . In addition, a Detroit designer has estimated that if fiber-reinforced plastics (FRP) successfully displace steel in automobile body panels, automobile weight would be reduced during the $1990 \mathrm{~s}$ to $2000 \mathrm{lb}$ through the use of up to $45 \%$ plastics.

As can be seen in Table 1.1 , the use of steel remained nearly constant and cast iron use increased by $36 \%$ from 1965 to 1977 ; both then fell off slightly from 1977 to 1980 . Iron and steel remain the predominant materials in present-day cars, accounting for $72.7 \%$ of vehicle weight in 1980 , plastics participation increased dramatically over the 15-yr period -- from $1.0 \%$ in 1965 to $6.0 \%$ in 1980 . The compound annual growth rate in pounds of plastic per vehicle was $12.3 \%$. Aluminum also increased its market penetration but at a slower rate, growing from $1.8 \%$ in 1965 to $4.0 \%$ in 1980 . Plastics and aluminum were the only automobile materials whose use increased over the entire 1965-1980 period.

\footnotetext{
*A substantial amount of work is underway to develop coal-based feedstocks for petrochemical processes.
} 
Table 1.1 Automotive Materials Composition for Selected Car Model Years ( $1 \mathrm{~b} /$ automobile)

\begin{tabular}{lrrrrrrr}
\hline & Material & 1965 & 1968 & 1971 & 1974 & 1977 & $1980^{\text {á }}$ \\
\hline Iron & 469 & 500 & 572 & 590 & 640 & 515 \\
Steel & 2133 & 2210 & 2400 & 2250 & 2320 & 1900 \\
Aluminum & 62 & 66 & 76 & 83 & 110 & 132 \\
Zinc & 59 & 58 & 60 & 34 & 24 & 19 \\
Copper & 35 & 36 & 32 & 23 & 20 & 30 \\
Lead & 35 & 36 & 40 & 36 & 26 & 22 \\
Glass & 97 & 98 & 104 & 96 & 90 & 92 \\
Rubber & 166 & 182 & 204 & 199 & 100 & 100. \\
Plastics & 35 & 73 & 104 & 152 & 190 & 200 \\
Miscellaneous & 359 & 375 & 408 & 378 & 230 & 310 \\
Average vehicle dry weight & 3450 & 3640 & 4000 & 3841 & 3750 & 3320 \\
\hline
\end{tabular}

${ }^{a}$ General Motors Corporation average vehicle.

bVehicle inertia weight equals vehicle dry weight plus passengers and fluids. Average vehicle inertia weight was $3650 \mathrm{lb}$ in 1980 .

Sources: Refs. 1 (1965-1974), 2(1977), and 3(1980).

This report examines the energy tradeoffs associated with increased plastics use in automobiles. Fiber-reinforced plastics are emphasized,* because they are strong enough to compete directly with iron, steel, and aluminum in automotive structural applications. Because the final product fabrication steps represent such a small fraction of overall production energy, the materials are compared with.regard to the energy consumed along the entire production sequence. ' Consumption of automotive fuels also is taken into account.

On the basis of total energy consumption, FRP are preferable to steel and aluminum. In addition, because of the large petroleum requirements for vehicle transportation energy, FRP and aluminum both provide significant reductions in petroleum consumption compared to steel. However, greatly expanded usage of FRP in automotive applications is constrained by undeveloped assembly techniques and by a lack of materials property data.

* Reinforced reaction-injected molded (RRIM) plastic components are also being: introduced into some automobile body component applications. This report restricts its attention to FRP components as representative of the type of market competition and resulting energy adjustments taking place. 


\section{FIBER-REINFORCED PLASTIC SYSTEMS}

Fiber-reinforced plastics were first employed during World War II for military applications. Subsequently, FRP shipments grew steadily to an estimated $2.05 \times 10^{9} \mathrm{lb}$ in 1979, then declined with the economy in 1980 (see Table 2.1). While marine applications dominated in the early 1970s, they were displaced in 1976 by land transportation uses. Land transportation applications represented $27 \%$ of the estimated total in 1979 , reflecting an annual growth in land transportation uses of $13.4 \%$ from 1974 through 1979.

Each FRP contains two essential components that form a synergistic composite -- plastic resin and reinforcing material. The resin provides a matrix to stabilize the fiber and acts to resist compression. The resin also establishes the chemical, electrical and, to a large extent, the thermal properties of the composite. The reinforcing material provides mechanical strength, taking the load when FRP are subjected to tensile stress.' A third and less expensive constituent - filler - is now employed in most FRP systems to reduce costs and to achieve desired flow properties. The granular fillers flow more easily than the viscous resins or the geometrically awkward fibers.

Fiber-reinforced plastics are generally 25-35\% (by weight) resin, with the remainder allocated between reinforcement and filler according to desired

Table 2.1 Shipments of Fiber-Reinforced Plastics by Market $\left(\begin{array}{ll}10^{6} & 1 \mathrm{~b}\end{array}\right)^{\mathrm{a}}$

\begin{tabular}{lrrrrrrrr}
\hline \multicolumn{1}{c}{ Market } & 1974 & 1975 & 1976 & 1977 & 1978 & 1979 & $\begin{array}{c}1980 \\
\text { Estimate }\end{array}$ \\
\hline Aircraft and aerospace & 30 & 24 & 22 & 23 & 22 & 23 & 25 \\
$\begin{array}{l}\text { Appliances and equipment } \\
\text { Construction }\end{array}$ & 82 & 64 & 98 & 112 & 123 & 130 & 104 \\
Consumer goods & 198 & 175 & 248 & 276 & 323 & 335 & 265 \\
Corrosion-resistant & 75 & 64 & 102 & 116 & 116 & 126 & 99 \\
products & 174 & 163 & 157 & 189 & 216 & 238 & 249 \\
$\begin{array}{l}\text { Electrical rods, tubes } \\
\text { and parts }\end{array}$ & 94 & 82 & 123 & 154 & 170 & 190 & 162 \\
$\begin{array}{l}\text { Marine and marine } \\
\text { accessories }\end{array}$ & 320 & 285 & 365 & 400 & 430 & 385 & 275 \\
Land transportation & 293 & 265 & 398 & 460 & 532 & 550 & 436 \\
Miscellaneous & 75 & 58 & 66 & 72 & 74 & 79 & 70 \\
$\quad$ Total & 1341 & 1180 & 1579 & 1802 & 2006 & 2056 & 1685 \\
\hline
\end{tabular}

aThermoset and thermoplastic: Weights include resin, reinforcement, and filler.

Sources: Refs. $1(1974-1975)$ and 4 (1976-1980). 
product properties. Although as much as $80 \%$ reinforcement is employed for high-strength applications, reinforcement usually accounts for only $30 \%$ of the total. Generally, filler represents $35-45 \%$ (by weight).

In addition to discussing the three principal components, Sec. 2 describes the preparation of molding compounds and the molding operation. Most automobile applications employ molding compounds.

\subsection{PLASTIC RESINS}

Plastic resins are either thermoplastic (TP) or thermosetting (TS). Thermoplastic resins consist of long molecules ( 1 inear or branched) having side chains or groups that are not attached to other molecules. They can be repeatedly softened by heating and hardened by cooling. Thermosetting resins have a three-dimensional, relatively rigid structure as a result of cross linking between adjacent molecules during the polymerization process. Once hardened, these resins cannot be softened without breaking some of the cross linkages.

Thermoplastic resins are far more common. They accounted for approximately $85 \%$ of total plastics production from 1975 to 1980 (see Table 2.2). However, in F.RP systems, TS resins account for approximately $90 \%$ of the total; unsaturated polyester (UPE) resins alone account for nearly $80 \%$. The disparity between overall resin use. and use in FRP can be traced to resin mechanical properties. Thermoplastic resins have good mechanical properties even when unreinforced; the high-performance, more costly TP resins are known as "engineering plastics." In contrast, many TS resins are more brittle. However, reinforced TS resin systems achieve substantially. better mechanical properties at lower cost than the strongest TP resins.

\subsubsection{Thermosetting Resins}

The five major classes of TS resins are 1 isted in Table 2.2. Since UPE resins are used more often than the others in FRP systems, these resins will be used to illustrate the principal features of TS resins in FRP. The reasons for the market success of UPE resins are twofold: (1) good overall properties (dimensional stability; ease of handling; and mechanical, electrical, and chemical resistance) and (2) relatively low cost (\$0.56-0.59/1b in June, $1980^{5}$ ) of general-purpose UPE resins.

Unsaturated polyester resin products are produced in four steps as depicted in Fig. 2.1. First, a set of dibasic acids (or anhydrides) are combined with a polyhydric alcohol* to produce the basic UPE polymer. This polymer is then combined with a reactive monomer, which subsequently reacts in the curing step to form the final UPE product. Next, additives can be mixed with the resin to establish desired properties. These additives may include: (1) an inhibitor to retard curing of the resin prior to the molding process; (2) a thickener to impart the desired handling properties; (3) a

*Dibasic acids have two replaceable hydrogen atoms, and polyhydric alcohols have several hydroxyl groups. 
Table 2.2 Iotal U.S. Plastics Production and Captive Use by Material, 1975-1980 (106 $1 \mathrm{~b})$

\begin{tabular}{|c|c|c|c|c|c|c|}
\hline \multirow[b]{2}{*}{ Resin } & \multicolumn{2}{|c|}{$1 \subseteq 75$} & \multicolumn{2}{|c|}{1976} & \multicolumn{2}{|c|}{1977} \\
\hline & Production & Captive Use & Production & Captive Use & Production & Captive Use \\
\hline \multicolumn{7}{|l|}{ Selected thermosetting plastics } \\
\hline $\begin{array}{l}\text { Epoxy } \\
\text { Phenolic } \\
\text { Unsaturated polyester (UPE) } \\
\text { Urea } \\
\text { Melamine }\end{array}$ & $\begin{array}{r}198 \\
1,051 \\
834 \\
690 \\
115\end{array}$ & $\begin{array}{r}187 \\
1,034 \\
771 \\
685 \\
117\end{array}$ & $\begin{array}{r}244 \\
1,340 \\
1,042 \\
821 \\
186\end{array}$ & $\begin{array}{r}250 \\
1,305 \\
959 \\
809 \\
182\end{array}$ & $\begin{array}{r}261 \\
1,458 \\
1,061 \\
963 \\
200\end{array}$ & $\begin{array}{r}278 \\
1,400 \\
1,045 \\
951 \\
203\end{array}$ \\
\hline Total & 2,888 & 2,794 & 3,633 & $\Xi, 505$ & 3,943 & 3,877 \\
\hline \multicolumn{7}{|l|}{ Selected thermoplastics } \\
\hline $\begin{array}{l}\text { Acrylonitrile butadiene-styrene (A3S) } \\
\text { Styrene-acrylonitrile (SAN) } \\
\text { High-density polyethylene (HPPE) } \\
\text { Low-density polyethylene (LDPE) } \\
\text { Nylon } \\
\text { Polypropylene (PP) } \\
\text { Polystyrene (PS) } \\
\text { Polyvinyl chloride (PVC) }\end{array}$ & $\begin{array}{r}642 \\
110 \\
2,468 \\
4,743 \\
135 \\
1,902 \\
2,662 \\
3,648\end{array}$ & $\begin{array}{r}621 \\
75 \\
2,305 \\
4,725 \\
143 \\
1,903 \\
2,640 \\
3,615\end{array}$ & $\begin{array}{r}988 \\
113 \\
3,125 \\
5,813 \\
247 \\
2,632 \\
3,195 \\
4,716\end{array}$ & $\begin{array}{r}925 \\
104 \\
\Xi, 127 \\
5,765 \\
.221 \\
2,536 \\
3,145 \\
4,638\end{array}$ & $\begin{array}{r}1,069 \\
115 \\
3,652 \\
6,471 \\
254 \\
2,747 \\
3,446 \\
5,253\end{array}$ & $\begin{array}{r}1,057 \\
113 \\
3,557 \\
6,488 \\
250 \\
2,698 \\
3,557 \\
5,232\end{array}$ \\
\hline Total & 16,310 & 16,027 & 20,829 & $2 C, 461$ & 23,007 & 22,952 \\
\hline Total selected plastics & 19,198 & 18,821 & 24,462 & 23,966 & 26,950 & 26,829 \\
\hline All other plasti=s & 3,630 & 2,341 & 4,734 & 3,018 & 6,998 & 4,227 \\
\hline Total & 22,828 & 21,162 & 29,196 & 26,984 & 33,948 & 31,106 \\
\hline
\end{tabular}


Table 2.2 (Cont'd)

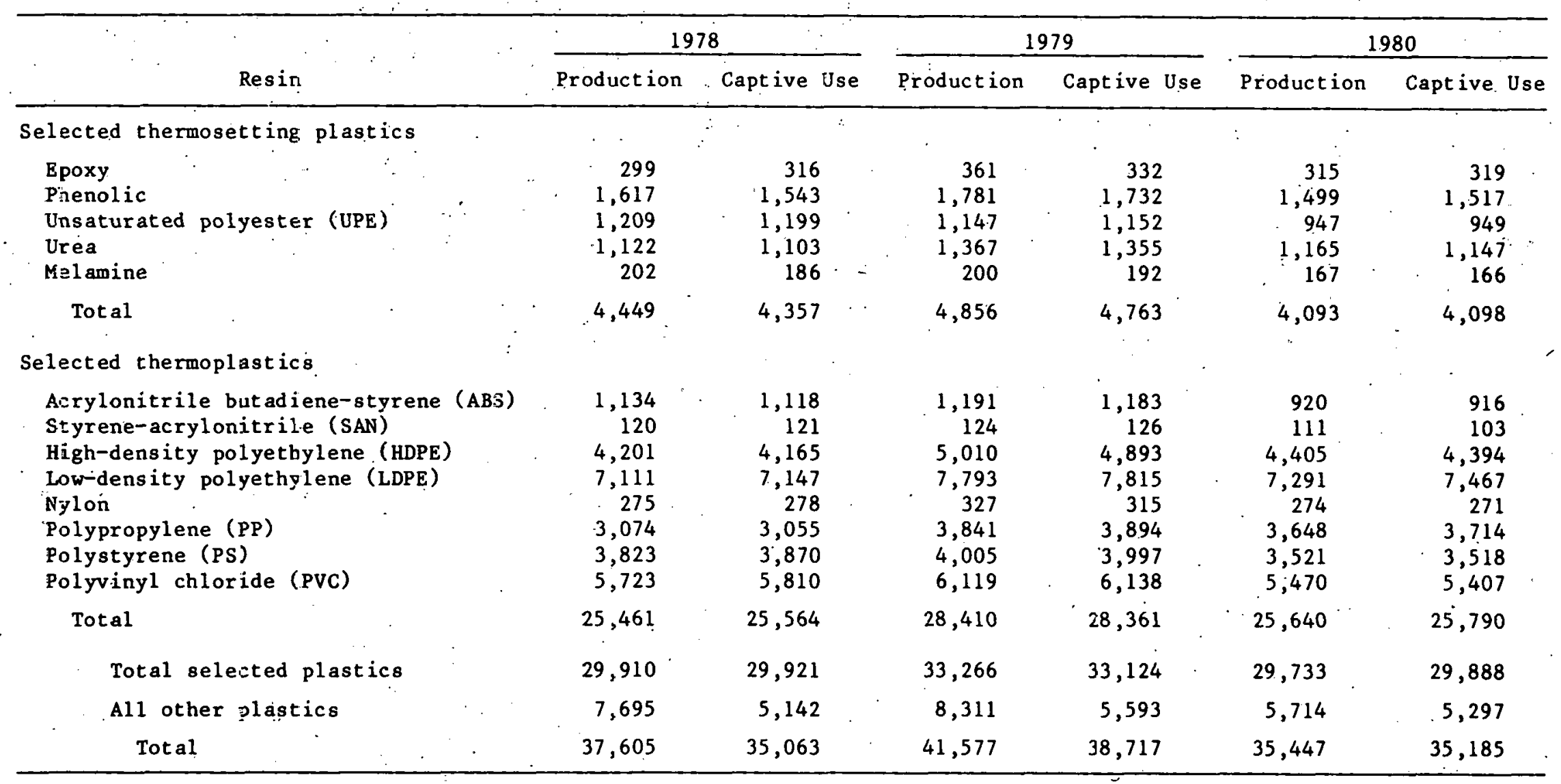

Sources: Refs. 1 (1974-1975) and 4 ( $: 976-1980)$. 


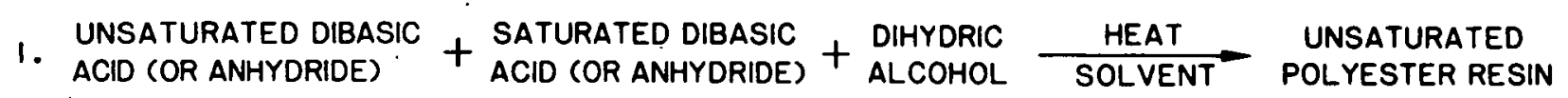

2. UNSATURATED $\quad+$ REACTIVE MONOMER $\rightarrow$ COPOLYMER RESIN

3. COPOLYMER RESIN $\quad+\quad$ ADDITIVES $\quad \longrightarrow$ MOLDING COMPOUND

4. MOLDING COMPOUND $\frac{\text { HEAT/CATALYST }}{\text { PRESSURE }}$ CURED PRODUCT

Fig. 2.1 Ŝteps in the Production of. Unsaturated Polyester Resin Products

pigment or dye to achieve the desired color; (4) a TP additive to improve surface properties; (5) a stabilizer to improve product resistance to light and heat; (6) fiber reinforcement (see Sec. 2.2); and (7) filler (see Sec. 2.3). The additives may be mixed with the resin at the plastics material manufacturer or at a separate set of processors known as compounders. The fourth step is the molding process, during which the product shape is formed and resin curing takes place. A curing agent (catalyst) and heat usually are employed to initiate the cure. The molding process, which is accomplished at the fabricator, is discussed in Sec. 2.5 .

The first step in the sequence is the condensation reaction of two dibasic acids -- one saturated, one unsaturated -- with a dihydric alchohol to form the UPE polymer. The relative amounts of saturated and unsaturated acids determine the extent of cross linking in the polymer. As more unsaturated acid is used, a more rigid final product is produced due to greater cross linking. The unsaturated dibasic acid used in most instances is maleic anhydride. Various saturated acids (or anhydrides) are employed, depending on the desired properties of the product. Phthalic anhydride is by far the most frequently used, Alternatives include isophthalic acid, bisphenol $A$, and "Het" anhydride. Isophthalic acid yields a resin with higher viscosity and end products with greater hydrolytic stability, greater toughness, higher heat distortion temperature, and better chemical resistance. Bisphenol A and "Het" anhydride also lead to improved hydrolytic stability. The former improves corrosion resistance, and the latter reduces flammability. The dihydric alcohols employed include propylene glycol, ethylene glycol, dipropylene glycol, diethylene glycol, and neopentyl glycol. Propylene glycol is the most widely used, accounting for nearly $70 \%$ of the total.

Reaction of the dibasic acids or anhydrides and the dihydric alcohol produces the basic polymer. Usually a solvent and heat are used to facilitate this esterification reaction. It is a condensation reaction in that the reactant molecules are joined in the product molecule, with water as the only by-product. The reaction mixture is cooled to stop the reaction when the desired molecular weight and viscosity are reached. 
A reactive monomer is added to the UPE resin in the second step. Its addition at this stage serves to impart desired flow properties. The monomer transforms the resin paste into a liquid, which can be handled easily during intermediate processing and during the final molding operation. Styrene is frequently used as the reactive monomer; other alternatives include vinyl toluene, methyl methacrylate, diallyl phthalate (DAP), and mono-chlorostyrene. Vinyl toluene is less volatile than styrene, reducing subsequent monomer evaporation. Methyl methacrylate provides improved ultraviolet stability. Diallyl phthalate is even less volatile than vinyl toluene and provides good electrical properties. Mono-chloro-styrene provides more rapid cures. The monomer that is added eventually reacts with the resin in the curing, or molding, process.

Curing can begin as soon as the reactive monomer is added. Therefore, an inhibitor must be added, usually during the third step, unless the resinmonomer system is to be used immediately. The inhibitor is added in very low concentrations $(0.02-0.05 \%)$ and acts to absorb the energy of the resin-monomer reactions. This prevents the onset of the chain reaction leading to the copolymer product. The inhibitor can only delay curing, because it loses its effectiveness over time due to the activation of its molecules. A wide range of inhibitors are employed (e.g., hydroquinone, p-t butyl cotechol, phenolic resins, aromatic amines, picric acid, and quinones).

Other additives may be introduced during the third step. In addition to reinforcements and fillers, colorants are employed, including dyes and pigments as well as metallics and pearlescent powders or inclusions. Some colorants provide ultraviolet stability. The colorants may be subject to fading, present uniformity problems, or speed up or delay the polymerization process. Other additives include: (1) stabilizers; (2) antistatic agents that reduce the buildup of static electricity in the final product; (3) lubricants that improve polymer flow during subsequent molding or extrusion operations; (4) flame retardants; and (5) processing aids, such as viscosity depressants, mold releases, slip agents, emulsifiers, and antiblocking agents. At the end of the third step, the resin system enters the molding (or product fabrication) process. Resin curing takes place during this operation.

The most significant components to be taken into account from an energy usage point of view are the two dibasic acids or anhydrides, the dihydric alcohol, and the reactive monomer. The typical UPE used in FRP systems employs maleic anhydride as the unsaturated acid, phthalic anhydride as the saturated acid, propylene glycol as the dihydric alcohol, and styrene as the reactive monomer. Representative participations of each are $16 \%, 21 \%$, $28 \%$, and $35 \%$ (by weight), respectively. This chemical composition will be used in this report as characteristic of UPE resins.

\subsubsection{Thermoplastic Resins}

As shown in Table 2.2, TP resins are the largest volume plastic resins. Their greater production volume and generally simpler chemistry make them less expensive. For example, high-density polyethylene.(HDPE), low-density polyethylene (LDPE), polypropylene (PP), polyvinyl chloride ( $P V C$ ), and polystyrene (PS) were priced in 1979 at about $\$ 0.35 / 1 \mathrm{~b}$, compared to nearly $\$ 0.50 / 1 \mathrm{~b}$ for 
UPE.* The lower cost of high-volume TP resins has motivated efforts to make greater use of them in FRP systems. Such reinforced thermoplastics (RTP) were first introduced in 1955, and their annual sales volume grew to $15 \times 10^{6}$ $1 \mathrm{~b}$ by 1967 and $182 \times 10^{6} 1 \mathrm{~b}$ by 1973. Estimated sales for 1978 and 1979 were $214 \times 10^{6} \mathrm{lb}$ and $242 \times 10^{6} \mathrm{lb}$, respectively. This latter figure represents $11.8 \%$ of 1979 FRP sales (see Table 2.1).

A significant advantage of TP resins is their excellent compatibility with injection molding, the highest volume molding process. (Thermosetting resins also can be molded in this way, but not as easily.) A second advantage is that TP resin wastes can be remelted and fed back into the production process. Also, $T P$ resins can be used with TS resins if a good surface finish is required. Using $T P$ resins alleviates the sink mark and surface crack difficulties experienced by TS resin products during cooling. Up to $40 \%$ $T P$ resin can be employed in Class A surface molding compounds. For these reasons, TP resins should occupy a gradually increasing share of the FRP market. Nevertheless, TS resins should retain their dominant FRP market position because of their favorable physical properties.

\subsection{REINFORCEMENT}

A variety of reinforcing materials have been used, including glass, asbestos, cotton, nylon, sisal, and cellulose. Asbestos has been one of the largest volume, low-cost filler-reinforcement materials, but it is being phased out in nearly all applications because of its health hazards. Several high-performance advanced composite materials (ACM) have been developed (e.g., whiskers, carbon/graphite fibers, and aramids), but their higher cost severely 1 imits their use. Fiberglass, type $E$, is the most widely used reinforcement at the present time and should continue to be for the foreseeable future.

Discussion of reinforcing material properties requires a brief introduction to the terminology conventionally employed in describing mechanical properties. Figure 2.2 shows how material strain develops in an elastic manner. Upon removal of the stress, the rod will return to its original dimensions. Stress and strain in the elastic region are related by Hooke's Law:

$$
S=E \varepsilon
$$

where:

$$
\begin{aligned}
& S=\text { stress (psi) } \\
& \varepsilon=\text { strain (in./in.), and } \\
& E=\text { Young's modulus (psi). }
\end{aligned}
$$

Young's modulus, in this case the elastic or tensile modulus, is the slope of the stress-strain curve from the origin to $A$. The greater the value of the

\footnotetext{
*Engineering TP are much more costly $(\$ 1-15 / 1 \mathrm{~b}$ in June, 1980). 'Engineering TP include acetal, polycarbonate, polyphenylene sulfide, TP polyester, polysulfone, modified polyphenylene oxide, polyimide, and polyamide-imide.
} 


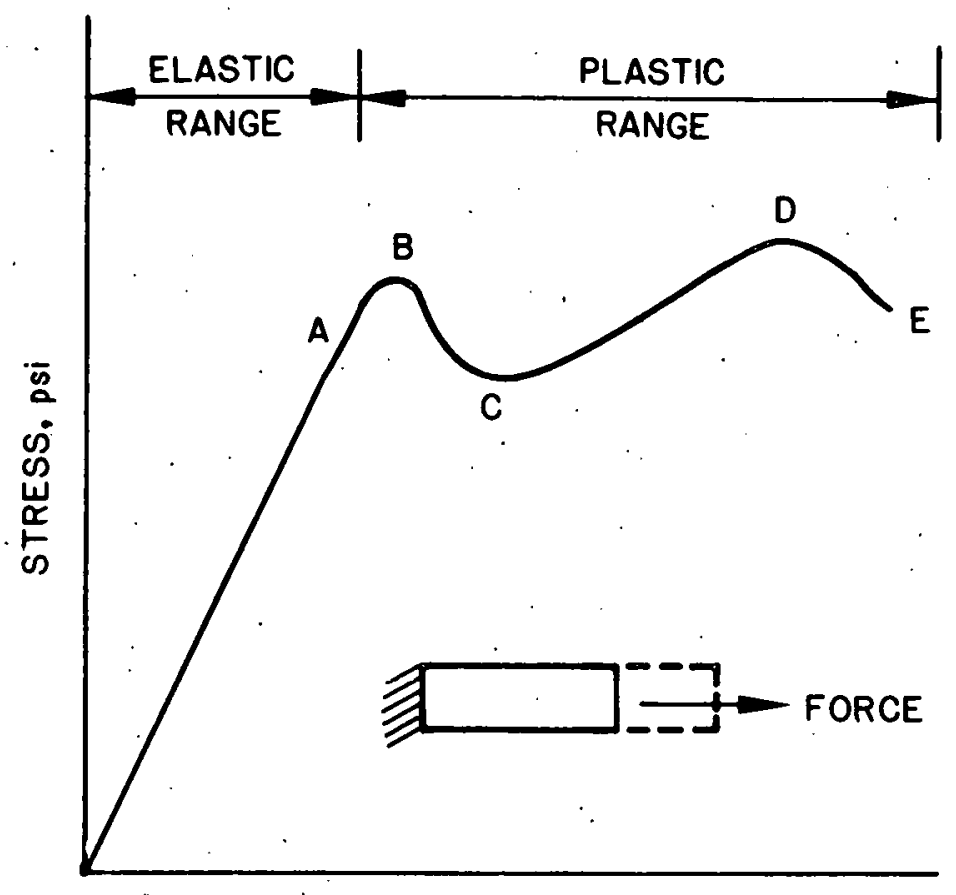

STRAIN, in./in.

Fig. 2.2 Tensile Stress-Strain Curve

elastic modulus, the stiffer and more resistant to elongation is the material. Once $A$, known as the elastic limit, is exceeded, further increases in stress move the strain along a nonlinear path through $B, C$, and $D$, until the material ruptures at E. Points B, C, and D are termed, respectively, the upper yield point, lower yield point, and ultimate strength of the material. Frequently, materials are characterized simply by their elastic modulus and ultimate strength. Similar curves can be developed. for torsion, bending, compression, and shear.

Reinforcing materials take on essentially the entire mechanical stress when it is applied to the composite. In effect, the resin matrix is transparent. to the mechanical stress, passing it directly to the reinforcing fibers. The modulus of the resin must be less than the modulus of the reinforcement, or the resin will assume part of the stress and will tend to crack.

The three most important parameters determining reinforcement effectiveness are the orientation of the reinforcing fibers relative to the applied stress, and the amount and length of the fibers. The fibers can be thought of as a set. of ropes scattered throughout the resin matrix. Like ropes, their strength can be exerted only when they are stretched taut by tension along their axes. Also of importance is a good bond between the fiber and resin so that the resin matrix can transfer the stress to the fiber and elastically deform in a way that maintains the resin-fiber contact.

The design of composite products must take into account the nature of the stresses encountered during use. If all of the fibers are aligned in a 
single direction, stress applied in that direction will be resisted by all of the fibers, providing maximum strength; however, stresses applied in a different direction will encounter little resistance. Therefore, only the very specific situation of one-dimensional stress can utilize the maximum possible tensile properties of the fibers. In all other cases, a tradeoff must be made between maximum strength in any one direction and load-bearing capacity in other directions. Generally, reinforcements are either unidirectional, bidirectional, or multidirectional (isotropic).

The second parameter, the amount of reinforcing fibers, is expressed by the following law of mixtures for composites:

$$
s_{c}=v_{f} S_{f}+v_{m} s_{m}
$$

where:

$$
\begin{aligned}
& \mathrm{s}_{\mathrm{c}}=\text { composite strength, } \\
& \mathrm{s}_{\mathrm{f}}=\text { fiber strength, } \\
& \mathrm{s}_{\mathrm{m}}=\text { resin matrix strength, } \\
& \mathrm{v}_{\mathrm{f}}=\text { volume fraction of fiber, and } \\
& \mathrm{v}_{\mathrm{m}}=\text { volume fraction of resin matrix. }
\end{aligned}
$$

This relationship must be corrected for the effects of short fiber lengths, transfer efficiency between fiber and resin, and fiber orientation. Some extremely high-strength composites have recently been introduced that employ long, unidirectionally oriented fibers in quantities up to $80 \%$. In this case, the resin serves primarily as a means of holding the fibers in place. Figure 2.3 illustrates the combined effect of orientation and fiber quantity on' composite tensile strength.

The third parameter is fiber length. The longer the fiber length in a given direction, the greater is the continuity of stress transfer in that direction and the greater is the load-bearing capacity in that direction. This benefit, of course, is subject to the same directional constraints as were discussed for fiber orientation. In addition, longer fibers are more difficult to process than shorter fibers. Consequently, fiber lengths are. less than 2 in. in most applications. Attention has recently been given to shorter fiber reinforcements (i.e., $1 / 4$ in. to $1 / 32$ in. and 1 ess). These lengths provide ease of processing. and aid in dimensional stability.

Fiberglass reinforcements come in eight principal forms: continuous strand, continuous strand roving, spun strand roving, chopped strand, milled fibers, reinforced mat, woven roving, and industrial textile yarn, the latter being used for woven fabrics: The basic unit is the glass filament, which $r$ anges in diameter from $0.1 \mathrm{mils}$. to $0.75 \mathrm{mils}$. More than 200 filaments are gathered together to form a single fiberglass strand. Continuous strand rovings are formed by gathering a group of essențially parallel strands into a ribbon and winding them on to a cylindrical tube. In spun strand roving, the strands are looped back and forth on themselves and held in place by a slight twist and resinous sizing. Chopped strands and chopped rovings $1 / 8$ in. to 2 in. are the most widely used reinforcement. 


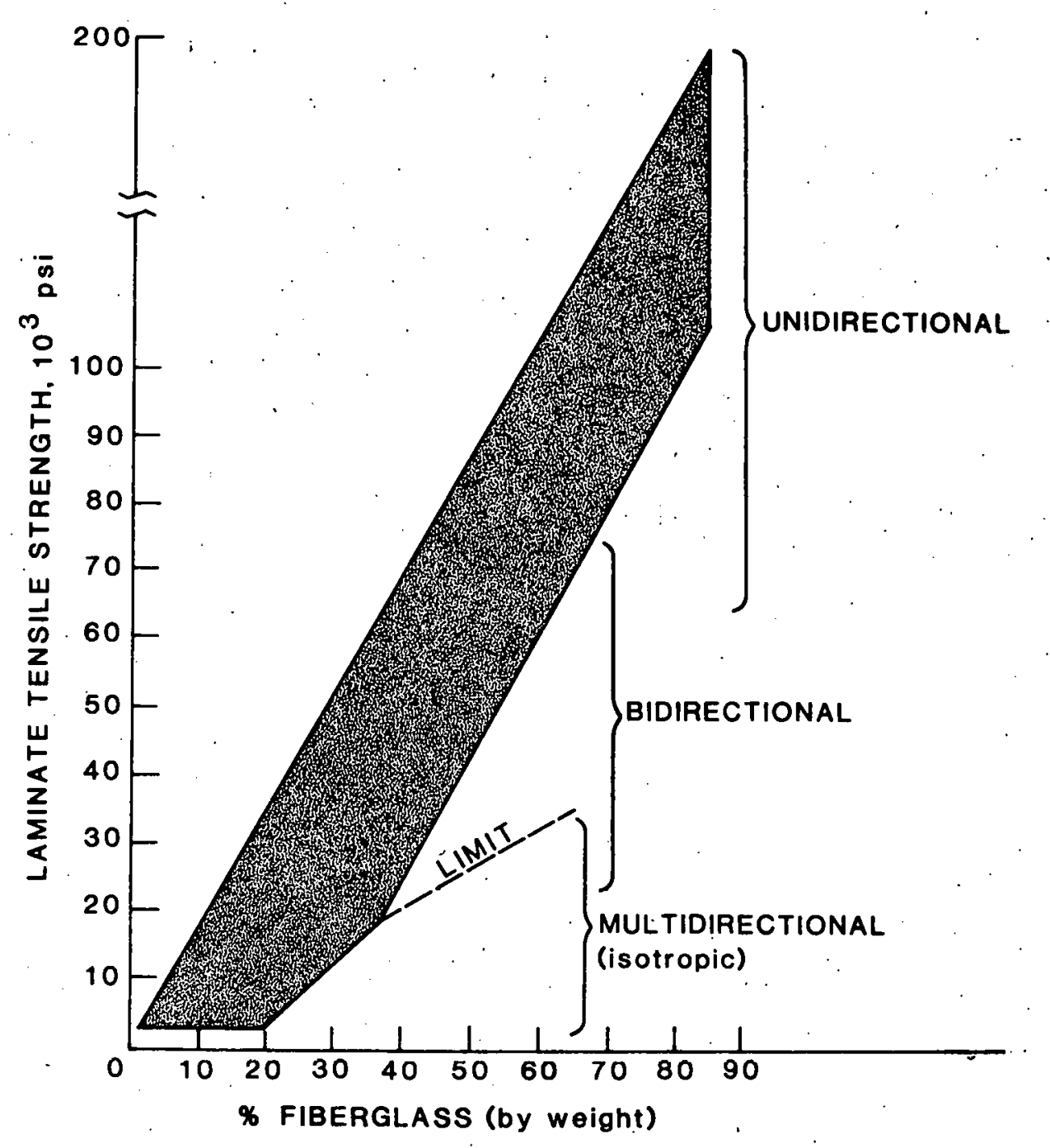

Fig. 2.3 Fiber-Reinforced Plastic Composite Tensile Strength as a Function of Fiberglass Quantity and Orientation (Source: Adapted from Ref. 6)

Milled fibers are continuous strands that have been hammer-milled into short particles of glass ranging in length from $1 / 64$ in. to $1 / 4$ in. Reinforced mats are formed by dropping chopped strands in a swirling pattern onto a flat surface, so that the strands are randomly oriented in a twodimensional pattern. The strands are usually held together by resinous binders. Woven rovings are formed by weaving rovings with conventional techniques into a material weighing $12-48 \mathrm{oz} / \mathrm{yd}$. Table 2.3 gives the relationship of fiberglass form to fiber orientation and molding processes (see Sec. 2.5).

Advanced composite materials deserve attention because of their potential future importance. However, their high cost has thus far prevented their adoption in al.1 but specialty applications, such, as oporto equipment. Graphite reinforced tennis rackets and archery bows, for example, have begun to 
Table $2.3^{-}$Relationship between Fiberglass Orientation; Form, and Fabricating Process

\begin{tabular}{|c|c|c|}
\hline Orientation & $\because$ Form & Fabricating Process \\
\hline Unidirectional & $\begin{array}{l}\text { Cont inuous strand } \\
\text { Continuous strand roving }\end{array}$ & $\begin{array}{l}\text { Continuous pultrusion } \\
\text { Filament winding }\end{array}$ \\
\hline$\therefore \therefore$ & Spun strand roving & Hand lay-up \\
\hline Bidirectional & $\begin{array}{l}\text { Woven roving } \\
\text { Woven fabrics }\end{array}$ & $\begin{array}{l}\text { Hand lay-up } \\
\text { Fil ament winding. }\end{array}$ \\
\hline Multidirectional & $\begin{array}{l}\text { Chopped strand or roving } \\
\text { Reinforced mat } \\
\text { Millfd fibers }\end{array}$ & $\begin{array}{l}\text { Hand lay-up } \\
\text { Spray-up } \\
\text { Comprcssion } \\
\text { Injection ... } \\
\text { Stamping } \\
\text { Laminating }\end{array}$ \\
\hline
\end{tabular}

be popular.* . Additional situations may be expected to develop in the future where ACM performance benefits outweigh cost considerations. 'An extremely important instance where this may occur is in automobile materials usage. Standard FRP are already being introduced at a rapid rate in order.to achieve improved fuel economy. If rigorous regulatory standards are imposed for the years beyond 1985, ${ }^{*}$ ACM may have to be employed regardless of cost. With this in mind, Ford Motor Company built and exhibited at the 1979 SAF Exposition in Detroit an experimental car that uses ACM as much"as possible. The car was designed to match the appearance and performance rhararteristics of the intermediate-sized Ford Granada. The impressive weight reductions achieved by displacing steel components with ACM are shown in Table 2.4.

Different kinds of ACM have been developed; including silicon carbide whiskers, carbon/graphite fibers, and aramids.7 Whiskers are the ultimate reinforcement in that they have mechnical strengths equivalent to the forces between adjacent atoms. Their strength stems from their essentially perfect. crystalline structure and their extremely small diameter. These characteristics allow little room for the defects that weaken larger crystals. Figure 2.4 shows how whisker strength increases with decreasing in diameter. Test data on sapphire whiskers have demonstrated tensile strengths greater than $4 \mathrm{x} \cdot 10^{6}$. psi and a Young's modulus greater than $100 \times 10^{6} \mathrm{psi}$. This' compares with steel!'s. tensile: strength of $50 \times 10^{3} \mathrm{psi}$ and Young's modulus of $28 \times 10^{6}$ psi. However, whiskers have not been produced commercially and their projected price is quite high.

*The costs of ACM are expected to decrease as increased production leads to economies of scale. For example, graphite fihers now costing $\$ 20 / 1 \mathrm{~b}$ are. projected to decrease to less than $\$ 10 / 1 \mathrm{~b}$ when annual output reaches $1 \times 10^{6}$ 1b. Even that price, however, greatly exceeds the $\$ 0.60-0.70 / 1 \mathrm{~b}$ cost of fiberglass: For this reason, hybrid systems of graphite and glass fibers. have the greatest potential for high-strength applications.

* Congress has debated standards of $35-40 \mathrm{mpg}$ in the $1990 \mathrm{~s}$. General Motors Corporation has indicated they can attain such levels. 8 
Table 2.4 Component Weight Savings in the Ford Motor Company Lightweight Vehicle Program

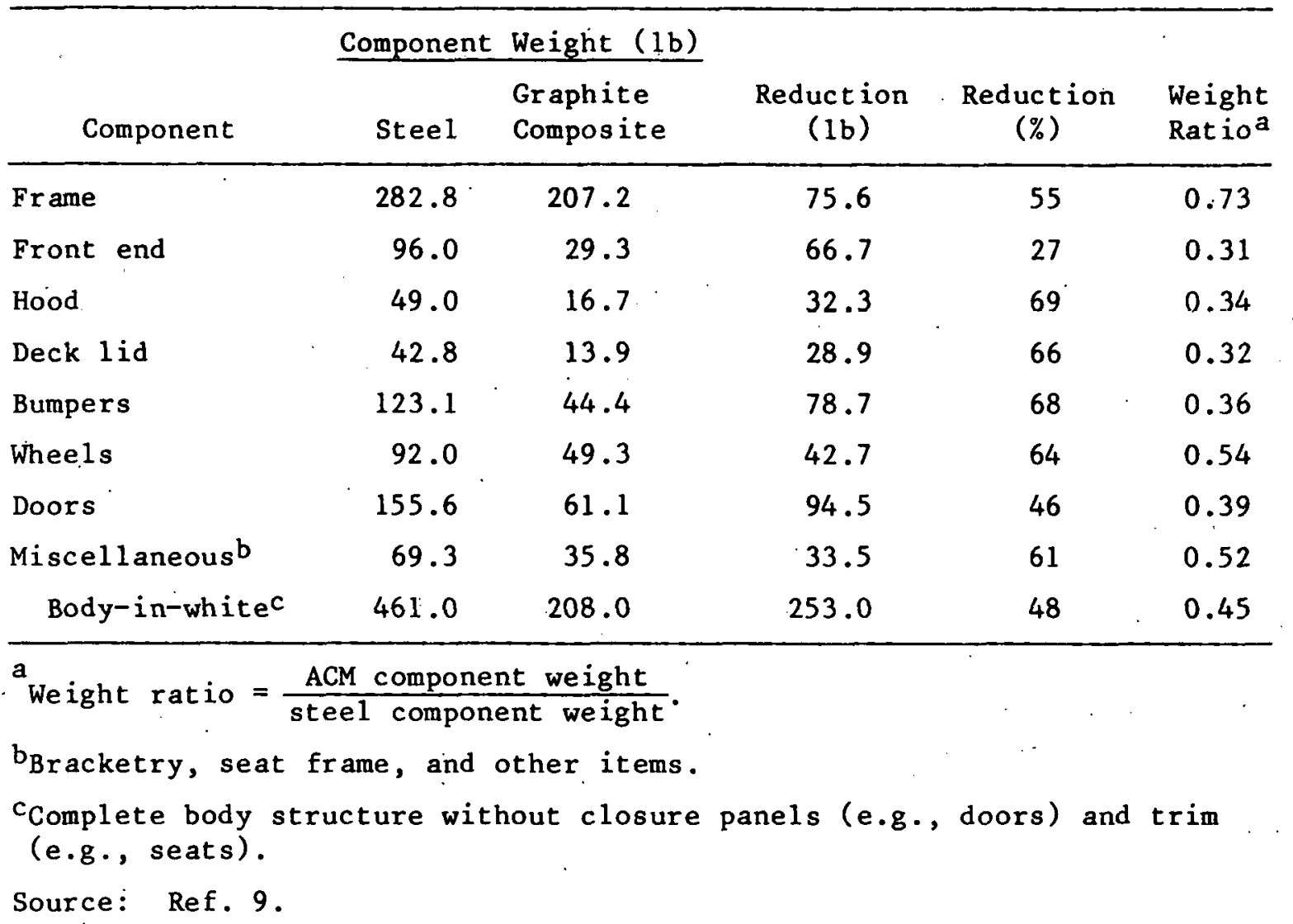

Most discussion of ACM centers on carbon/graphite and aramid fibers. Carbon/graphite fibers have a matrix of amorphous carbon filled with acicular microcrystallite fibrils. Aramid fibers, such as Kevlar ${ }^{\text {tw }}$; consist of lightly bound bundles of relatively long polymer chains in a semiparallel array. A comparison of the tensile properties of whiskers and carbon/ graphite, aramid, and glass fibers is shown in Fig. 2.5. Each ACM has a larger Young's modulus than glass fiber and, except for whiskers, has approximately the same yield strength.

\subsection{FILLERS}

Historically, fillers have been employed in FRP systems to reduce costs and to achieve desired flow properties. The most widely used fillers cost less than $\$ 0.20 / 1 \mathrm{~b}$, compared to $\$ 0.55-0.70 / 1 \mathrm{~b}$ for the fiberglass or resin that they displace. For example, UPE resin costs $\$ 0.56-0.59 / 1 \mathrm{~b}$. Approximately 55\% (by volume) resin is required to achieve the necessary wetting of fiber and filler under most conditions. During processing, the granular or platelet filler particles flow more easily than the rodlike

* Kevlar is a registered trademark of E.I. DuPont de Nemours \& Company. 


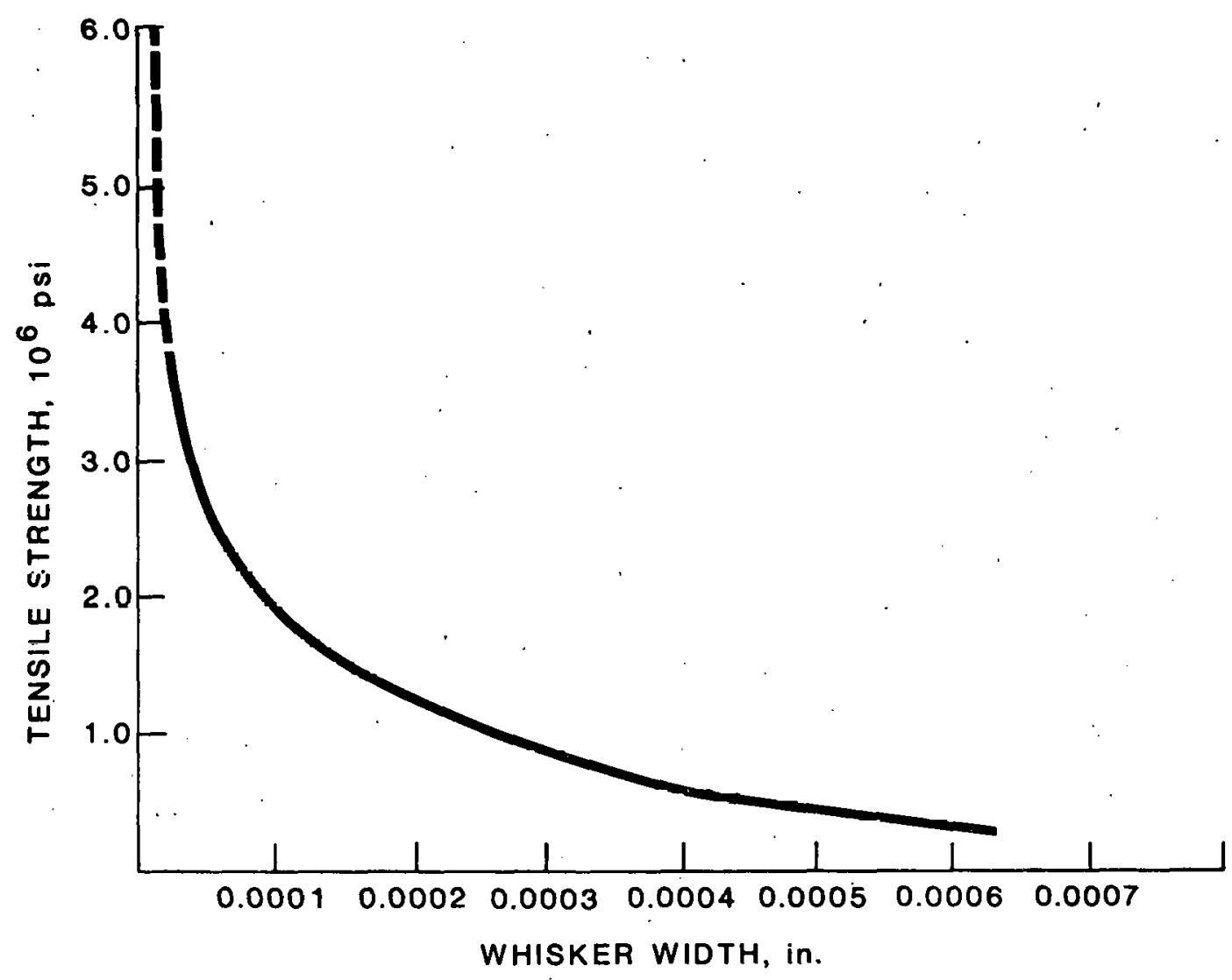

Fig. 2.4 Whisker Tensile Strength as a Function of Diamctcr (Eource: Adapted fium Ref. 7)

reintorcement fibers. Therefore, fillers reduce the pressure necessary for molding and permit more complex shapes.

The quantities of fillers consumed in 1979 and estimated consumption for 1980 are shown. in Table 2.5. Calcium carbonate represents by far the largest usage, with talc minerals and clays a distant second and third. These three fillers account for $87 \%$ of total usage. An important filler, which is included under "Miscellaneous" in Table 2:5, is hydrated alumina. It furnishes good electrical properties and flame resistanre.

A property of calcium carbonate that leads to its extensive usage is its low oil absorptivity. This property is a function of the specific. surface of the particles, with nonporous particles absorbing less oil than porous particles of the same size. Since low oil absorptivity permits more filler to be used, other fillers often are used in conjunction with calcium carbonate to achieve a desired property. Clay, for example, provides better flow and molding properties than calcium carbonate, but is poor with regard to color. The clay usually comprises only $10-20 \%$ of the filler.

Another capability of fillers has been recently recognized, i.e., when properly matched to the resin and reinforcement system, fillers themselves provide significant reinforcement. 11 Filler manufacturers have been pursuing an active research and development program in this area in order to 


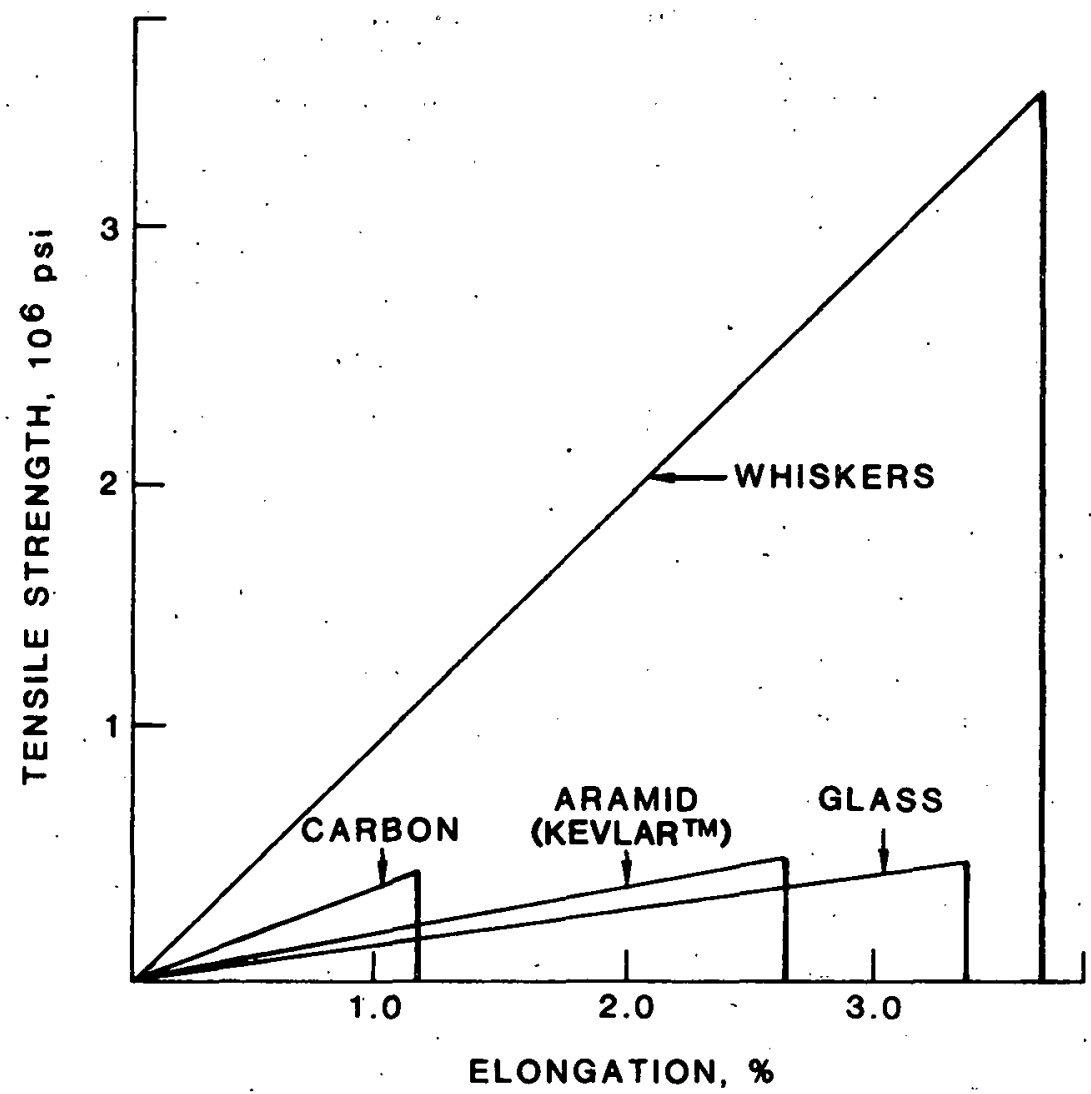

Fig. 2.5 Tensile Strength of Whiskers and Carbon, Aramid, and Glass Fibers (Source: Adapted from Ref. 7)

capitalize on the cost advantage they now have over both resin and reinforcing materials. The primary focus has been on TP resin applications, including RTP, but the results apply to TS systems as well.

The nature of the findings obtained for filler reinforcement is illustrated in Fig. 2.6. The top curve in this figure is for glass-fiberreinforced $P P$, with no filler. The bottom curve is for PP with inorganic filler, but no glass reinforcement. Each of the intermediate curves represents $P P$ with $a$ mixture of glass-fiber reinforcèment and inorganic filler. For example, the curve 1 abeled $20 \% \mathrm{~g} 1$ ass fiber also. contains $10 \%$ filler at a total reinforcement of $30 \%, 20 \%$ filler at $40 \%$ reinforcement, and so on. The figure shows that a substantial fraction of the flexural strength at $40 \%$. total reinforcement can be obtained by a system containing equal parts of glass and filler. This represents. a considerable cost reduction relative to the glass-only system.

\section{$2.4^{-}$MOLDING COMPOUNDS}

The resin, filler, and reinforcement can be joined together during the molding operation, as is done in hand lay-up and spray-up'molding. In high throughput operations, however, as is the case for most automotive 
Table 2.5 Filler Consumption $\left(10^{6}\right.$

1b)

\begin{tabular}{|c|c|c|}
\hline \multirow[b]{2}{*}{ Material } & \multicolumn{2}{|c|}{ Consumption } \\
\hline & 1979 & $1980^{a}$ \\
\hline Carbonates $^{b}$ & 2805 & 3366 \\
\hline Clays & 264 & 316.8 \\
\hline Cork & 2.2 & 4.4 \\
\hline Glass $c$ & 24.2 & 28.6 \\
\hline Mica & 26.4 & 33 \\
\hline Perlite & 8.8 & 11 \\
\hline Shell flourgd & 11 & 13.2 \\
\hline Silicase & 101.2 & 121 \\
\hline Starch and cellulosics & 147.4 & 176 \\
\hline Talc minerals & 330 & 396 \\
\hline Wood flour & 112.2 & 132 \\
\hline Miscellaneous $f$ & 77 & 92.4 \\
\hline Total & 3909.4 & 4690.4 \\
\hline
\end{tabular}

astimated.

${ }^{b}$ Calcium carbonate, chalk, limestone, eti.

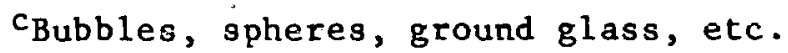
Docs not include fiber reiufurcements.

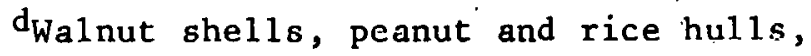
soybeans, etc.

eNovaculite, sand, quartz, etc.

$f_{\text {Plastic spheres, various inorganic }}$ compounds, etc.

Sulcie: Ref. 10.

applications, a molding compound containing all the necessary chemical, filler, and reinforcement constituents is formulated at an earlier stage in the production sequence. The molding operation then consists of pressing the compound into the desired shape, holding it in position until the cure is complete, and removing the heat released during curing. Uniform heat removal is essential as the product cools from a maximum polymerization temperature slightly above $350^{\circ} \mathrm{F}$. Otherwise, sink marks and surface cracks appear on the finished product.

There are three main types of molding compound: preforms, bulk molding compounds (BMCs), and sheet molding compounds (SMCs). Preforms are 


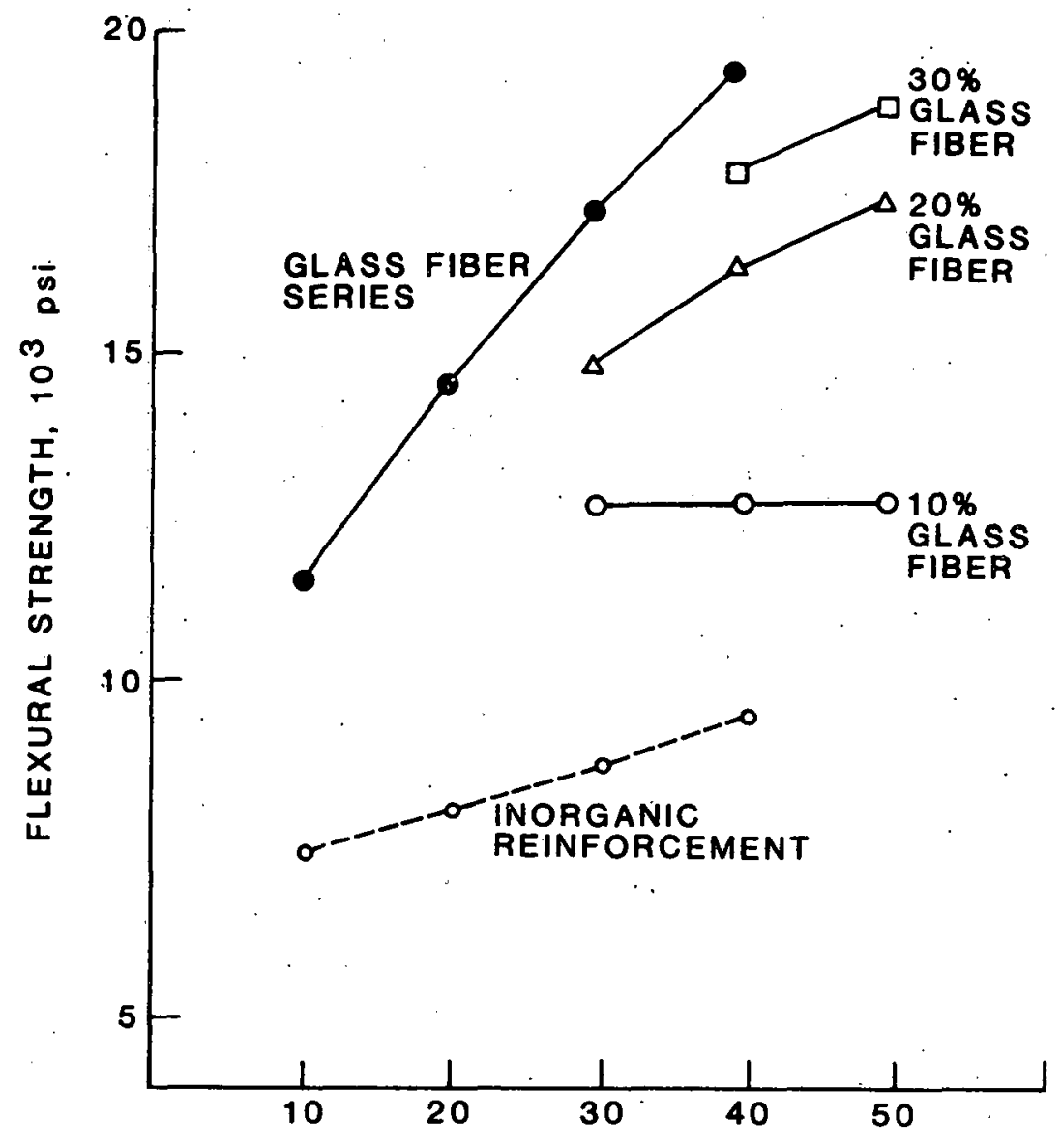

\% TOTAL REINFORCEMENT CONTENT (by weight)

Fig. 2.6 Flexural Strength of Polypropylene as

a Function of Total Reinforcement

(Source: Adapted from Ref. 11)

mats of chopped strands held together by binder and formed into the approximate shape of the part to be molded. The use of preforms is gradually being. phased out in most automotive applications. Bulk molding compounds are modeling-clay-like mixtures provided in bulk form or extruded into ropelike shapes to facilitate handling. The glass fibers are from $1 / 8$ in. to $1-1 / 4$ in. in length. As their name indicates, SMCs are assembled in sheet form. Sheet molding compounds can accommodate fiberglass lengths up to 2 in., which enhances their mechanical properties relative to BMCs. Sheet molding compounds must be layered before molding if parts of greater than $1 / 4 \mathrm{in}$. thickness or of variable cross section are to be formed." Recently, a thick molding compound, $\mathrm{TMC}^{\mathrm{m}}$, * version of $\mathrm{SMC}$ has been developed that reduces the need for layering, thereby avoiding the internal weaknesses that such joints involve. This compound can be molded in thickness up to 2 in. However, SMC thickness suffices for most automotive needs.

The process sequence for producing SMCs is shown in Fig. 2.7. The resin mix is spread on two carrier films (e.g., polyethylene or nylon) by

*TMC is a registered trademark of USS Chemicals. 


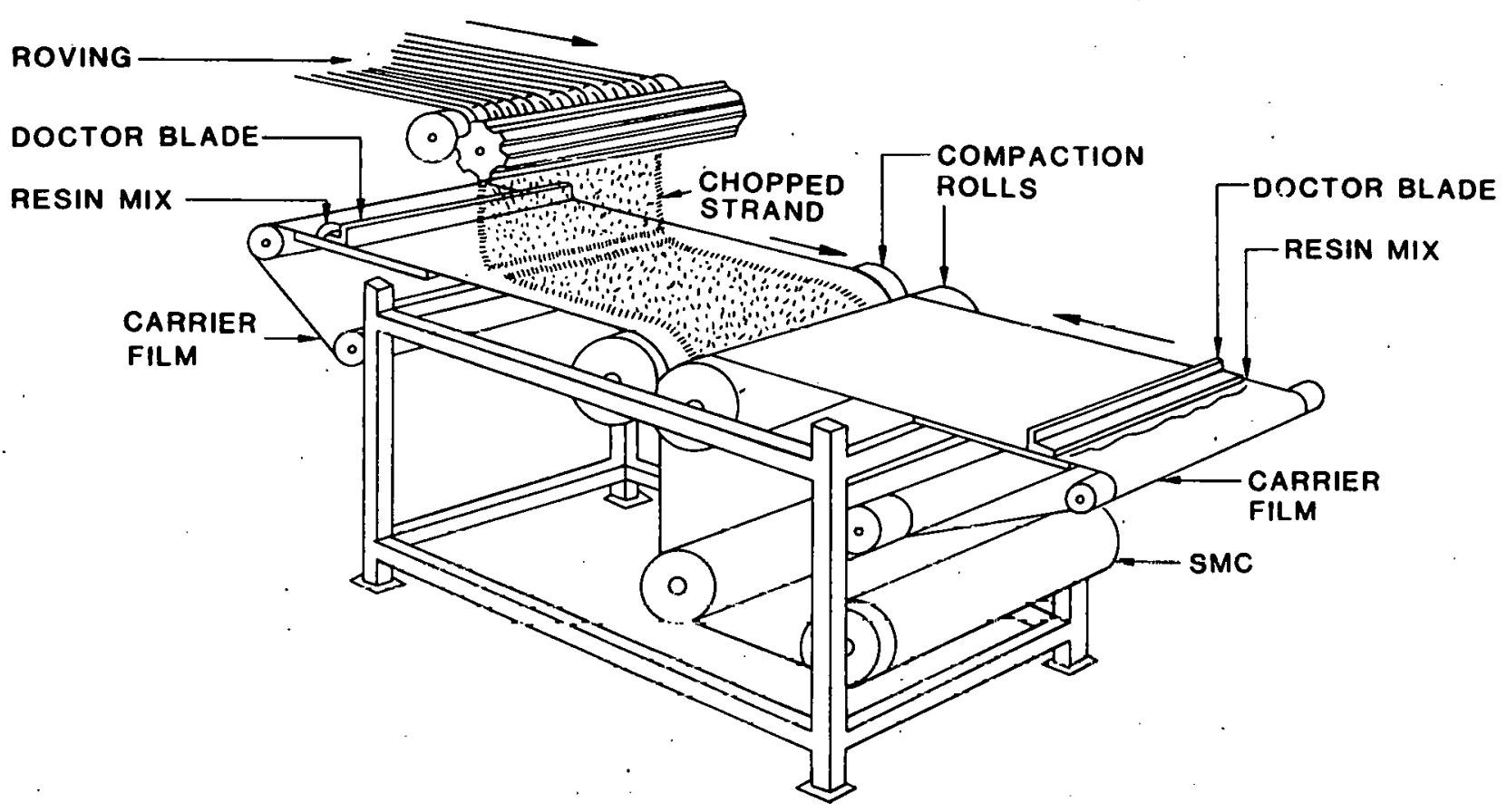

Fig. 2.7 Sheet Molding Compound Process (Source: Adapted from Ref. 6)

doctor blades. As the two films move together, chopped roving fiberglass strands are dropped in a random pattern onto one of the resin films. The two films are pressed together by compaction rolls to wet out the fiberglass and form the SMC product. The SMC is then rolled or cut up into sections and stacked in a maturation room having controlled temperature and humidity. Its apparent viscosity increases dramatically over time from $7000 \mathrm{cp}$ after mixing to 15-8U x $10^{6} \mathrm{cp}$. A thickening agent, such as magnesiun oxide, is usually added to facilitate the thickening process. At the end of the treatment period, the SMC can be handled and shipped easily. During molding, the viscosity is initially reduced by heating; then, being pseudoplastic, the viscosity adjusts further. under mold pressure so that the material flows readily.*

\subsection{MOLDING PROCESSES}

The second, or curing, stage of the chemical reaction sequence desur ibed in Sec. 2.1.1 takés place. during the molding process. The reactive monomer participates in the development of cross-linkages between the unsaturated dibasic anhydride groups. The reaction takés place under pressure in the mold and is initially energized by heat. In addition, a catalyst, or curing agent, is usually added to the SMC formulation to insure that the reaction proceeds rapidly. Typical curing agents are benzoyl peroxide,

* The viscosity of pseudoplastic materials decreases as stress is increased. Thus, resistance to flow is greatest at low stress and decreases steadily as greater stress (molding pressure) is applied. 
MEK-peroxide, di-t-butyl peroxide, and dicumyl peroxide. Rapid curing is extremely important. Although the actual molding operation can be completed in about $20 \mathrm{~s}$, the part must remain in the mold for nearly $2 \mathrm{~min}$ until curing is complete. This 2-min requirement increases capital cost, because a number of molds must be operated in parallel in order to achieve the large throughputs desired in the automobile industry. For example, if the molding time were reduced to $1 \mathrm{~min}$, the number of molds required for a given throughput could be nearly cut in half. The time required for curing can be contrasted with the few seconds required for a steel or aluminum stamping operation. Manufacturers of FRP have attempted to counteract this disadvantage by achieving parts consolidation, so that a single nolding operation accomplishes the same function as a number of stamping and joining operations.

The two molding processes most widely used for FRP applications in the automotive industry are shown in Fig. 2.8. In compression molding, a measured amount of molding compound is placed in the heated mold, and the mold sections are forced together to form the part. After the approximately 2-min curing period, the mold is opened and the part ejected. In injection molding, on the other hand, the heated plastic is forced into a closed mold. If the FRP is based on a TP resin, the resin is heated before entering the mold, which is then cooled. For TS-resin FRP, cool material is forced into a heated mold. Compression molding is usually used for TS-resin FRP, and injection molding for

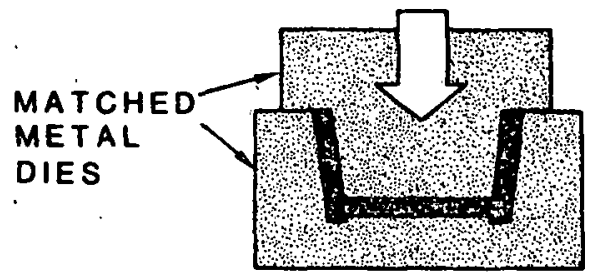

(a) COMPRESSION MOLDING

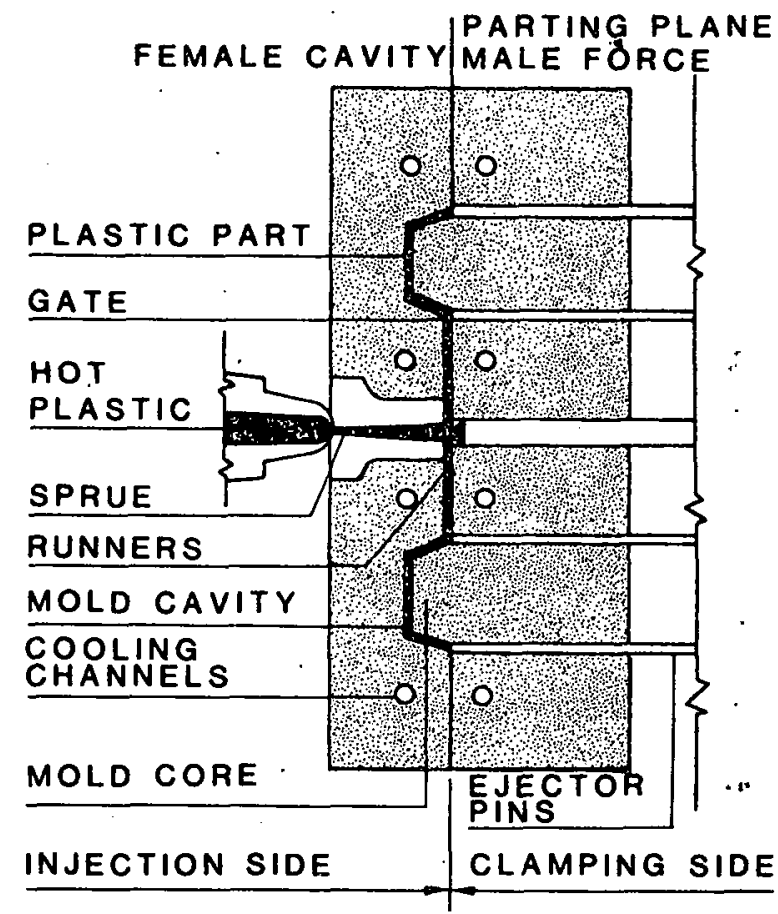

(b) INJECTION MOLDING

Fig. 2.8 Compression and Injection Molding, the Two Most Important Automobile Molding Processes (Source: Adapted from Refs, 12 and 13) TP-resin FRP. The advantages of compression molding are its ability to accommodate longer, oriented fibers and its lower scrap rate. The advantage of injection molding is higher throughput.

Additional closed-mold approaches for FRP are resin transfer and rotational molding. Pultrusion is used when continuous cross-sectional shapes are desired and is a semi-closed mold technique, whereby the filament is pulled through the die. Finally, a number of open-mold techniques are used, 
including hand lay-up, spray-up, and filament winding. Hand lay-up and spray-up were the earliest methods used in FRP, applications. Highly labor interisive, these open-mold techniques continue to be used in special applications, such as large boat hulls. Filament winding is employed when large, symmetrical shapes with continuous, oriented fibers are desired; such as aerospace fuel tanks. 


\section{ENERGY REQUIREMENTS}

As discussed in Sec. 2, FRP systems consist of three principal components: plastic resin; reinforcement, and filler. The relative types and quantities of each component depend on the material characteristics desired. From an energy viewpoint, the plastic resins are of greatest interest because they involve substantially larger amounts of energy and because a wide variety of alternative processes and material combinations are possible. In addition, plastic resins are the only component requiring hydrocarbon feedstocks in their manufacture.

\subsection{PLASTIC RESINS}

\subsubsection{Chemical Process Sequences}

Each plastic resin is the end product of a process sequence derived from one or more hydrocarbon feedstocks. The nature of such process sequences can be most easily described by considering a specific example, polyethylene manufacture. Figure $3.1(a)$ indicates that polyethylene can be manufactured via a two-step process sequence starting with ethane as the feedstock. In order to determine the feedstock and process energies attributable to polyethylene production via this sequence, it is necessary to trace back along the sequence, accumulating the relevant energies at each step. Thus, process energy includes the energy consumed in processes 17 and 1 , the latter being weighted for level of participation. (The manner of weighting process and feedstock participations is described in Sec. 3.1.2.) The feedstock energy is the combustion energy of the amount of ethane required to produce 1 ib of polyethylene.

Ethylene also can be manufactured from alternative sets of raw materials via different process sequences as illustrated in Fig. 3.1(b). This diagram indicates that ethylene can be manufactured by two alternative process sequences, from naphtha as well as from ethane. Other feedstocks include propane, butane, refinery gas, and gas oils (atmospheric and vacuum gas oil). In fact, approximately $50 \%$ of the ethylene manufactured in the United States is derived from naphtha and gas oils. For the sequences illustrated by Fig. $3.1(b)$, it is necessary to allocate the energy requirements between the two branches in proportion to the relative participation of each. These participations, termed process splits, must be determined before the sequence energies can be. calculated.

An additional complexity is that chemical processes frequently produce more than one marketable product. This io illustrated in Fig. $3.1(\mathrm{c})$. Other olefins (e.g., propylene and butadiene) are produced in processes 1 and 2. If the additional products are of equivalent value, they are termed coproducts. If they are of significantly less value, the economics of the process are dominated by the main product and the additional. products are known as by-products. In either case, it is important that the energy costs of the process be allocated among all products. The energy costs could be allocated in a number of ways, e.g., by the economic value or by the embodied energy of the various outputs. However, allocation usually is made on the 


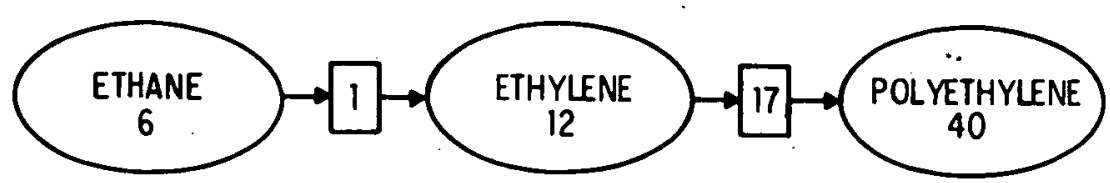

(a) TWO-STEP PROCESS SEQUENCE

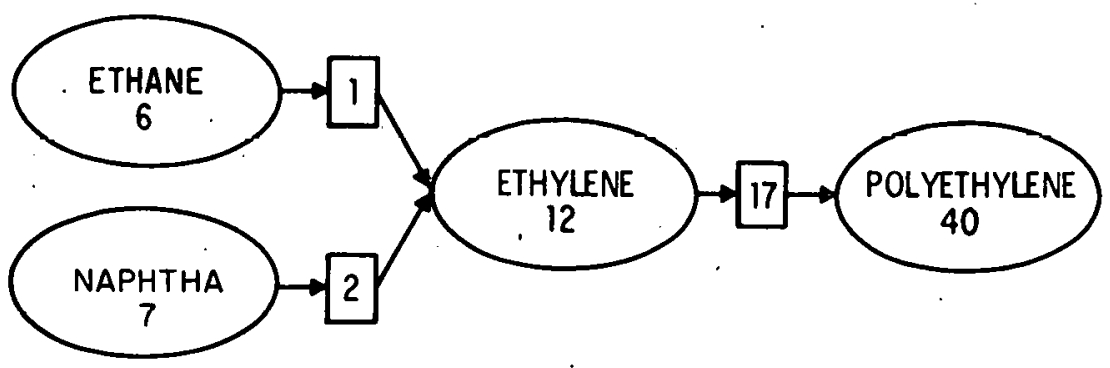

(b) PROCESS AND RAW MATERIAL ALTCRNATIVIS

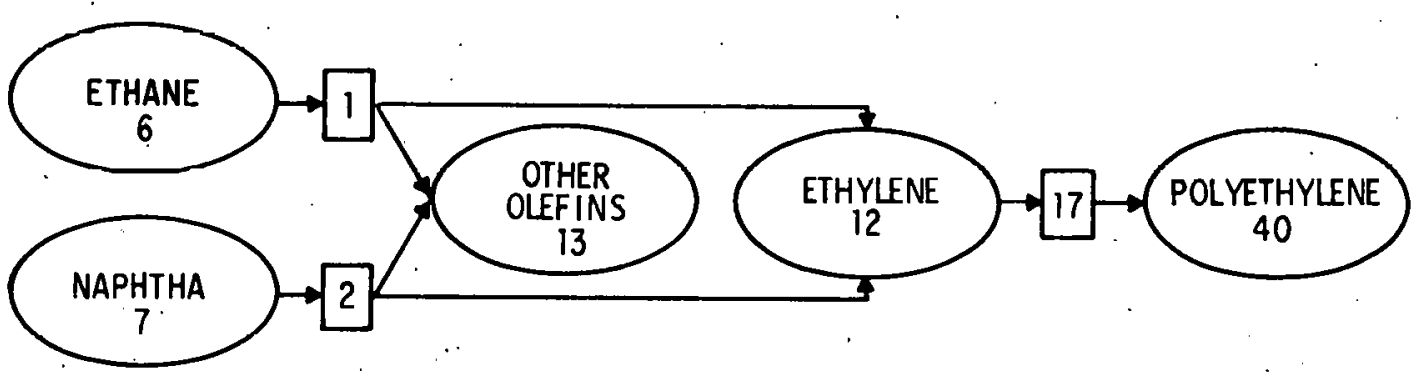

(c) COPRODUCTS

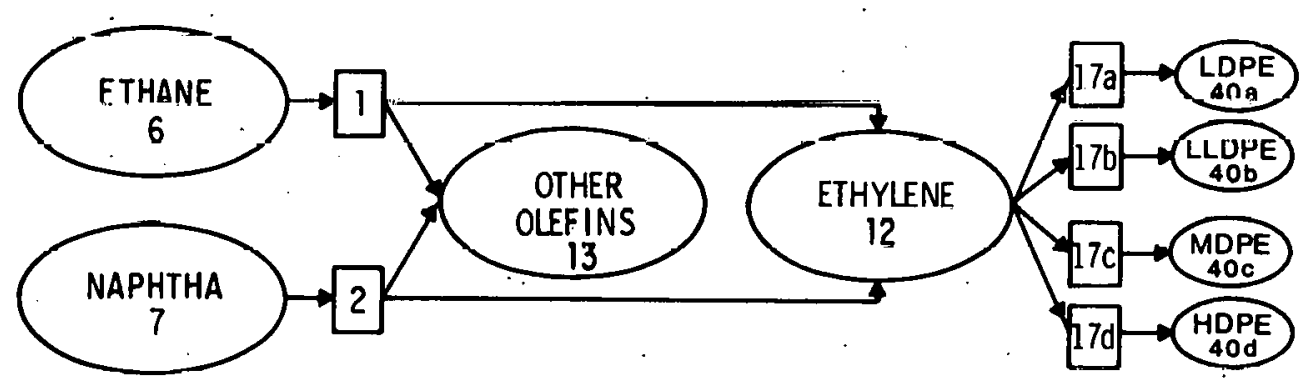

(d) CLOSELY RELATED PRODUCTS

OVALS DENOTE MATERIALS; BOXES DENOTE PROCESSES

Fig. 3.1 Chemical Process Sequences

basis of weight shares of the product output. Thus, if $\alpha 1 \mathrm{~b}$ of product $A$ and - $B$ 1b of product $B$ are produced from a process requiring $P_{c}$ units of process energy, the energy cost to $A$ is specified as $[\alpha /(\alpha+\beta)] P_{c}$ and that of $B$ as $[\beta /(\alpha+\beta)] P_{C}$. Feedstock energy allocations are made in the same way.

Another aspect of process sequences is shown in Fig. 3.1(d). In this case, four different, but closely related, plastic resins can be produced from ethylene. The four products are LDPE, 1 inear-1ow-density polyethylene (LLDPE), medium-density polyethylene (MDPE), and HDPE. These products require 
different catalyst systems and reaction conditions (e.g., temperature and pressure) and have significantly different characteristics. In addition, the energy requirements can be quite different, even for the same product. For example, a recent development in LLDPE manufacture has reduced the process energy requirements for process $17 \mathrm{~b}$ by $45 \%$. However, most of the process energy rquirements for processing LLDPE occur at earlier steps in the process sequence. This highlights the fact that energy analyses of chemical production processes must be made within the context of the overall process.

An additional property of petrochemicals necessitating that their economic. and energy aspects be appraised within the process sequence context is shown in Fig. 3.2. This diagram illustrates how: (1).ethylene acts as a full participant in process sequences leading to three competing plastic end products (HDPE, PS, and PVC), and (2) propylene, which is produced as a coproduct to ethylene in processes 1 and 2 , acts within another process sequence leading to a fourth plastic end product, PP. In fact, ethylene participates in many other process sequences leading to both plastic and nonplastic end products. A comparable situation with respect to metals would be if steel and aluminum were produced as coproducts in several processes and then were employed as key ingredients in the manufacture of other metallic products, such as copper and zinc. Metal alloys are produced, of course, but in most instances one metal plays the dominant role. Petrochemicals are unique in the diversity of products that can be obtained from a single feedstock. In a way, this has a simplifying effect. No matter which chemical end product wins out, the demand for olefins (ethylene, propylene, and butylenes) will be generally maintained. Although there are several other important chemicals, especially the aromatics (benzene, toluene, and xylene), olefins are the central participants in the petrochemical industry. Thus, energy conservation achieved in their manufacture reduces the energy/product ratio for nearly all petrochemicals.

Figures 3.1 and 3.2 illustrate what must be taken into account in determining plastic resin energy requirements. However, the sequence examined in Fig. 3.1 is one of the simplest to be encountered for plastic resins. The more complex sequences will be illustrated through an examination of the

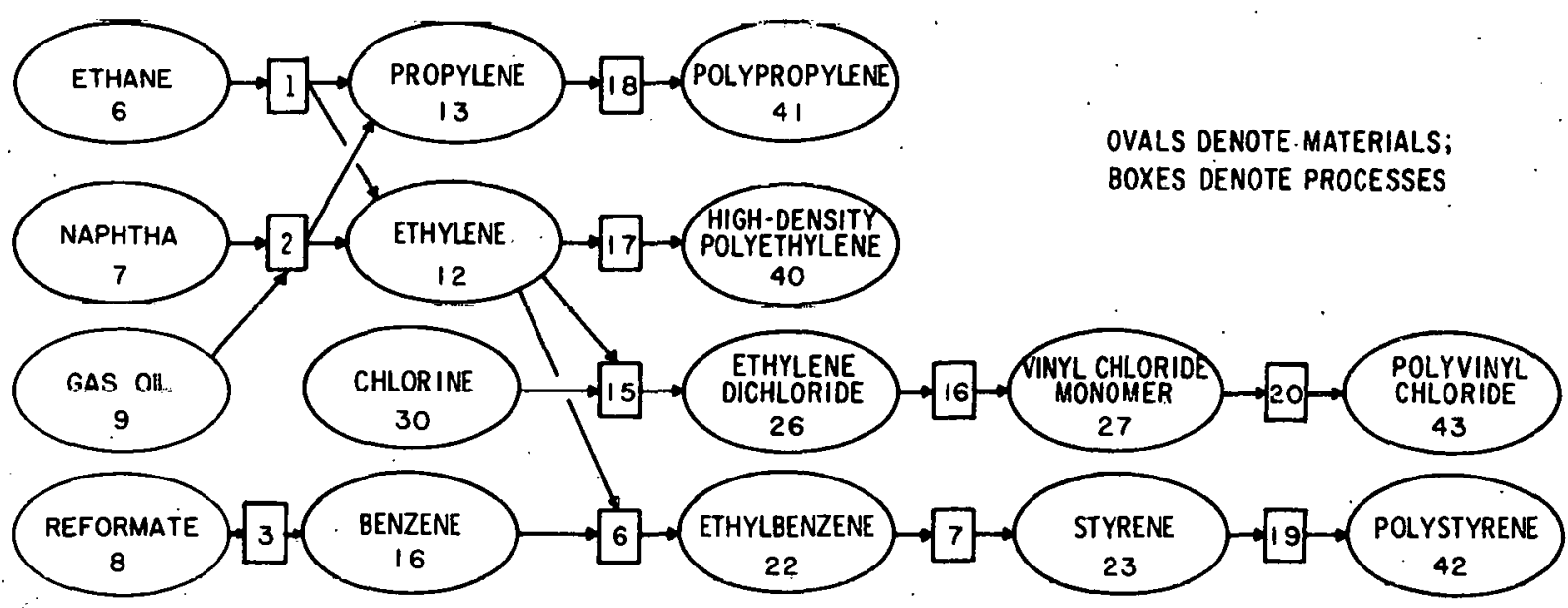

Fig. 3.2 Interrelationships among Market-Competitive Plastic Resins 
process sequences involved in UPE manufacture. First, though, a general set of equations will be developed to enable systematic evaluation of process and feedstock energies, even for the more complex situations.

\subsubsection{Sequence Energy Computations}

To evaluate sequence energies, it is necessary to establish nomenclature regarding the participating materials, processes, and their interrelationships, Figure 3.3 depicts a gencric sequence configuration that includes the major parameters. Here, material 4 is made from material 3 via process 3 . The pounds of material 3 required to produce 1 lb of material 4 via process 3 is given by $a_{4}^{3}$, where the superscript denotes the process and the two subscripts denote, ${ }^{4}$ respectively, the output and input materials. This variable is known as an input cneffirient, sinse it idcntifies the necessary input quantity for a unit output, * The process encrgy of process 3 io designated ds $P_{3}$.

Moving back along the process sequence, material 3 can be made from either material 1 or material 2. In any given year, the fraction of material 3 made from material 1 via process 1 is given by $x_{1}^{3}$. This variable is known as the process split. Likewise, the fraction of material 3 made via process 2 is designated $x_{2}^{3}$; the superscript denotes the output material and the subscript denotes the process. Since the two processes encompass all contributions to production of material $3, x_{1}^{3}+x_{2}^{3}=1$. The other variables shown for processes 1 and 2 have the same meaning as the equivalent variables defined for process 3 .

The final variables in Fig, 3.3 are the feedatock energies, $I_{1}$ and $f_{2}$. These represent the combustion energies of materials 1 and 2 . In most

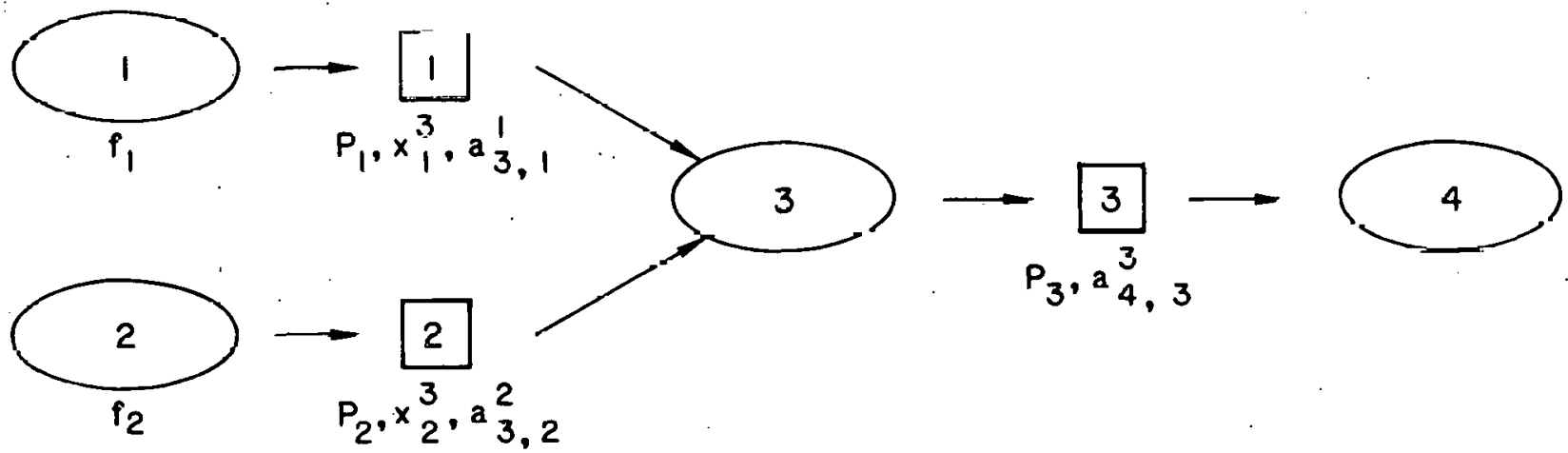

Fig. 3.3 Configuration and Parameters of a Generic Process Sequence.

*Output coefficients, on the other hand, designate where the outputs of a given material go. For example, if material 3 contributes to production of materials 4, 10 , and 12 , its output coefficients would identify for each pound of material 3, what fraction of the pound enters into production of each of the three materials. 
evaluations, the convention is to take the higher heating value (HHV) as the representative combustion energy. Higher heating value is defined as the total heat released when the hydrocarbon is completely converted to carbon dioxide and water at $25^{\circ} \mathrm{C}$ and constant pressure and when the water is condensed to release its latent heat of vaporization. Lower heating value (LHV) is obtained by subtracting water's latent heat of vaporization from the HHV.

As Fig. 3.3 shows, the first step in evaluating the energies associated with process sequences leading to plastic end products is to characterize the individual participating processes. Each process must be defined as to the quantity of inputs -- materials and energy -- required to produce the desired output. For example, consider the production of ethylene from ethane, shown as process 1 of Fig. $3.1(\mathrm{c})$. Ethylene is produced as the principal product, accompanied by a set of olefin coproducts. The material and energy requirements of this and related processes are examined in Refs. 14 and 15 . Using the nomenclature just defined, the material and energy requirements of process 1 were found to be:

$$
\begin{aligned}
a_{12,6}^{1} & =1.27 \\
f_{6} & =22.3 \times 10^{3} \mathrm{Btu} / 1 \mathrm{~b} \\
\mathrm{P}_{1} & \left.=3.76 \times 10^{3} \mathrm{Btu} / 1 \mathrm{~b} \text { (fue } 1\right)
\end{aligned}
$$

Feedstock requirements cannot generally be assigned to a specific process, because they also depend on the preceding steps in the process sequence. In this case, however, ethylene production acts as the first step in the sequence. As a result, the feedstock energy requirement can be directly determined:

$$
\begin{aligned}
f_{12}^{S} & =a_{12,6}^{1}\left(f_{6}\right) \\
& =1.27\left(22.3 \times 10^{3}\right) \\
& =28.3 \times 10^{3} \mathrm{Btu} / 1 \mathrm{~b}
\end{aligned}
$$

where $\mathrm{f}_{12}$ is the sequence feedstock energy of producing material 12 (ethylene) from material 6 (ethane) via the one-step process sequence (process 1 ). The sequence process energy of the one-step sequence is:

$$
\begin{aligned}
P_{12}^{s} & =P_{1} \\
& =3.76 \times 10^{3} \mathrm{Btu} / 1 \mathrm{~b}
\end{aligned}
$$

More generally, process energy an be aggregated. into three overall categories: fuels, electric power, and steam. Fuels are usually expressed directly in thousand British thermal units required. Electric power is expressed in kilowatt hours required. Electric power can be converted into fuel equivalents by specifying the thermal factor, e.g., British thermal units per kilowatt hour. If the overall efficiency of electricity generation is taken to be $34.12 \%$, the thermal value of the electric power requirements is obtained in thousand British thermal units per pound by multiplying kilowatt hours by 10 . Steam requirements are usually expressed in terms of the 
pressure required. This suffices to designate both the steam temperature and energy content at saturation. Saturated steam between pressures of 100 psi and 3000 psi has an enthalpy ranging from $1000 \mathrm{Btu} / 1 \mathrm{~b}$ to $1200 \mathrm{Btu} / 1 \mathrm{~b}$, while typical steam generation efficiency ranges from $85 \%$ to $90 \%$. A reasonable estimate can be made by assigning steam the average energy value of $1.2 \times 10^{3}$ Btu/1b; as its energy does not vary widely over the usable pressure range. Process energy can then be calculated by the formula:

$$
P_{\alpha}=F_{\alpha}+(10)\left(K_{\alpha}\right)+(1.2)\left(S_{\alpha}\right)
$$

where:

$$
\begin{aligned}
P_{\alpha}= & \text { process energy per unit output of process } \alpha\left(10^{3} \mathrm{Btu} / 1 \mathrm{~b}\right), \\
\mathrm{F}_{\alpha}= & \text { fuel requirements per unit output of process } \alpha\left(10^{3}\right. \\
& \mathrm{BLu} / 1 \mathrm{~b}), \\
\mathrm{K}_{\alpha}= & \text { electricity requirements per unit output of process } \alpha \\
& (\mathrm{kWh} / 1 \mathrm{~b}), \text { and } \\
\mathrm{S}_{\alpha}= & \text { steam requirements per unit output of process } \alpha(1 \mathrm{~b} / \mathrm{b}) .
\end{aligned}
$$

As illustrated by the polyethylene example, calculation of sequence energies -- process and feedstock -- requires knowledge of the materials requirements of each process, the process splits, the individual process energies, and the feedstock energies. The approach to computing sequence energies will now be developed for specific plastic end products. Five plastic resins widely used in the automobile industry will be considered: HDPE, PP, PS, PVC, and UPE resins. The UPE resins are of greatest interest since; as discussed in Sec. 2, these TS resins are by far the most widely employed for $\mathrm{FH}$. 'The other four, which are TP resins, are more extensively used in general, and their use in FRP is increasing.

The first step in assessing the sequence energies of each resin is to identify the specific pathways leading from feedstock to resin. This is done for the four TP resins in Fig. 3.2 and for UPE in Fig. 3.4. The nomenclature used in these figures will facilitate later computation of sequence energies. The descriptive names and numerical designations used in these figures are listed for the materials and processes in Tables 3.1 and 3.2 , respectively.

Examination of the five plastics process sequences in Figs. 3.2 and 3.4 shows that the complexity of the sequences varies considerably. Polyethylene and $P P$ are both relatively simple sequences, involving only three processes. Polystyrene and PVC are of intermediate romplexity, involving six and five processes, respectively. Unsaturated polyester resins are of significantly greater complexity, involving 25 processes. In addition, each of these process sequences involves even greater variety or complexity than is shown in the figures. For example, ethylene can be made from ethane, propane, liquid petroleum gas ( $L P G$ ), naphtha, gas oil, and coal. Commercial processes already exist for each of these raw materials, except coal, and coal processes are being developed. Energy requirements vary among processes using different raw materials and among different commercial processes. Thus, while the two processes shown for olefin manufacture (processes 1 and 2) are representative of the range of processes employed, they are not the complete set. 


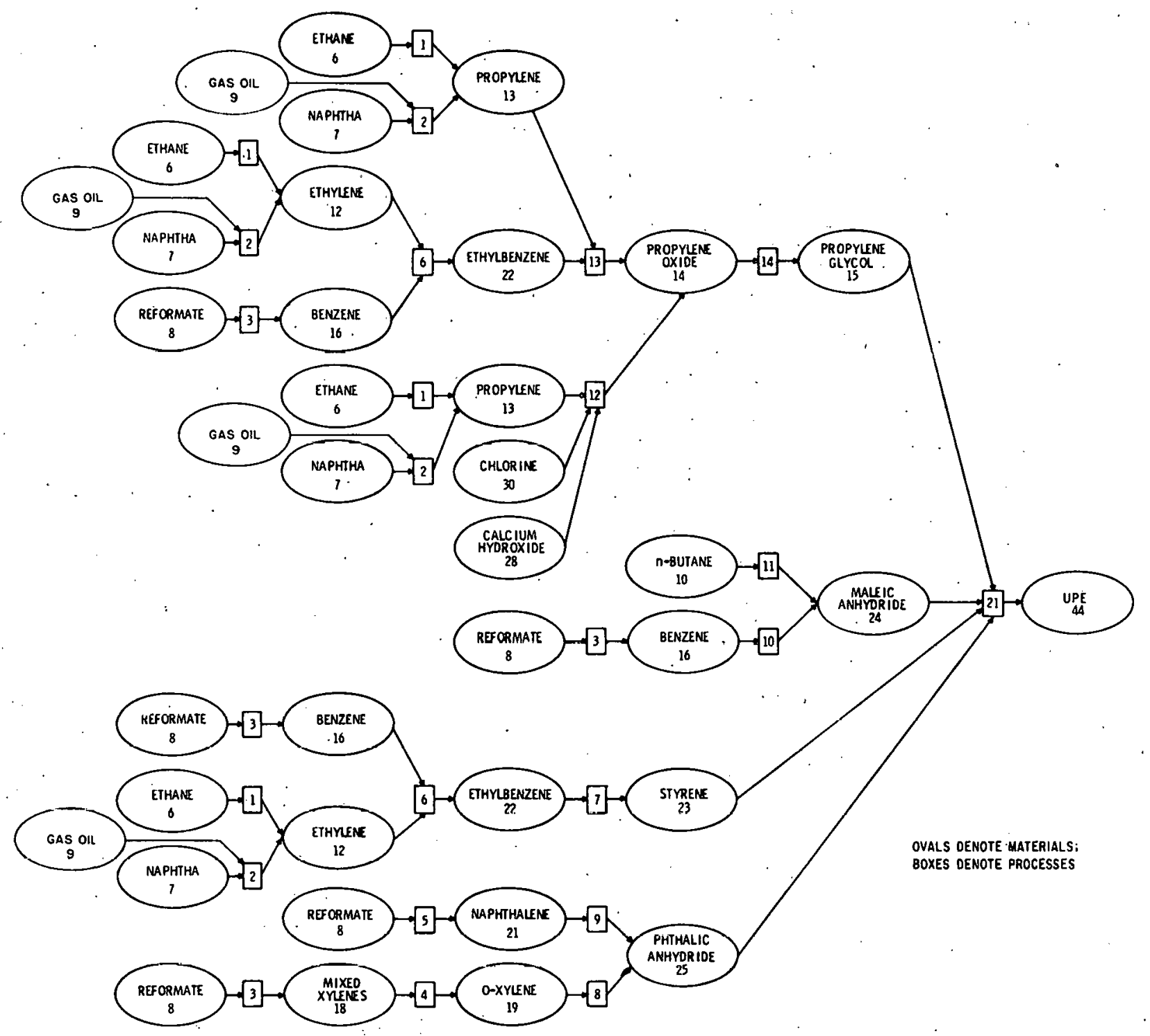

Fig. 3.4 Unsaturated Polyester Resin Process Sequence

Having identified the process sequence pathways, sequence energies can be determined. The formulas for doing this for a three-step sequence (processes $\alpha, \beta$, and $\gamma$ ) are:

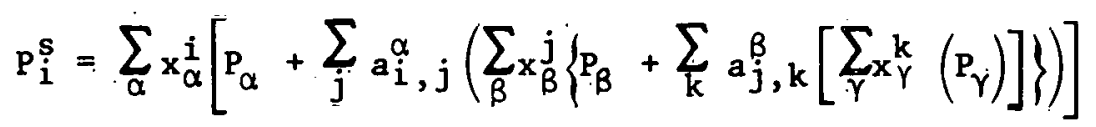

for process energy and

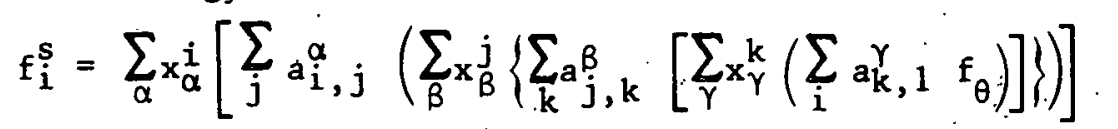

for feedstock energy where:

$$
\begin{aligned}
& \mathbf{P}_{\mathbf{i}}^{s}=\text { sequence process energy of chemical } i, \\
& \mathbf{x}_{\alpha}=\text { fraction of chemical } i \text { manufactured via process } \alpha,
\end{aligned}
$$




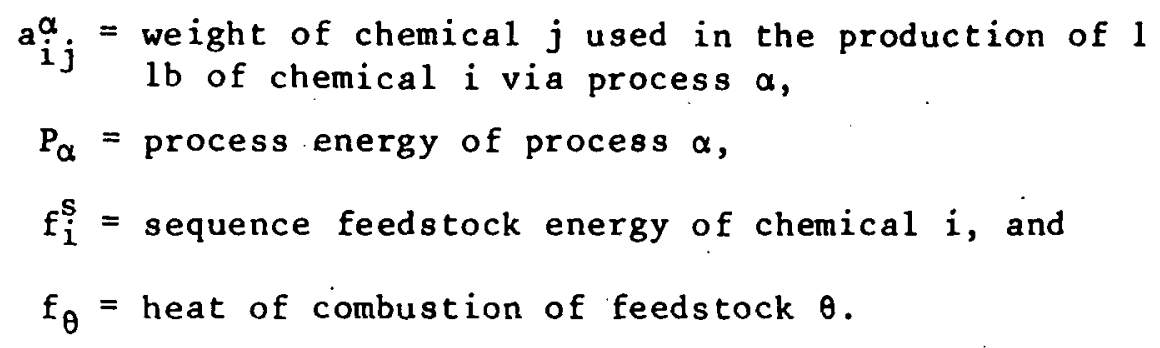

Equation 7 solves for the sequence process energy given the process splits, individual process energies, and chemical inputs for each process. Equation 8 solves. for the sequence feedstock energy. given the process splits, chemical inputs, and'feedstock heats of combustion. The formulas for longer or shorter sequences can be easily established by extending or contracting the repeating elements of Eqs: 7 and 8 .

In ordei to pruceed with the sequence energy computations for the five plastics, the data specified in Eqs. 6-8 must be assembled for the 21 processes 1 isted in Table 3.2. These data are available in Refs. 11 and 12, and are summarized in Tables 3.3 and 3.4. Table 3.3 lists the chemical inputs in rows and the processes in columns. Thus, the entry 0.741 in row 16 , column 6 indicates that 0.741 1b of chemical 16 (benzene) are used in process 6 (ethylbenzene production). Using the nomenclature defined for Eqs. 7 and $8, a_{22,16}=0.741$. Row 4 gives the individual process energies computed using Eq. 6. The combustion energy (HHV) of each feedstock is shown in brackets beside its name. The process splits (see Table 3.4) are given separately because, in: the case of coproducts, the process participations may

Tahle 3.1 Utilities and Matcrials Participatiug iu Plastics Manufacture

\begin{tabular}{ll}
\hline Utrlities & Chemical intermediates \\
1 Fuel & 12 Ethylene \\
2 Electricity & 13 Propylene \\
3 Steam & 14 Prnylene oxide \\
4 Prnsess onergy & 15 Flupyletle glycul \\
Feedstocks & 16 Benzene \\
6 Ethane & 18 Mixed xylenes \\
7 Naphtha & 19 o-Xylene \\
8 Reformate & 21 Naphthalene \\
9 Gas oil & 22 Ethylbenzeno \\
10 n-Butanes & 23 Styrene \\
Plastic resins & 24 Maleic anhydride \\
40 High-density polyethylene & 25 Phthalic anhydride \\
41 & 26 Ethylene dichloride \\
42 Polystyrene & 27 Vinyl chloride monomer \\
43 Polyvinyl chloride & 28 Calcium hydroxide \\
44 Unsaturated polyester & 30 Chlorine \\
\hline
\end{tabular}


Table 3.2 Processes Participating in Piastics Manufacture

1. Olefins from ethane and propane via fired tubular reactor

2. Olefins from naphtha and gas oil via fired tubular reactor

3. Benzene-toluene-xylene from reformate via solvent extraction

4. o- and p-Xylene from mixed xylenes via distillation and molecular sieves

5. Naphthalene from reformate via dealkylation

6. Ethylbenzene from ethylene and benzene via catalytic alkylation

7. Styrene from ethylbenzene via dehydrogenation

8. Phthalic anhydride from o-xylene via tubular reactor

9. Phthalic anhydride from naphthalene via tubular reactor

10. Maleic anhydride from benzene via catalytic oxidation

11. Maleic anhydride from n-butanes via catalytic oxidation

12. Propylene oxide from propylene, chlorine, and calcium hydroxide via chlorohydrin process

13. Propylene oxide from propylene and ethylbenzene via hydroperoxide process

14. Propylene glycol from propylene oxide via hydration

15. Ethylene dichloride from ethylene and chlorine via oxychlorination

16. Vinyl chloride monomer from ethylene dichloride via pyrolys is

17. High-density polyethylene from ethylene via Ziegler catalysis in bulk polymerization

18. Polypropylene from propylene via Ziegler catalysis in solution polymerization

19. Polystyrene from styrene via bulk polymerization

20. Polyvinyl chloride from vinyl chloride monomer via suspension polymerization

21. Unsaturated polyester from maleic anhydride, phthalic anhydride, propylene glycol, and styrene via batch polymerization 
Table 3.3 Input Coefficients and Process Energies for Selected Plastic Resin Sequences

\begin{tabular}{|c|c|c|c|c|c|c|c|c|c|c|}
\hline-1 & Utilities anc Materials & & $\begin{array}{l}1 \\
\text { olefins } \\
\text { from } \\
\text { Ethanel } \\
\text { Propane }\end{array}$ & $\begin{array}{l}2 \\
\text { Olefins } \\
\text { from } \\
\text { Napitha/ } \\
\text { Gas } 0=1\end{array}$ & $\begin{array}{c}3 \\
3 \\
\text { BTX } \\
\text { (xeformate) }\end{array}$ & $\begin{array}{l}\quad 4 \\
\text { o-Xylene/ } \\
\text { P-Xylene } \\
\text { (mixed } \\
\text { xylenes) }\end{array}$ & $\begin{array}{c}5 \\
5 \\
\text { Naphthalene } \\
\text { (reformate) }\end{array}$ & Ethylbenzene & $\begin{array}{c}. \\
. \\
\text { styrene } \\
\end{array}$ & $\begin{array}{l}\quad 8 \\
\text { Phthal ic } \\
\text { Anhydride } \\
\text { from } \\
\text { o-Xylene }\end{array}$ \\
\hline \multicolumn{11}{|c|}{ Utilities } \\
\hline $\begin{array}{l}1 \\
2 \\
3 \\
4\end{array}$ & $\begin{array}{l}\text { Fuel }\left(10^{3} \text { Btu) }\right. \\
\text { Electricity (kWh) } \\
\text { Steam (1b) } \\
\text { Process energy }\left(10^{3} \text { Btu) }\right.\end{array}$ & & $\begin{array}{l}3.75 \\
3.75\end{array}$ & . & $\begin{array}{r}0.006 \\
1.57 \\
1.95\end{array}$ & $\begin{array}{r}7.57 \\
0.016 \\
0.35 \\
8.13\end{array}$ & $\begin{array}{r}6.96 \\
0.074 \\
0.70 \\
8.50\end{array}$ & $\begin{array}{l}(-) 0.30 \\
(-) 0.30\end{array}$ & $\begin{array}{r}1.55 \\
0.039 \\
4.0 \\
6.43\end{array}$ & $\begin{array}{l}0.41 \\
4.10\end{array}$ \\
\hline \multicolumn{11}{|c|}{ Feedstocks } \\
\hline $\begin{array}{r}6 \\
7 \\
8 \\
9 \\
10\end{array}$ & $\begin{array}{l}\text { Ethane/prcpane }\left(22.3 \times 10^{3}\right. \\
\text { Naphtha }\left(20.4 \times 10^{3} \mathrm{Btu}\right) \\
\text { Reformate }\left(19.6 \times 10^{3} \mathrm{Btu}\right) \\
\text { Gas oil }\left(19.6 \times 10^{3} \mathrm{Btu}\right) \\
\text { n-Butanes }\left(21.2 \times 10^{3} \mathrm{Btu}\right)\end{array}$ & Btu) & 1.27 & $\begin{array}{l}0.99 \\
0.6 .9\end{array}$ & 1.0 & & 1.053 & . & & : \\
\hline $\begin{array}{c}\text { Chemi } \\
12 \\
13 \\
14 \\
15\end{array}$ & $\begin{array}{l}\text { cal intermediates } \\
\text { Ethylene } \\
\text { Propylene } \\
\text { Propylene oxide } \\
\text { Propylene glycol }\end{array}$ & . & & · & & & . & 0.266 & . & \\
\hline $\begin{array}{l}16 \\
18 \\
19 \\
21 \\
\end{array}$ & $\begin{array}{l}\text { Benzene } \\
\text { Mixed xylenes } \\
\text { o-Xylene } \\
\text { Naphthal ene } \\
\end{array}$ & & & & $\cdot$ & 1.01 & & 0.741 & & $\begin{array}{l}0.97 \\
1.09\end{array}$ \\
\hline $\begin{array}{l}22 \\
23 \\
24 \\
25\end{array}$ & $\begin{array}{l}\text { Ethylbenzene } \\
\text { Styrene } \\
\text { Maleic anhodride } \\
\text { Phthalic anhydride }\end{array}$ & & & & . & . & . & & 1.12 & \\
\hline $\begin{array}{r}26 \\
27 \\
28 \\
30\end{array}$ & $\begin{array}{l}\text { Ethylene dichloride } \\
\text { Vinyl chloride monomer } \\
\text { Calcium hydroxide } \\
\text { Chlorine }\end{array}$ & . & & & - & & . & . & & \\
\hline
\end{tabular}


Table $3.3^{\circ}$ (Cont'd)

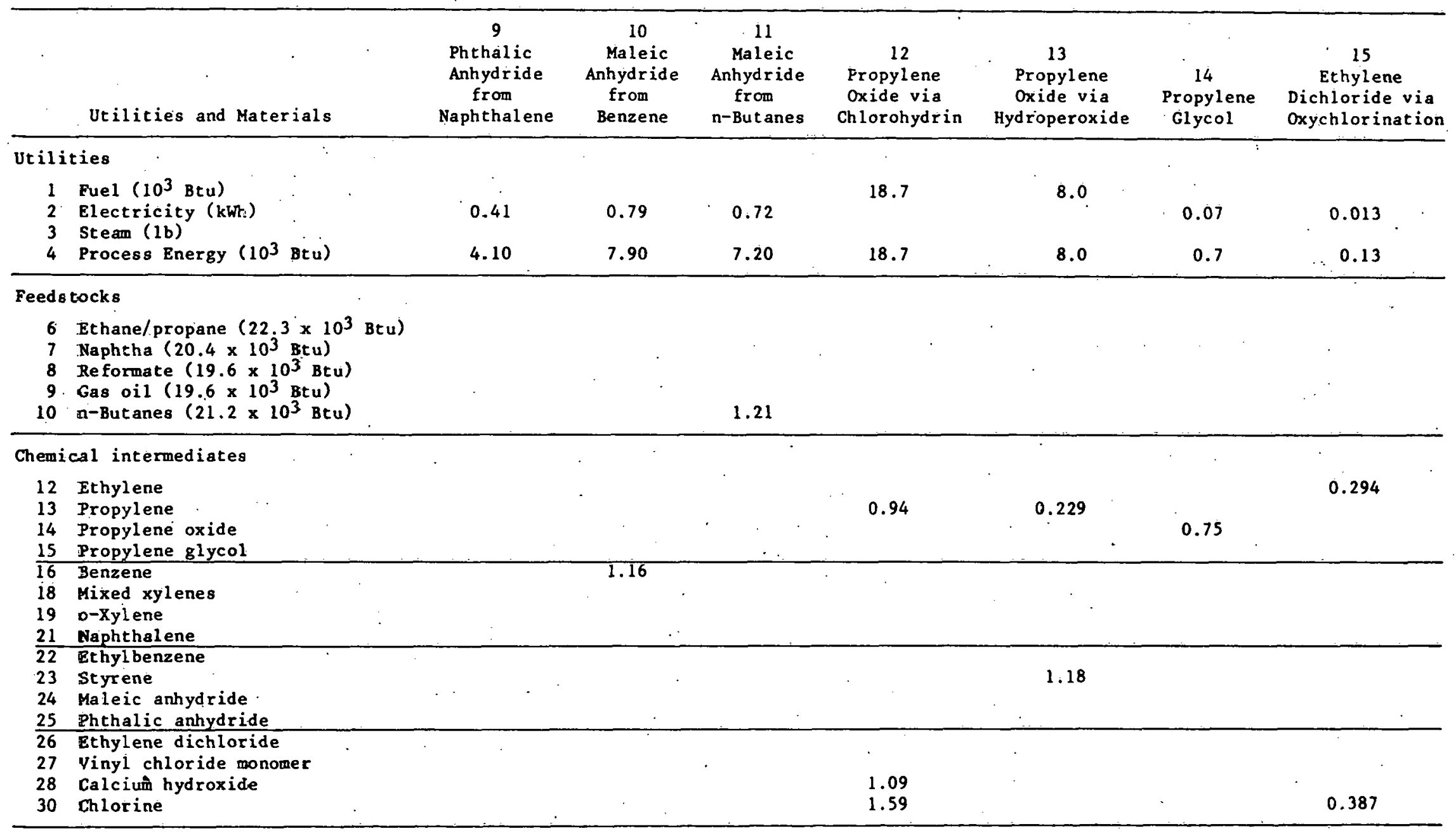


Table 3.3 (Cont'd)

\begin{tabular}{|c|c|c|c|c|c|c|c|c|}
\hline & Utilities and Materials & & $\begin{array}{c}1 \epsilon \\
\text { Vir.yl } \\
\text { Chloride } \\
\text { Moncmer }\end{array}$ & $\begin{array}{l}\quad 17 \\
\text { High-Density } \\
\text { Polyethylene }\end{array}$ & $\begin{array}{c}18 \\
\text { Polypropylene }\end{array}$ & $\begin{array}{c}19 \\
\text { Polystyrene }\end{array}$ & $\begin{array}{c}20 \\
\text { Polyvinyl } \\
\text { Chloride }\end{array}$ & $\begin{array}{l}21 \\
\text { Unsaturated } \\
\text { Polyester }\end{array}$ \\
\hline \multicolumn{3}{|c|}{ Utilities } & & & & & & \\
\hline $\begin{array}{l}1 \\
2 \\
3 \\
4\end{array}$ & $\begin{array}{l}\text { Puel }\left(10^{3} \mathrm{Btu}\right) \\
\text { Electricity }(\mathrm{kWh}) \\
\text { Steam (1b) } \\
\text { Process Energy }\left(10^{3} \text { Btu }\right)\end{array}$ & & $\begin{array}{r}3.7 \\
0.53 \\
4.0\end{array}$ & $\begin{array}{r}0.375 \\
2.5 \\
6.60\end{array}$ & $\begin{array}{r}0.27 \\
2.1 \\
5.20\end{array}$ & $\begin{array}{r}0.119 \\
0.38 \\
1.63\end{array}$ & $\begin{array}{r}1.04 \\
0.082 \\
1.86\end{array}$ & $\begin{array}{r}0.30 \\
0.025 \\
0.243 \\
0.83\end{array}$ \\
\hline \multicolumn{3}{|c|}{ Feedstacks } & & & & & & \\
\hline $\begin{array}{r}6 \\
7 \\
8 \\
9 \\
10\end{array}$ & $\begin{array}{l}\text { Ethane/propane }\left(22.3 \times 10^{3}\right. \\
\text { Naphtha }\left(20.4 \times 10^{3} \mathrm{Btu}\right) \\
\text { Reformate }\left(19.6 \times 10^{3} \mathrm{Btu}\right) \\
\text { Gas oil }\left(19.6 \times 10^{3} \mathrm{Btu}\right) \\
\text { n-Butanes }\left(21.2 \times 10^{3} \mathrm{Btu}\right)\end{array}$ & Btu) & & . & . & & . & . \\
\hline \multicolumn{3}{|c|}{ Chemical intermediates } & & & & & & . \\
\hline $\begin{array}{l}12 . \\
13 \\
14 . \\
15\end{array}$ & $\begin{array}{l}\text { Ethylene } \\
\text { Propylene } \\
\text { Propylene oxide } \\
\text { Propylene glycol }\end{array}$ & . & . & 1.02 & 1.045 & & & 0.28 \\
\hline $\begin{array}{l}16 . \\
18 \\
19 \\
21\end{array}$ & $\begin{array}{l}\text { Benzene } \\
\text { Mixed xylenes } \\
\text { o-Xylene } \\
\text { Naphthalene }\end{array}$ & & & & . & & & -10.0 \\
\hline $\begin{array}{l}22 . \\
23: \\
24 . \\
25 .\end{array}$ & $\begin{array}{l}\text { Ethylbenzene } \\
\text { Styrene } \\
\text { Maleic anhydride } \\
\text { Phthalic anhydride. }\end{array}$ & & $\cdot$ & $\cdot$ & & 0.983 & . & $\begin{array}{l}0.35 \\
0.16 \\
0.21\end{array}$ \\
\hline $\begin{array}{l}26 . \\
27 . \\
28 . \\
30 .\end{array}$ & $\begin{array}{l}\text { Ethylene dichloride } \\
\text { Vinyl chloride monomer } \\
\text { Calcium hydroxide } \\
\text { Chlorine }\end{array}$ & - & & 1.61 & ? & . & 1.02 &. \\
\hline
\end{tabular}

a Numbers are not consecutive. 
Table 3.4 Process Splits

\begin{tabular}{|c|c|c|c|c|c|c|c|c|c|}
\hline . & Material & $\begin{array}{l}1 \\
\text { Olefins } \\
\text { from } \\
\text { Ethane/ } \\
\text { Propane }\end{array}$ & $\begin{array}{l}2 \\
\text { olefins } \\
\text { from } \\
\text { Naphthal } \\
\text { Gas oil }\end{array}$ & $\begin{array}{c}8 \\
\text { Phthalic } \\
\text { Anhydride } \\
\text { from } \\
\text { o-Xylene }\end{array}$ & $\begin{array}{c}9 \\
\text { Phthalic } \\
\text { Anhydride } \\
\text { from } \\
\text { Naphthalene }\end{array}$ & $\begin{array}{c}10 \\
\text { Maleic } \\
\text { Anhydride } \\
\text { from } \\
\text { Benzene }\end{array}$ & $\begin{array}{c}11 \\
\text { Maleic } \\
\text { Anhydride } \\
\text { from } \\
\text { n-Butanes }\end{array}$ & $\begin{array}{c}12 \\
\text { Propylene } \\
\text { Oxide via } \\
\text { Chlorohydrin }\end{array}$ & $\begin{array}{c}13 \\
\text { Propylene } \\
\text { Oxide via } \\
\text { Hydroperoxide }\end{array}$ \\
\hline 12 & Ethylene & .0 .55 & 0.45 & & & & . & . & \\
\hline 13 & Propylene & 0.25 & 0.75 & & & . & & . & \\
\hline 14 & $P=o p y l e n e$ oxide & & & & & . & . & 0.6 & 0.4 \\
\hline 24 & Maleic anhydride & - & $\cdot$ & & & $0.8^{\circ}$ & 0.2 & . & $\cdot$ \\
\hline 25 & Phthalic anhydride & & & 0.7 & 0.3 & . & & $\cdot$ & \\
\hline
\end{tabular}


differ among products. In olefins manufacture, for example, more ethylene is produced from ethane and more propylene from naphtha.

Use of Eqs. 7 and 8 and the data in Tables 3.3 and 3.4 can be illustrated by considering HDPE and UPE, which 1 ie at opposite ends of the sequence complexity spectrum. From Eq. 7, the sequence process energy of HDPE is given by:

$$
\mathrm{P}_{40}^{\mathrm{S}}=\mathrm{P}_{17}+\mathrm{a}_{40,12}^{17}\left(\mathrm{x}_{1}^{12} \mathrm{P}_{1}+\mathrm{x}_{2}^{12} \mathrm{P}_{2}\right)
$$

where $x_{17}^{40}=1$. Inserting the values given in Tables 3.3 and 3.4 for process energies, chemical inputs, and process splits (with energies expressed in $10^{3} \mathrm{Btu} / \mathrm{ib}$.

$$
\mathrm{p} / 40=6.60+1.02(0.55)(3.76)
$$

In this case, $P_{2}=0$ because all the fuel energy requirements are satisfied by combustion by-products generated during feedstock conversion. Proceeding in the same manner, Eq: 7 can be used to calculate sequence feedstock energy:

$$
\begin{aligned}
\mathrm{f}_{40}^{8}= & a_{40,12}^{17}\left[\mathrm{x}_{1}^{12} \mathrm{a}_{12,6}^{1} \mathrm{f}_{6}+\mathrm{x}_{12}^{2}\left(\mathrm{a}_{12,7}^{2} \mathrm{f}_{7}+\mathrm{a}_{12,9}^{2} \mathrm{f}_{9}\right)\right] \\
= & 1.02[(0.55)(1.27)(22.4)+(0.45)(0.59)(20.2) \\
& +(0.45)(0.69)(19.6)] \\
= & 27.64 \times 10^{3} \mathrm{Btu} / 1 \mathrm{~b}
\end{aligned}
$$

The total sequence energy required to manufacture. HDPE resins is then:

$$
\begin{aligned}
t_{40}^{s} & =P_{40}^{s}+f_{40}^{s} \\
& \equiv 36.35 \times 10^{3} \mathrm{Btu} / 1 \mathrm{~b}
\end{aligned}
$$

Computations for UPE proceed in the same manner, but are substantially more complex. Equation.7, yields for sequence process energy:

$$
\begin{aligned}
P_{44}^{s}= & P_{21}^{44}+a_{44}^{21}, 15\left[P_{14}+a_{15}^{14}, 14\left(x _ { 1 2 } ^ { 1 4 } \left\{P_{12}\right.\right.\right. \\
& \left.+a_{14,13}^{12}\left[x_{1}^{13} P_{1}+x_{2}^{13} P_{2}\right]\right\}+x_{13}^{14}\left\{P_{13}\right. \\
& +a_{14,13}^{13}\left[x_{1}^{13} P_{1}+x_{2}^{13} P_{2}\right]+a_{14,22}^{13}\left[P_{6}\right. \\
& \left.\left.\left.\left.+a_{22,12}^{6}\left(x_{1}^{12} P_{1}+x_{2}^{12} P_{2}\right)+a_{22,16}^{6} P_{3}\right]\right\}\right)\right] \\
& +a_{44,23}^{21}\left[P_{7}+a_{23,22}^{7}\left(P_{6}+a_{22,12}^{6}\left\{x_{1}^{12} P_{1}\right.\right.\right. \\
& \left.\left.\left.+x_{2}^{12} P_{2}\right\}+a_{22,16}^{6} P_{3}\right)\right]+a_{44,24}^{21}\left[x _ { 1 0 } ^ { 2 4 } \left(P_{10}\right.\right.
\end{aligned}
$$




$$
\begin{aligned}
& \left.\left.+a_{24,16}^{10} P_{3}\right)+x_{11}^{24} P_{11}\right]+a_{44,25}^{21}\left[x _ { 8 } ^ { 2 5 } \left(P_{8}\right.\right. \\
& \left.\left.+a_{25,19}^{8}\left\{P_{4}+a_{19,18}^{4} P_{3}\right\}\right)+x_{9}^{25}\left(P_{9}+a_{25,21}^{9} P_{5}\right)\right]
\end{aligned}
$$

Clearly, the number of terms required for the UPE sequence process. energy computation is much greater than for HDPE. Nevertheless, all of the necessary information is contained in Tables 3.3 and 3.4 , and the evaluation procedure remains the same. The result for UPE sequence process energy is $12.47 \times 10^{3}$ $\mathrm{Btu} / 1 \mathrm{~b}$.

The comparable equation for the UPE sequence feedstock energy is:

$$
\begin{aligned}
f_{44}^{s}= & a_{44}^{21}, 15 a_{15}^{14}, 14\left(x _ { 1 2 } ^ { 1 4 } \left\{a_{14}^{12}, 13\left[x_{1}^{13} a_{13,6}^{1} f_{6}\right.\right.\right. \\
+ & \left.x_{2}^{13}\left(a_{13,7}^{2} f_{7}+a_{13,9}^{2} f_{9}\right)\right]+a_{14,28}^{12} f_{28} \\
+ & \left.a_{14,30}^{12} f_{30}\right\}+x_{13}^{14}\left\{\left[a_{14}^{13}, 13+a_{22,12}^{6}\right]\right. \\
& {\left[x_{1}^{13} a_{13,6}^{1} f_{6}+x_{2}^{13}\left(a_{13,7}^{2} f_{7}+a_{13,9}^{2} f_{9}\right)\right] } \\
+ & \left.\left.a_{22,16}^{6} a_{16,8}^{3} f_{8}\right\}\right)+a_{44,23}^{21} a_{23,22}^{7}\left\{a_{22,12}^{6}\right. \\
& {\left[x_{1}^{12} a_{12 ; 6}^{1} f_{6}+x_{2}^{12}\left(a_{12,7}^{2} f_{7}+a_{12,9}^{2} f_{9}\right)\right]+a_{22,16}^{6} } \\
& \left.a_{16,8}^{3} f_{8}\right\}+a_{44}^{21}, 24\left(x_{10}^{10} a_{24,16}^{10} a_{16,8}^{3} f_{8}\right. \\
& \left.x_{11}^{24} a_{24}^{11}, 10 f_{10}\right)+a_{44}^{21}, 25\left(x_{8}^{25} a_{25,19}^{8}\right. \\
& \left.a_{19,18}^{4} a_{18,8}^{3} f_{8}+x_{9}^{25} a_{25,21}^{9} a_{21,8}^{5} f_{8}\right)
\end{aligned}
$$

Substituting the data from Tables 3.3 and 3.4 into this equation, the UPE sequence feedstock energy is $22.16 \times 10^{3} \mathrm{Btu} / \mathrm{lb}$. The total sequence energy for UPE is:.

$$
\begin{aligned}
t_{44}^{s} & =P_{44}^{s}+f_{44}^{s} \\
& =34.63 \times 10^{3} \mathrm{Btu} / 1 \mathrm{~b}
\end{aligned}
$$

The sequence energies for UPE, HDPE, and the other three TP resins are given in Table 3.5. The values are expressed in both unit weight and unit volume terms. Both are important because energy comparisons (e.g., between plastics and steel) depend on the specific application. Since plastics are approximately seven times lighter than steel $\left(0.040 \mathrm{lb} / \mathrm{in.}^{3}\right.$ for UPE versus $0.284 \mathrm{1b} / \mathrm{in}^{3}$ for steel), the volume of each product for a given function has a significant impact on the comparison. The energy required to fabricate a typical steel product is $24.8 \times 10^{3} \mathrm{Btu} / 1 \mathrm{~b}$, or $7.04 \mathrm{Btu} / \mathrm{in} .^{3}$. Thus, relative 
Table 3.5 Plastic Resin Sequence Energies

\begin{tabular}{|c|c|c|c|c|c|}
\hline \multirow{2}{*}{$\begin{array}{c}\vdots \\
\text { Plastic }\end{array}$} & \multirow[b]{2}{*}{$\begin{array}{l}\text { Density } \\
\left(1 \mathrm{~b} / \mathrm{in}^{3}\right)\end{array}$} & \multicolumn{3}{|c|}{ Energy/Weight } & \multirow[b]{2}{*}{$\begin{array}{c}\text { Total } \\
\text { Energy/Volume } \\
\left(10^{3} \mathrm{Btu} / \mathrm{in}^{3}\right)\end{array}$} \\
\hline & & $\begin{array}{c}\text { Process } \\
\text { Energy } \\
\left(10^{3} \text { Btu/1b) }\right.\end{array}$ & $\begin{array}{c}\text { Feedstock } \\
\text { Energy } \\
\left(10^{3} \text { Btu/1b) }\right.\end{array}$ & $\begin{array}{c}\text { Total } \\
\left(10^{\text {Energy }} \text { Btu/1b) }\right.\end{array}$ & \\
\hline High-density polyethylene & 0.0343 & 8.71 & 27.64 & 36.35 & 1.25 \\
\hline Polypropylene & 0.0325 & 6.18 & 27.24 . & 33.42 & 1.09 \\
\hline Polystyrene & 0.0379 & 8.17 & 23.94 & 32.11 & 1.22 \\
\hline Polyvinyl chloride & 0.0433 & 15.50 & 13.11 & 28.61 & 1.24 \\
\hline Unsaturated polyester ${ }^{a}$ & 0.0404 & 12.47 & 22.16 & 34.63 & 1.40 \\
\hline
\end{tabular}

aThe sequence process energies for polyvinyl chloride and unasturater pnlyegter include tho process energy contribution from chlorine manufacture, although this process is not shown in Flgs. 3.2 and 3.4. Process energy for chlorine is estimated to be $9.75 \times 10^{3}$ Btu, based on $26 \%$ mercury cell and $74 \%$ diaphragm cell participation and energy allocation by weight between coproduct chlorine and caustic soda.

to steel, all of the plastics listed in Table 3.5 are at an energy disadvantage on a weight basis, yet have a fivefold advantage on a volume basis.*

\subsection{REINFORCEMENTS}

\subsubsection{Glass Fibers}

The principal aspecto of the fibcrglass manufacturing sequence are schematically depicted in Fig. 3.5. The three process steps are: (1) mixing the malnly inorganic raw materials to form the glass batch, (2) heating the batch to approximately $2 / 100^{\circ} \mathrm{F}$ in order to melt and refine the mixture. and (3) extruding the glass through platinum bushings in order to form the $0.1-$ $0.75 \mathrm{mil}$ glass fibers. Sand and limestone represent $75 \%$ of the raw materials for type-E glass. It is estimated that $1.2 \mathrm{lb}$ of glass batch are necessary to make 1 lb of glass product. Total energy for this process, including binder application, high-speed winder, job efficiencies, heat ing, and lighting, is $21,805 \mathrm{Btu} / 1 \mathrm{~b}$. The energy resources used are $14.97 \times 10^{3} \mathrm{Btu}$ natural gas and $0.68 \mathrm{kWh}$ electricity. Most of the energy is consumed in the melting and refining step.

The only other energy contribution to the fiberglass sequence is mining the raw materials. Mining energy requirements are $300 \mathrm{Btu} / \mathrm{lb}$ of fiberglass. The energy resources employed are 110 . Btu diesel fuel and $0.02 \mathrm{kWh}$ electricity. Total process energy for fiberglass manufacture is $22.10 \times 10^{3} \mathrm{Btu} / \mathrm{b}$. No feedstock energy is involved. 16

*The plastic resins must be fiber reinforced in order to compete with steel.in structural applications. The density of the composite is somewhat greater than that of the resin. Glass fiber density is $0.0921 \mathrm{~b} / \mathrm{in} .{ }^{3}$ and calcium carbonate filler density is $0.100 \mathrm{lb} / \mathrm{in}^{3}$ Nevertheless, composite density remains less than $25 \%$ that of steel. 
RAW MATERIALS

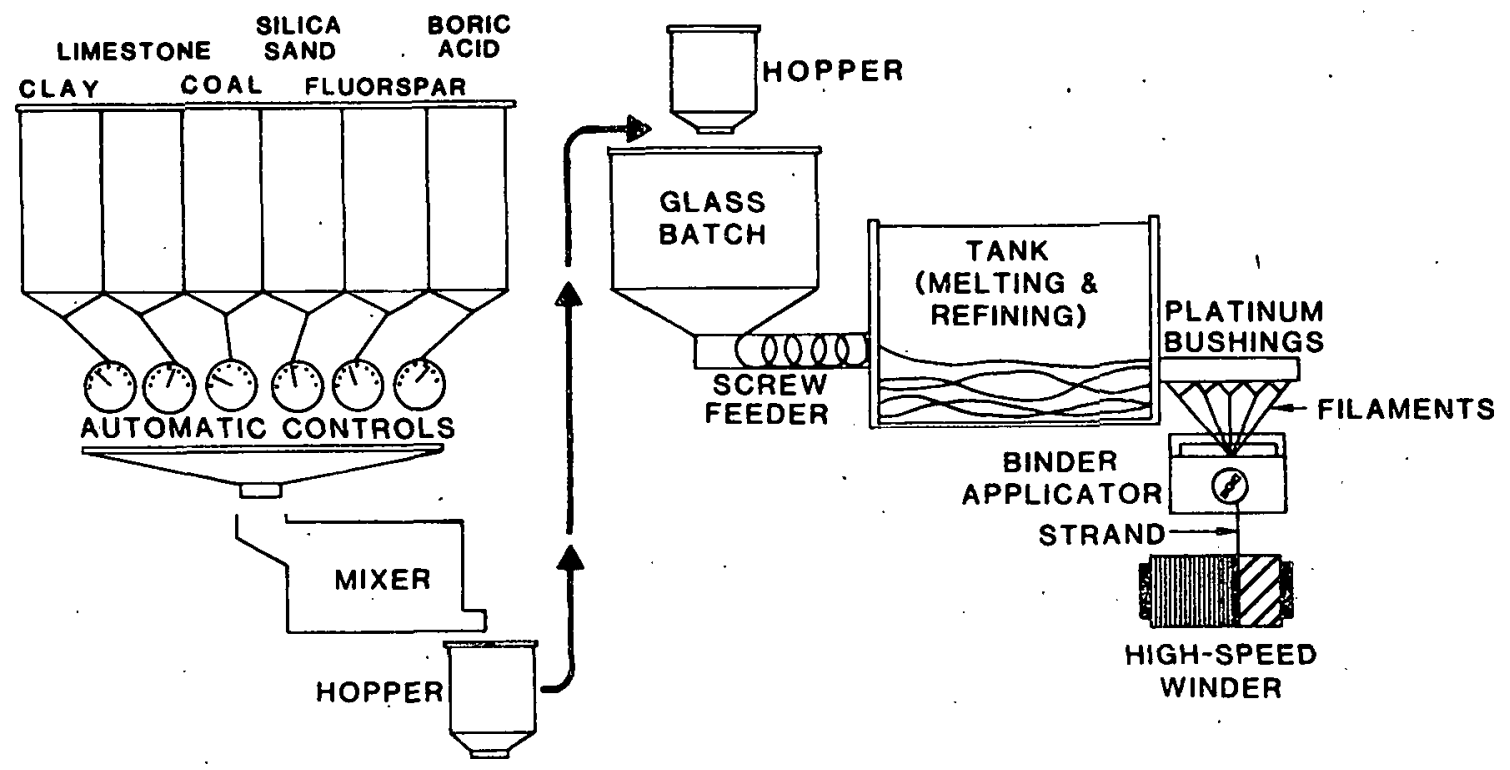

Fig. 3.5 Fiberglass Process Sequence (Source: Adapted from Ref. 6)

\subsubsection{Graphite Fibers}

In terms of molecular structure, graphite consists of a series of parallel planes, each plane being composed of an interconnecting matrix of hexagonally linked carbon atoms. The atoms are strongly bonded within each plane, but relatively weak bonds exist between planes. As a result, graphite's mechanical properties vary by 100-1000, depending on whether the stress is exerted parallel or perpendicular to the layer planes. For this reason, a principal objective of graphite fiber manufacturing is to orient the layer planes parallel to the fiber axis. This is done by starting with a precursor fiber having the desired orientation, then systematically driving off the noncarbon atoms.

Rayon was the precursor material for the first graphite fibers. Since research on graphite fibers and suitable precursors was initiated in 1964,. fibers based on polyacrylonitrile (PAN) precursors have become the dominant commercial variety. A disadvantage of PAN-based fibers, is that PAN costs $\$ 3 / 1 \mathrm{~b} . *$ Research is underway on the use of petroleum pitch as a lower cost alternative.

Graphite fibers are manufactured in a two-step sequence. First, the precursor PAN is heated to $480-750^{\circ} \mathrm{F}$ while the fiber is held under tension. The PAN molecules are oxidized at this temperature to produce a stable state. In the second step, the temperature is increased to $2730-4530^{\circ} \mathrm{F}$ in order to pyrolyze all atoms except the carbon ladder backbone. Tension is maintained on the fiber throughout the process to maintain the desired orientation of the carbon basal plane. The temperature employed also contributes to the degree

*Glass fibers cost only $\$ 0.60-0.70 / 1 b$. 
of basal plane orientation and determines the degree of graphitization attained.

The high temperatures needed to convert the precursor material into graphite fiber translates into large process energy requirements. The production sequence from $r$ aw materials through PAN to graphite fiber is estimated to require $88.8 \times 10^{3} \mathrm{Btu} / \mathrm{lb} .^{3}$ This high energy intensity can be partially offset by the lighter weight of the graphite component.

\subsection{FILLERS}

Filler energy requirements are related to mining and beneficiating the inorganic material. In the case of calcium carbonate, which is used for most automotive applications, this energy requirement is $0.35 \times 10^{3} \mathrm{Btu} / 1 \mathrm{~b} .16$ The energy resources employed are $233 \mathrm{Btu}$ diesel fuel and $0.0117 \mathrm{kWh}$ elertricliy per pound of calcium carbonate. Filler energy requirements are considerably smaller than the $34.63 \times 10^{3} \mathrm{Btu} / \mathrm{lb}$ for UPE resin and $22.10 \times 10^{3} \mathrm{BLu} / 1 \mathrm{~b}$ for glass fibers. Use of $40 \%$ filler, therefore, greatly reduces the aggregate embodied energy of the FRP.

\subsection{FIBER-REINFORCED PLASTIC PRODUCTS}

The final two steps in the FRP manufacturing sequence are to assemble the molding compound and perform the molding operation. Sheet molding compound with $30 \%$ fiberglass content is the most widely used type of FRP in the automobile industry. A schematic diagram of the SMC manufacturing sequence is given in Fig. 2.7, and the molding operation was described in Ser. 2.5 .

Materials efficiency in SMC manufacture is $96-97 \%$. The energy required for SMC manufacture and molding is $0.42 \mathrm{kWh} / 1 \mathrm{~b}$ for electricity and $80 \mathrm{Btu} / \mathrm{lb}$ tor fuel, yielding a total energy requirement of $4.28 \times 10^{3} \mathrm{Btu} / 1 \mathrm{~b} .6$ This amount of energy. is substantially less than the embodied energy requirements of the resin and fiberglass. In fact, the overall molding process is exothermic. The small fuel requirements are needed to initiate the reaction and to soften the SMC for molding; the electrical energy powers the equipment that forms the SMC and the presses that mold the product.

The aggregate energy for manufacturing the FRP product includes: (1) the embodied energies of the resin, fiberglase, and fillcr; (2) the energy for SMC manufacture; (3) the transportation energy associated with SMC (estimated to be $218 \mathrm{Btu} / \mathrm{lb}$ ); and (4) the molding energy. Materials losses are estimated to be $4 \%$ during SMC manufacture and $10 \%$ during product molding. The process, feedstock, and total energies are given in Table 3.6 . 
Table 3.6 Energy Requirements for Fiber-Reinforced Plastics $\left(10^{3} \mathrm{Btu} / \mathrm{lb}\right)$

\begin{tabular}{lccc}
\hline \multicolumn{1}{c}{ Material } & $\begin{array}{c}\text { Process } \\
\text { Energy }\end{array}$ & $\begin{array}{c}\text { Feedstock } \\
\text { Energy }\end{array}$ & $\begin{array}{c}\text { Total } \\
\text { Energy }\end{array}$ \\
\hline Unsaturated polyester resin (30\%) & 12.47 & 22.16 & 34.63 \\
Fiberglass (30\%) & 22.10 & - & 22.10 \\
Calcium carbonate filler (40\%) & 0.35 & - & 0.35 \\
Fiber-reinforced plastic & 16.46 & 7.69 & $24.15^{\mathrm{b}}$ \\
\hline
\end{tabular}

ancludes molding compound assembly and molding operation. energies. Assumes a nonrecyclable $10 \%$ scrap rate.

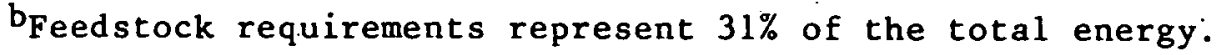


4 AUTOMOBILE MATERIALS COMPETITION AMONG FIBER-

REINFORCED PLASTICS, STEEL, AND ALUMINUM

\subsection{BACKGROUND}

Cost has historically dominated decision making in the automotive industry. Although attributes like performance, appearance, durability, and safety have been important considerations, great emphasis has been placed on achieving a given design at minimum production cost. In fact, the automotive industry has gone beyond orher industries in their cost planning. Because the industry's product is complex and expensive, an extremely large number of design decisions are necessary. By systemizing their entire planning and production sequence, automubile manufacturers have been able to achieve significant economies of scale.

The automotive industry's use of materials has reflected the importance given to cost. Figure 4.1 shows the relationship between the amounts of different materials consumed in 1976 and their prices in that year. The five materials having the largest tonnages were shown in Table 1.1 to he among the principal components of automobiles. Iron and steel, the lowest cost materials, for example, constitute $70 \%$ of automobile weight. There is a certain chicken-nr-eg8 aspect to this situation in that the automotive industry in 1978 consumed: $53.3 \%$ of malleable iron, $29.9 \%$

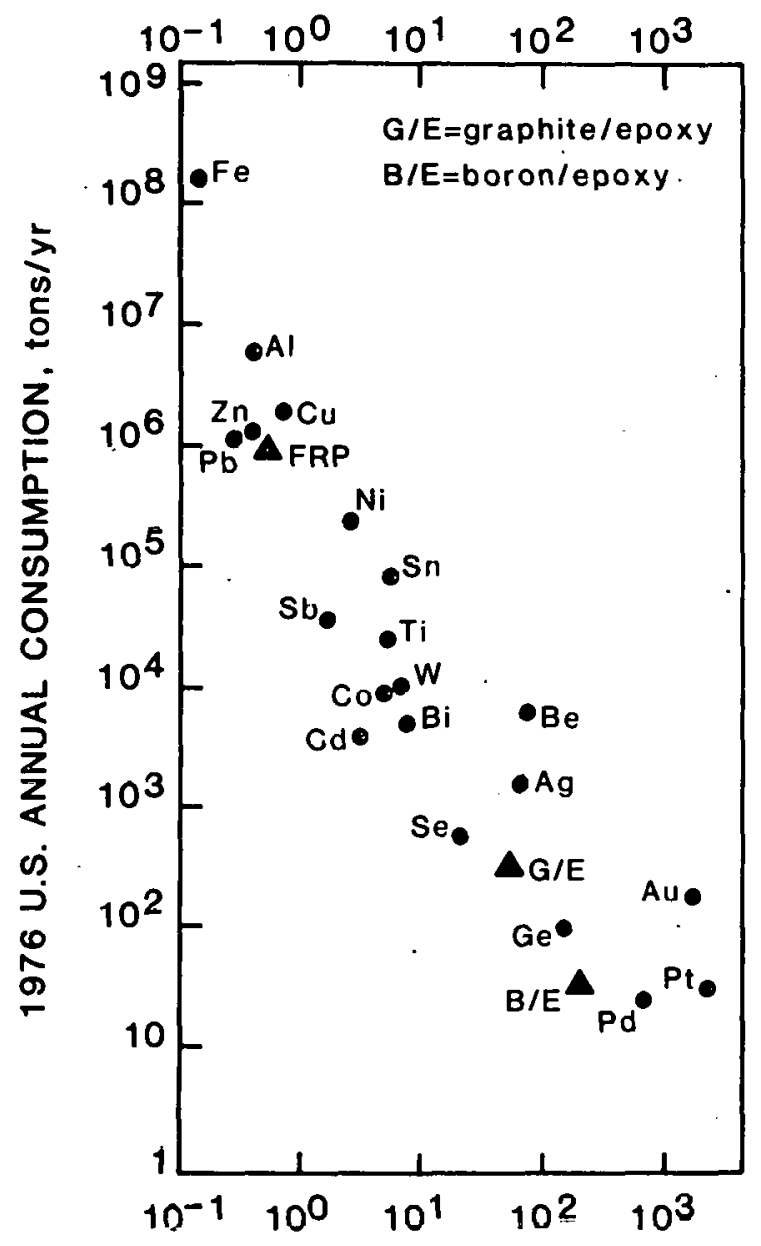

\$./LB (1976 average price)

Fig. 4.1 Materials Usage as a Function of $P_{t}$ ice (Source: Ref. 17) of zinc, $21.7 \%$ of steel, $16.5 \%$ of aluminum, and $12.0 \%$ of copper. 18 In other words, selection by the automotive industry guarantees that a material will bc used in large quantity, thereby insuring cost reductions based on economies of scale.

Another historical aspect of the automotive industry had been a trend toward more spacious and luxurious cars; Table 1.1 shows steadily increasing vehicle weight from 1965 to 1971. The oil embargo of 1973-1974 put a halt to this trend. Sales of smaller cars reduced average vehicle weight by $4 \%$ in 1974, even though manufacturers had not yet had the opportunity to introduce weight-saving design changes. Since then, consumer preferences have fluctuated with the price of gasoline. However, a downward trend in preferred vehicle size has persisted and has been expressed to some extent through the purchase of small, imported cars. 
The need for automobile manufacturers to produce lighter, fuelefficient cars was given the force of law by passage of the Energy Policy and Conservation Act in December, 1975. The CAFE standards established by this act require each automobile manufacturer to achieve specified levels of fuel economy in given years. The standards are based on combined city and highway result.s for a composite fleet. The average fuel economy of all vehicles sold by each manufacturer had to be $18 \mathrm{mpg}$ in 1978 and will have to increase to $27.5 \mathrm{mpg}$ in 1985. The manufacturers have introduced a number of design changes to improve vehicle fuel economy, including reducing the overall size of the vehicle (downsizing), adding more diesel engines to the fleet, and reducing vehicle weight. Since FRP and aluminum, even though much 1 ighter, can perform many of the same functions as steel, they are being used for applications that have usually been reserved for lower cost steel.

Table 4.1 shows how materials usage is being adjusted to achieve lighter weight cars. The participation of iron and steel will have decreased from $7.4 .3 \%$ in 1971 to $68.8 \%$ in 1985 . Over the same period, use of plastics and aluminum will have increased from $4.5 \%$ to $18.1 \%$. Overall vehicle weight in 1985 will be $35 \%$ less than that in 1971. The trend in average weight over the period 1965-1985 is shown in Fig. 4.2. The average weight shown for 1985 represents a mix of heavier diesel vehicles and 1 ighter gasoline vehicles, which reflects projected sales in the various vehicle size categories. After 1985 it is anticipated that fuel economy goals will be set even higher. Standards of $40 \mathrm{mpg}$ for 1990 have been discussed in Congress, and an 80-mpg standard has been suggested as. an eventual goal. The latter standard will require some members of the fleet to be two-passenger cars having two or three cylinders. From a FRP standpoint, such stringent standards may require use of the more expensive ACM.

Table 4.1 Adjustments in U.S. Automobile Materials Usage Motivated by Efforts to Improve Fuel Economy

\begin{tabular}{|c|c|c|c|c|c|c|}
\hline \multirow{2}{*}{ Material } & \multicolumn{2}{|c|}{1971} & \multicolumn{2}{|c|}{1977} & \multicolumn{2}{|c|}{1985} \\
\hline & $1 b$ & $\%$ & $1 b$ & $\%$ & 1b & $\%$ \\
\hline Cast iron & 572 & 14.3 & 640 & 17.1 & 260 & 10.0 \\
\hline High-strength steel & - & - & 110 & 2.9 & 260 & 10.0 \\
\hline Other steels & 2400 & 60.0 & 2210 & 58.9 & 1270 & 48.8 \\
\hline Aluminum & 76 & 1.9 & 110 & 2.9 & 210 & 8.1 \\
\hline P1astics & 104 & 2.6 & 190 & 5.1 & 260 & 10.0 \\
\hline Other materialsa & 848 & 21.2 & 490 & 13.1 & 340 & 13.1 \\
\hline Dry weight & 4000 & 100 & 3750 & 100 & $2600^{\circ}$ & 100 \\
\hline Inertia weight & $4500^{\circ}$ & - & 4200 & - & 3000 & - \\
\hline
\end{tabular}

ancludes but is not 1 imited to zinc, copper, lead, glass, and rubber.

Sources: Refs. 1 (1971) and 2(1977 and 1985). 


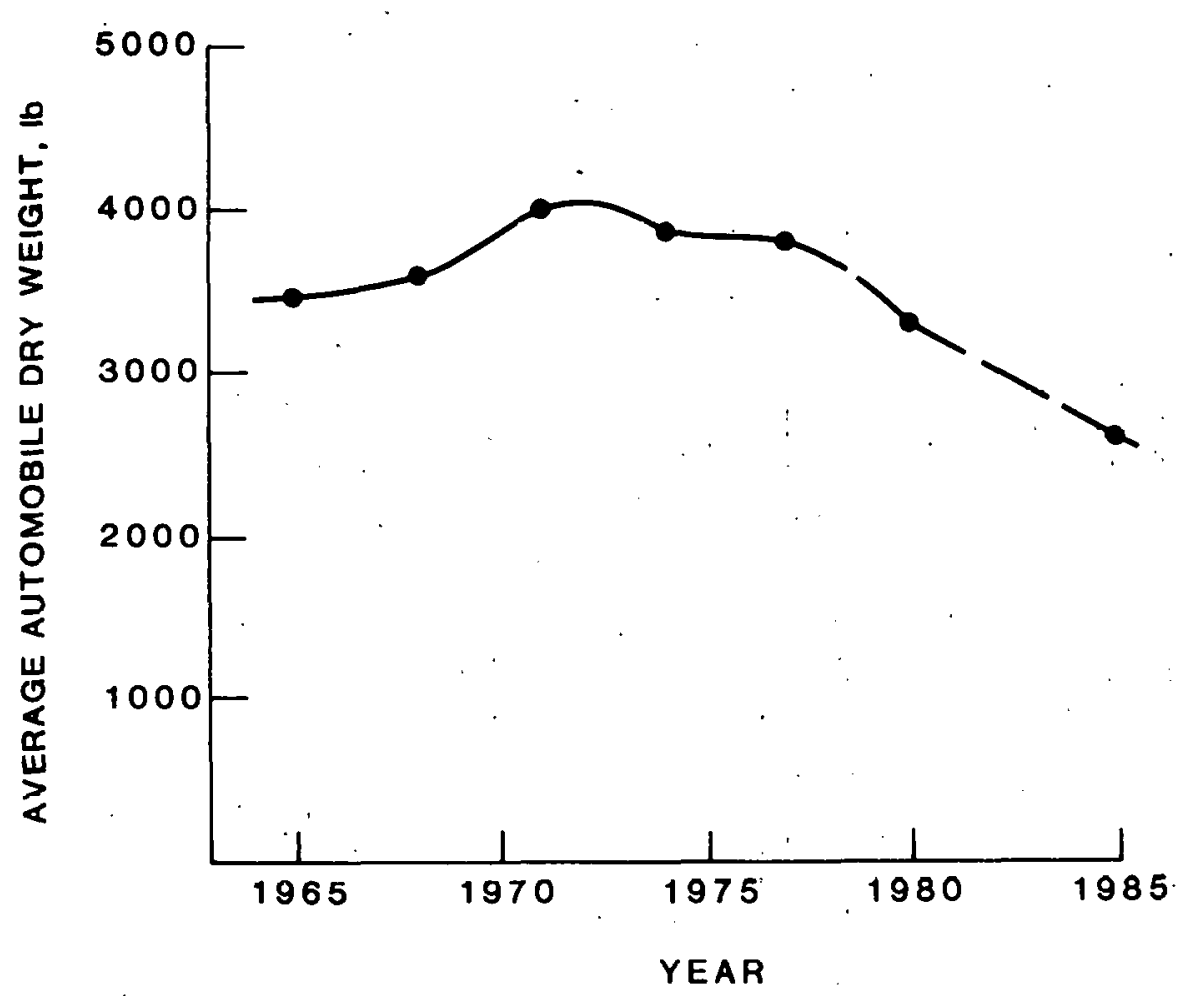

Fig. 4.2 Trend in Average Automobile Weight (Sources: Refs. 1 (1965, 1968, and 1971) and 2 (1977 and 1985)

One potentially important aspect of the materials competition that has not yet played a major role is corrosion resistance. The National Bureau of standards (NBS) has estimated that automobile corrosion costs $\$ 6-14$ billion annually in the United States and that \$2-8 billion of these costs are avoidable. Since applications requiring corrosion-resistant products already account for over $10 \%$ of FRP shipments (see Table 2.1), a trend to improve corrosion resistance in automobiles should favor increased use of plastics. Although aluminum also offers some corrosion protection, penetration of the protective aluminum oxide film leads to pitting. Galvanized steel also provides corrosion protection. Two-sided, hot-dip galvanized sheet is widely used, and one-sided galvanized sheet or zincirich, primer-cnated shppt are increasingly being used as sheet thickness is decreased to save weight.

\section{1 .1 Stee1}

The overall weight reduction shown in Fig. 4.2 means that all materials must expand their market share in order to maintain the same sales volume. For example, iron and steel's projected $10.1 \%$ reduction in share between 1.977 and 1985 translates into a $40 \%$ loss in sales volume $(1170 \mathrm{lb} / \mathrm{vehicle})$. Given such potentially large dislocations, market competition is intense. The most promising developments in steels are the high-strength. steels (HSS) that offer weight savings of 10-25\%. Although more expensive than low-carbon steel, HSS capitalize on the automotive industry's experience with and confidence in steel components. Since steel parts have excellent surface properties and 
high production throughput, HSS are projected to more than triple their market share between 1977 and 1985. This rate of growth would exceed that of either plastics or aluminum, even though the use of steel as a whole would be declining.

Dual-phase steels, so named because they consist of a dispersion of martensite in a ferrite matrix, are the most promising of the HSS. They offer the best combination of ductility and strength. They can be employed in applications requiring tensile strengths of 60,000-145,000 psi and avoid the formability problems encountered with conventional high-strength/low-alloy (HSLA) steels. The chief impediment to their broader use is developing market demand sufficient to justify substantial capital investment by the steel industry for the necessary continuous annealing facilities.

\subsubsection{Fiber-Reinforced Plastics}

Plastics possess significant marketing advantages based on their light weight and the opportunities they present for parts consolidation. These two aspects account for the automobile market penetration that plastic components have already achieved. Only about $8 \%$ of the plastics usage shown for 1977 in Table 4.1 was in the form of FRP, and this usage was confined primarily to body fascia and other nonstructural body panels.* To expand their market further, plastics must begin to compete successfully against steel and aluminum in structural applications. As Table 4.1 indicates, the total weight of plastics used per vehicle is not expected to increase substantially from 1977 to 1985. This projection assumes that FRP. will not be able to displace steel in structural applications over that period. Two considerations argue for this result: ( 1 ) vehicle downsizing and associated engine redesign will receive primary emphasis over the next two to three years and (2) it will take at least three to five years for the industry to resolve concerns regarding FRP usage. The 1985 estimate for plastics usage given in Table 4.1 was developed by Ford Motor Company and was widely supported in a series of meetings with other automobile and FRP manufacturers.

Concerns have been expressed regarding FRP usage, including: (1) inadequate surface quality, (2) low production rates because of the 2 -min cure constraint, ** (3) undeveloped assembly techniques, (4) uncertain energy absorption characteristics, (5) lack of information on basic material properties like fatigue behavior, and (6) lack of recyclability. Substantial progress has been made with respect to achieving Class $A$ surface quality. Up. to $40 \%$ TP resin has been employed in conjunction with the basic TS-resin FRP to reduce shrinkage during cooling. In addition, an in-mold urethane coating has been used to deal with surface irregularities. In this process, the press is opened briefly after forming and partial cure to inject a layer of urethane. The final surface finish forms during the remainder of the curing cycle.

With regard to production limitations, partial alleviation is expected through use of a rotating jig that ties up the large press only for the 20-s * Fiber-reinforced plastics also were used in heater and air-conditioning
housings, where surface appearance was not a consideration. **0pen-mold time is 1-2 min, for an overall cycle time of 3-4 min. 
molding operation and then rotates the clamped mold into a standby position for the remainder of the curing cycle. A representative assembly problem concerns making and testing bonds between parts. Steel components can be spot welded, with 20 or more welds done at once, and then visually inspected. Fiber-reinforced plastics, on the other hand, require adhesive or mechanical joining techniques. Adhesive bonds take time to cure, and a rapid, nondestructive test to insure bond integrity needs to be developed. Since mechanical attachments lead to point stresses, the material must be strengthened at that point. The concern with regard to energy absorption is that FRP (and HSS) can fail by "popping" and then letting go. This is in contrast to low-carbon steels, which absorb energy continuously throughout the buckling process. This difference is reflected in the reduced area under the stressstrain curve of FRP and HSS as compared to low-carbon steels. Work underway at Ford Motor Company, however, indicates that FRP can be configured so that delamination occurs continuously throughout the crushing phase. 19

Lack of information on basic material properties was identified consistently by workers in the field as the most pressing area for research. Because FRP are anisotropic materials and their properties are influenced by more than 150 variables in the production cycle,* the amount of data that must be gathered and systematically evaluated is immense. Because this process has barely begun, insufficient data are available to develop more than rough generalizations, such as the mixture rule expressed in Eq. 2. As for recyclability, little progress is expected. Fiber-reinforced plastics could be ground up and used as filler, but this is an extremely low value application. Alternatively, FRP resins could be pyrolyzed to produce fuel oils. Ford Motor Company has been investigating this possibility with the University of Tennessee but has not yet reported on the results. Although incineration would recover at least the heat of combustion, the resin represents only about $30 \%$ of the weight and the inorganic ash formed would retain much of the thermal energy.

To summarize, FRP have a number of significant hurdles to overcome before these materials can compete effectively against steel, including the new HSS. If FRP do prevail, one designer estimated that 2000-1b cars will be produced by the mid-1990s that utilize $45 \%$ plastic. The resulting $640-1 b$ increase in plastics usage beyond the $260 \mathrm{lb}$ estimated for 1985 will come mainly from hanging FRP body panels on a steel space frame. At $10 x 10^{6}$ cars per year, the $6401 \mathrm{~b} /$ vehicle translates into $6.4 \mathrm{x} 10^{9} 1 \mathrm{~b} / \mathrm{yr} \mathrm{FRP}$, more than three times the total FRP consumption shown for 1979 in Table 2.1 .

\subsubsection{Aluminum}

Aluminum is a wel1-known, lightweight material used in many diverse applications. In the automotive industry, aluminum has the added advantage that it can be handled in the same types of equipment as steel. Hence, assembly techniques for aluminum parts are well established, and aluminum and steel products are easily interchanged. There are a number of disadvantages to aluminum, however, that have 1 imited its use in automobiles. Foremost

* Owens Corning Fiberglas has identified more than .150 significant process variables as part of their SMC-1982 program. 16 
among these is cost. The current price of aluminum sheet is $\$ 0.90-1.40 / 1 \mathrm{~b}$, more than four times that of steel sheet. 20 In addition, its advantage in being three times lighter than steel is offset, in applications where. stiffness is the main design criterion, by having a tensile modulus only one-third that of steel. As a result of these two disadvantages, more than $50 \%$ of the aluminum usage projected for 1985 will be in the form of lower cost cast aluminum for engine heads, manifolds, and other structural housings. In general, the high cost of aluminum sheet has caused it to be used as a "Bandaid $^{\text {m" }}$ material in achieving improved vehicle efficiency. It is employed where necessary to meet specified weight objectives on selected product lines and is replaced as soon as possible by an improved (and less expensive) steel component. Here, the ease with which steel and aluminum components can be interchanged acts to the detriment of aluminum.*

Because aluminum is a soft material and easily scratched, it requires special handling. Also, it is extremely energy intensive to produce, mainly because of the energy required for the electrolysis of alumina. Historically, the aluminum industry has been able to capitalize on the relatively low cost of hydropower, but access to this energy source is gradually being curtailed. Future additions to aluminum capacity will have to rely on thermal plants. However, recycle of aluminum is much less energy intensive, requiring only about $10 \%$ of the energy needed for production from virgin materials. About $53 \%$ of the aluminum used in cars is already being recycled.21 This material is used mainly to produce cast aluminum. and not the aluminum sheet being considered in this assessment. Nevertheless, recycling represents an important mode of energy recovery that can be expected to increase in the future.

\subsection{WEIGHT REDUCTION}

Comparative mechanical properties of two steels, aluminum, fiberglass, graphite fiber, and three types of FRP are given in Table 4.2. The density of the competing materials is one-third or less that of steel. In addition, the graphite and glass fibers, respectively, have 5-10 times conventional coldrolled, low-carbon (CRLC) steel's tensile strength. Graphite fiber has a tensile modulus equal to that of steel, while the modulus for fiberglass is one-third as great. Fiberglass and graphite fibers are lighter than steel but have comparable mechanical properties, which leads to much greater specific strengths (25-fold) and somewhat greater specific moduli. When glass fibers are dispersed as random 1-in. fibers in conventional $30 \%$ SMC, the specific strength of the composite is approximately the same as steel, while the specific modulus is only one-third as great. If greater strength is required, the quantity of glass fibers can be increased. For example, XMC ${ }^{\mathrm{m} *}$. composite contains $65-80 \%$ (by weight) unidirectionally oriented glass fibers and $20-35 \%$ TS resin (no filler). Its specific strength is nearly seven times as great as that of steel, while its specific modulus is comparable. The epoxy/graphite (EG) composite offers a further threefold increase in specific properties over that of XMC. Aluminum achieves specific properties comparable to those of

\footnotetext{
* Fiber-reinforced plastics, on the other hand, usually introduce parts consolidation to help justify their use. Thus, once the adaptations necessary for the FRP components have been made, the manufacturer is unlikely to switch back to the steel component.
}

**XMC is a registered trademark of PPG Industries, Inc. 
Table 4.2. Comparative Mechanical Properties

\begin{tabular}{|c|c|c|c|c|c|c|}
\hline Material & Orientation & Density & $\begin{array}{l}\text { Tensile } \\
\text { Strength } \\
\left(10^{3} \mathrm{psi}\right)\end{array}$ & $\begin{array}{l}\text { Tensile } \\
\text { Modulus } \\
\left(10^{6} \mathrm{psi}\right)\end{array}$ & $\begin{array}{l}\text { Specific } \\
\text { Strength } \\
\left(10^{5} \text { in.) }\right.\end{array}$ & $\begin{array}{l}\text { Specific } \\
\text { Modulus } \\
\left(10^{6} \text { in.) }\right.\end{array}$ \\
\hline Steel (CRLC/1015) & Isotropic & 0.284 & 50 & 28 & $1.8^{\circ}$ & 98 \\
\hline $\begin{array}{l}\text { High-strength steel } \\
\text { (dual phase) }\end{array}$ & Isotropic & 0.284 & 100 & 28 & 3.5 & 98 \\
\hline Al umi num (5052) & Isotropic & 0.097 & 28 & 10 & 2.9 & 103 \\
\hline Fiberglass (Type E) & & 0.092 & 500 & 10.5 & $5 \dot{4}$ & 114 \\
\hline Graphite-HS ${ }^{b}$ fibex & & 0.063 & 400 & $32-34$ & 64 & $524^{\circ}$ \\
\hline Fiber-reinforced plastics & & & & & & \\
\hline $\begin{array}{l}\text { Sheet molding compound } \\
\text { ( } 30 \% \text { reinforcement) }\end{array}$ & Multidirectionsl & 0,067 & 14 & 2.0 & 2.1. & 30 \\
\hline $\begin{array}{l}\text { XMC/ } 3^{\text {me }} \\
\text { (70\% reiniorcement) }\end{array}$ & Unidirectionai & 0.071 & 80 & 5.2 & 12 & 73 \\
\hline $\begin{array}{l}\text { Epoxy } / \text { graphite } \\
\text { ( } 50 \% \text { reinforcement) }\end{array}$ & Unidirectional & 0.054 & 186 & 22 & 34 & 408 \\
\hline
\end{tabular}

a Type-E fiberglass is a lime-alumina-borosilicate glass designed primarily for electrical applications. bGraphite-HS is a PAN-based high-strength graphite fiber.

$\mathrm{CXMC}^{\mathrm{m}} 3^{\mathrm{m}}$ is a registered trademark of PPG Industries, Inc.

Sources: Refs. $6\left(\mathrm{XMC} / 3^{\mathrm{m}}\right), 16$ (sheet molding compound), 22 (steel and aluminum), 23 (high-strength steel), and 24 (type-E fiberglass, graphite-HS, and epoxy/graphite).

steel by offsetting lesser mechanical properties with substantially lower density.

The implications of the differences in material mechanical properties can be approximately evaluated with regard to vehicle weight redurtinn by the following empirical formula:

$$
\frac{W_{c}}{W_{s}}=\frac{\rho_{c}}{\rho_{s}}\left(\frac{E_{s}}{E_{c}}\right)^{m}
$$

where:

$$
\begin{aligned}
& W_{c}=\text { weight of the competitive material component, } \\
& W_{S}=\text { weight of the steel component, } \\
& \rho_{c}=\text { density of the competitive material, } \\
& \rho_{s}=\text { density of steel, } \\
& E_{c}=\text { Young's modulus of the competitive material component, } \\
& \mathrm{E}_{s}=\text { Young's nodulus of the steel component, and } \\
& m=\text { empirical exponent depending on the shape of the component. }
\end{aligned}
$$

This formula estimates the relative weights of two materials of the same geometrical configuration used to perform the same structural function. It provides an approximate guide to the relationship between their material properties, but the actual weight comparison depends on the specifics of the part design. Since FRP usage is frequently accompanied by parts 
consolidation, estimates provided by Eq. 16 tend to be conservative with regard to FRP.* Nevertheless, the equation provides a useful first approximation, especially since manufacturers may begin by introducing similarly shaped FRP components on some of the first year's output. The ratio of the Young's moduli is used, because stiffness is the most restrictive structural requirement in the majority of automotive applications.25 The empirical factor ranges from 0.33 to 1.0 . Representative values are: 1.0 for thin-walled beams, such as chassis, pillars, and rocker panels; 0.5 for panels, such as hoods, roofs, and door panels; and 0.33 for solid sections, such as reinforcement brackets and hinges. Most of a vehicle's weight is in the form of sheet stock used for thin-walled beams and panels.

Using Eq. 16 and the mechanical properties given in Table 4.2, aluminum and FRP composites can be compared to steel for various component shapes (see Table 4.3). In all cases, the competing materials perform best against steel in the solid sections, which contribute little to overali vehicle weight. In thin-walled beams, only the EG composite offers significant weight reduction. Therefore, it is in body panels that FRP and aluminum have the greatest potential for market penetration. The weight reductions predicted by $\mathrm{Eq}$. 16 for body panels are: $43 \%$ for aluminum, $12 \%$ for SMC, $42 \%$ for $X M C^{m}$, and $80 \%$ for EG.

As noted previously, the results predicted by Eq. 16 are conservative with respect to FRP, because parts consolidation increases their competitive

Table 4.3 Weight Comparisons for Alternative Materials by Component Shape

\begin{tabular}{lccc}
\hline \multicolumn{1}{c}{ Material } & \multicolumn{3}{c}{ Weight Ratioa } \\
\cline { 2 - 4 } & $\begin{array}{c}\text { Thin-Walled Beams } \\
(\mathrm{m}=1.0)\end{array}$ & $\begin{array}{c}\text { Panels } \\
(\mathrm{m}=0.5)\end{array}$ & $\begin{array}{c}\text { Solid Sections } \\
(\mathrm{m}=0.33)\end{array}$ \\
\hline Steel $^{\mathrm{b}}$ & 1.0 & 1.0 & 1.0 \\
Aluminum & 0.96 & 0.57 & 0.48 \\
$\begin{array}{l}\text { Fiber-reinforced plastics } \\
\text { Sheet molding compound }\end{array}$ & 3.30 & 0.88 & 0.57 \\
XMC/3 & 1.34 & 0.58 & 0.43 \\
Epoxy/graphite & 0.19 & 0.20 & 0.21 \\
\hline
\end{tabular}

aThe weight ratio values are the weight of the composite material component divided by the weight of the comparable steel component. Values less than one indicate that weight reduction is achieved when the composite material is employed.

b Steel serves as the basis for comparison.

Source: This analysis is patterned after that presented in Ref. 17.

* Steel and aluminum parts also are being redesigned in light of current needs to reduce vehicle weight. This could reduce the relative advantage gained in FRP parts consolidation. 
position. Manufacturers of FRP emphasize that it is function, not shape, that must be satisfied. For comparison, Table 4.4 identifies weight reductions actually achieved using SMC, XMC $\mathrm{mm}$, and EG composites for various components. The reductions achieved in the two body panels using SMC are $35 \%$ and $53 \%$, considerably better than the $12 \%$ predicted by $\mathrm{Eq} .16$. Likewise, $\mathrm{HMC}^{\mathrm{m}}$ and $\mathrm{XMC}^{\text {'m }}$ (see Table 4.4, footnote a) perform considerably better than predicted in the two thin-walled beam and the solid section applications, achieving $50-54 \%$ weight reductions. The EG composite achieves the greatest weight savings $(66 \%$ and $68 \%$ ), which is somewhat less than the $80 \%$ predicted by Eq. 16 . This discrepancy may be attributable to use of a different graphite fiber or to additional constraints placed on the part.

Based on Table 4.4, aluminum is assumed to offer a weight reduction relative to steel of approximately $50 \%$, while SMC offers $40 \%$ and EG offers $70 \%$. As noted previously, the high cost of graphite fibers preslunes their extensive use. Therefore, subsequent comparisons focus on the competition among steel, aluminum, and SMC in body panel applications. However, hybrid FRP composites using both glass and graphite fibers could achieve substantial weight reductions at intermediate cost.

The discussion to this point has focused on primary weight reductions, i.e., those attained by substituting one material for another in a specific component. If the materials substitution takes place within the context of an overall weight reduction effort, however, a number of secondary weight reductions $c$ an be achieved. These consist of opportunities to reduce the weights of the support structure; engine, braking system, and drive train as overall vehicle weight is reduced. For example, Ford Motor Company was able to demonstrate the potential for a 706-1b primary weight reduction in their 1979 Ford LTD by constructing a concept vehicle that made use of graphite-based composites. The composites were employed in a variety of applications for which, though technically suited, they cannot presently be economically justitied. The design achieved $540 \mathrm{lb}$ in secondary weight

Table 4.4 Representative Weight Savings

\begin{tabular}{|c|c|c|c|c|}
\hline Unit & $\begin{array}{l}\text { FRP } \\
\text { Type }\end{array}$ & $\begin{array}{c}\text { Sceel } \\
\text { Component } \\
\text { Weight } \\
\text { (1b) }\end{array}$ & $\begin{array}{c}\text { Fkr } \\
\text { Component } \\
: \text { Weight } \\
\text { (1b) }\end{array}$ & $\begin{array}{c}\text { Weight } \\
\text { Reduction } \\
(\%)\end{array}$ \\
\hline Ford. Econoline van hood & SMC & 29 & 19 & 35 \\
\hline GMC truck door & SMC & 75 & 35 & 53 \\
\hline Corvette bumper backup unit & $\mathrm{HMC}^{\mathrm{ma}} \mathrm{a}$ & 22 & 10 & 54 \\
\hline Door beam & $X M C^{m a}$ & 17 & 8.5 & 50 \\
\hline GMC Phoenix transmission support & $\mathrm{XMC}^{\mathrm{m}}$ & 8.5 & 4 & $53^{-}$ \\
\hline Hood & EG & 49 & 17 & 66 \\
\hline Deck lid. & EG & 43 & 14 & 68 \\
\hline
\end{tabular}

a HMC and XMC are registered trademarks of PPG Industries, Inc. 
savings, which included an adjustment from a 5.0-L to a $2.3-\mathrm{L}$ engine, while maintaining vehicle performance. 9

Values given in the literature for the ratio of secondary to primary weight savings vary from 0.4 to 1.6 .26 . The exact value achieved depends on the part or parts being replaced, the weight efficiency of the vehicle being modified, and the extent of redesign being undertaken. Significant secondary weight savings $c a n$ be achieved for parts located on the upper body of the vehicle, while minimal secondary weight savings can be achieved for lower body or structural parts, such as wheels. The ratio achieved by the numerous changes introduced in the Ford concept vehicle was 0.76 , starting from the relatively weight inefficient LTD vehicle. It is estimated that 0.5 is representative of the general potential for secondary weight reduction in present-day vehicles, i.e., $0.5 \mathrm{lb}$ of secondary weight is removed for each pound of primary weight reduction. In view of the great emphas is being placed on vehicle weight reduction, this level of secondary weight. reduction should generally be achievable.

\subsection{EMBODIED ENERGY}

\subsubsection{Fiber-Reinforced Plastics}

The FRP embodied energy requirements were given in Sec. 3. The total energy needed to manufacture SMC with $30 \%$ fiberglass reinforcement was $24.15 \mathrm{x}$ $10^{3} \mathrm{Btu} / 1 \mathrm{~b}$, with feedstock requirements representing $31 \%$ of the total. Transportation energy requirements of $220 \mathrm{Btu} / 1 \mathrm{~b}$ increase the total to $24.4 \times 10^{3}$ $\mathrm{Btu} / \mathrm{lb} .27$ On a volume basis, the energy requirements are $1.63 \times 10^{3} \mathrm{Btu} / \mathrm{in}^{3}$. A $10 \%$ scrap rate (without recycle) is included in these figures.

\subsubsection{Steel}

The material conventionally employed for automobile body panels is CRLC steel sheet. The process sequence for production of CRLC sheet is depicted schematically in Fig. 4.3, and the process steps are enumerated in Table 4.5. Because of its tremendous economic importance, the energy and materials flows associated with this process sequence have been extensively examined.28-30 Recently; the levels of process participation characteristic of automobile-related CRLC steel sheet have been identified.27 Since 1975 the steel industry has achieved a reduction in energy consumption of somewhat more than $10 \%$.

As shown in Fig. 4.3, the process alternatives for CRLC sheet manufacture primarily concern how the molten steel is generated and how it is converted into slabs. Molten steel can be produced from iron ore in two steps via a blast furnace and either a basic oxygen furnace (BOF) or an open-hearth furnace $(\mathrm{OHF})$. A third and quite different method of molten steel production is via an electric-arc furnace (EAF), using scrap as feed. This method is much less energy intensive than the other two. However, it cannot accommodate iron ore and is not used for automobile-related CRLC sheet. Reference 27 estimates that the 1976 process splits for automobile-related molten steel were $77.3 \% \mathrm{BOF}$ and $22.7 \% \mathrm{OHF}$, and that the average charge mix was $73.6 \%$ blast furnace hot metal and $26.4 \%$ scrap. 


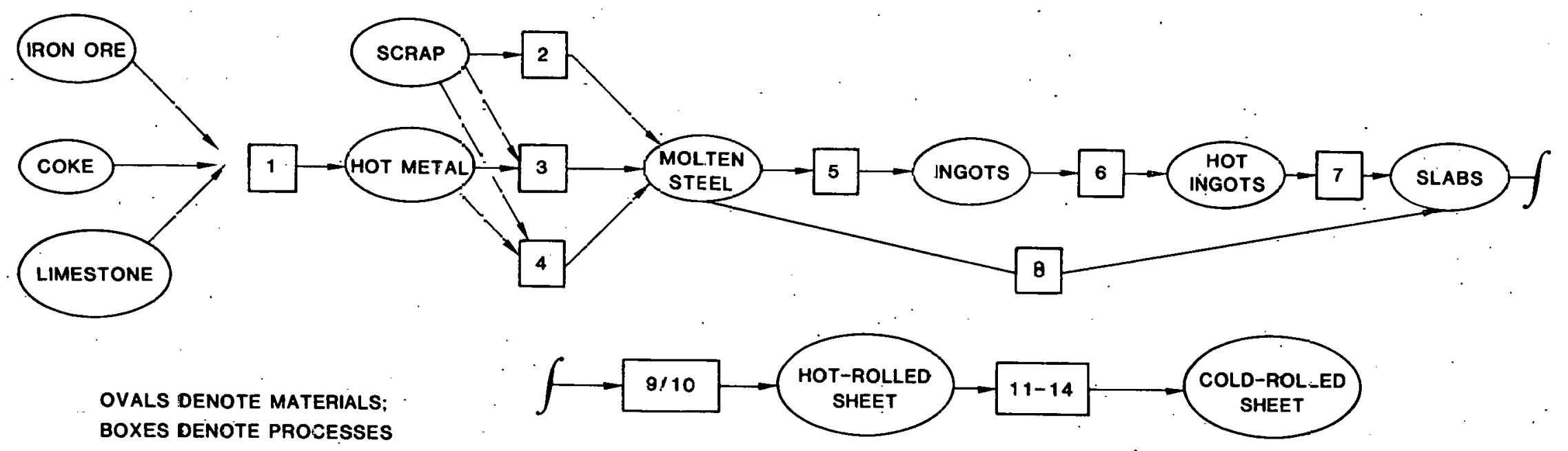

Fig. 4.3 Pracess Sequence for Cold-Rolled/Low-Carbon Steel Sheet 
The second process sequence variable is production of slabs from molten metal. Recent years have seen increasing use of continuous casting, which is $15 \%$ less energy intensive than production of conventional ingots. Reference 27 estimates that $17 \%$ of s 1 ab production was via continuous casting by 1 ate 1978 .

Energy consumption in . 1975 during CRLC sheet production via the 8 ix alternative process sequences is given in Table 4.6. Aggregate energy from all the participating processes in 1975 was $20.1 \times 10^{3} \mathrm{Btu} / \mathrm{lb}$, while present-day energy consumption is estimated to be $18.1 \times 10^{3} \mathrm{Btu} / 1 \mathrm{~b}$. Assuming an average distance of $300 \mathrm{mi}$ from the steel mill to Detroit, the transportation energy required is approximately $400 \mathrm{Btu} / 1 \mathrm{~b}$. The fabrication energy (stamping) is estimated to be $130 \mathrm{Btu} / \mathrm{lb}$ and the offal rate to be $25 \% .27$ The total embodied energy for the fabricated steel component is $(18.5 / 0.75)+0.13=24.8 \times 10^{3} \mathrm{Btu} / \mathrm{lb}$. The energy requirements for HSS are thought to be approximately the same as for CRLC steel.

\subsubsection{Aluminum}

The approach taken to assess the embodied energy of an aliminum automobile body panel is similar to that for steel. The process sequence for alıminum sheet production is shown in Fig. 4.4, and the participating processes are identified in Table 4.7. Figure 4.4 has been simplified by grouping processes 5-16 together, because most of the important process considerations are at the beginning of the sequence. For example, $75 \%$ of the energy needed for producing aluminum sheet from bauxite occurs during the HallHeroult electrolysis of alumina (process 2). In addition, use of scrap to produce aluminum ingots via the reverbatory furnace (process 4) requires only $10 \%$ of the energy needed to proceed from bauxite ore via processes 1 , 2 , and 3 .

Its extremely energy intensive nature has caused the aluminum process sequence, like that of steel, to be widely studied.27,31 Reference 27 has performed a literature review and has identified the levels of process participation associated with producing aluminum sheet for automobiles. The energy estimates in Refs. 27 and 31 are quite similar.

Because of the large differences in their processing energies; the relative participation of virgin ore and recycled scrap has a major impact 
Table 4.6 Energy Consumption in Cold-Rolled/Low-Carbon

Steel Sheet Manufacture, 1975

\begin{tabular}{|c|c|c|c|}
\hline Process Route & $\begin{array}{c}\text { Sequence } \\
\text { Energy } \\
\left(10^{3} \text { Btu/1b) }\right.\end{array}$ & Participation & $\begin{array}{c}\text { Aggregate } \\
\text { Energy } \\
\left(10^{3} \mathrm{Btu} / 1 \mathrm{~b}\right)\end{array}$ \\
\hline \multicolumn{4}{|l|}{ Conventional ingots } \\
\hline Basic-oxygen furnace & 20.8 & $0.773 \times 0.83$ & 13.3 \\
\hline Open-hearth furnace & 20.2 & $0.227 \times 0.83$ & 3.8 \\
\hline Electric-arc furnace & 11.9 & - & - \\
\hline \multicolumn{4}{|l|}{ Continuous casting } \\
\hline Basic=oxygen furnacé & $1 / .1$ & $0.773 \times 0.17$ & 2.3 \\
\hline Open-hearth furnare & 17.2 & $0.227 \times 0.17$ & 0.7 \\
\hline Electric-arc furnace & 9.9 & - & - \\
\hline Total & & & 20.1 \\
\hline
\end{tabular}

Source: Ref. 27.

on the aggregate energy required for aluminum sheet. From an energy standpoint, one would prefer to use as much scrap as possible. The major constraint to this is the effectiveness of the collection and recycling system for post-consumer scrap. Automobiles and aluminum cans are two of the best candidates for recycle. For automobiles, a recycle system for aluminum and other vehicle materials, primarily steel, is well established. In the case of cans, the can is composed solely of aluminum so that recycle processing is minimized. Studies have established that $53 \%$ of the aluminum in cars is being recovered, 21 and $26 \%$ of aluminum cans are being recycled.32 other aluminum products are not recycled to the same degree, so that only $10 \%$ of annual aluminum output is derived from post-consumer scrap. 33

The reverbatory furnace plays an important role, in that it processes the large quantities of mill scrap generated during aluminum shept fahriration. Thirty-five percent of the initial aluminum ingot is turned into mill scrap during processes 5-16. The overall materials flow for aluminum sheet is shown in Fig. 4.5. Although purchased scrap represents only $10 \%$ of the output, the reverbatory furnace, which has a $90 \%$ efficiency, processes $40.5 \%$ of the material.

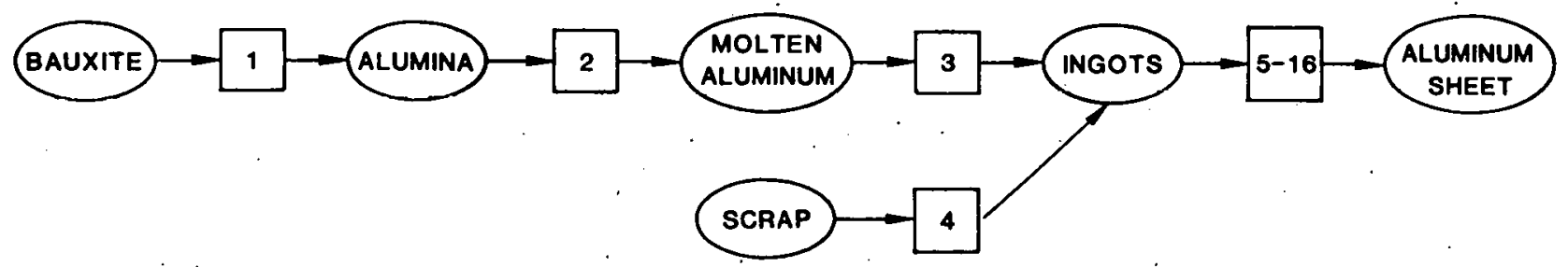

Fig. 4.4 Aluminum Sheet Process Sequence 
The process energy to produce aluminum sheet is given in Table 4.8 . Assuming an additional $400 \mathrm{Btu} / \mathrm{lb}$ for 300-mi transport to Detroit, the embodied energy of the sheet entering automobile part manufacture is $121.3 \mathrm{x}$ $10^{3} \mathrm{Btu} / \mathrm{lb}$. The fabrication energy is estimated to be the same as for steel (130 Btu/lb) and the same $25 \%$ offal rate is assumed. The embodied energy of aluminum sheet for automobile manufacture is $(121.3 / 0.75)+0.13=$ $161.9 \times 10^{3} \mathrm{Btu} / \mathrm{lb}$. This is more than six times as great as the $24.8 \times 10^{3}$ $\mathrm{Btu} / \mathrm{lb}$ for steel and the $24.4 \times 10^{3}$ Btu/1b for SMC (see Table 4.9).

\subsection{DEPENDENCE OF FUEL SAVINGS ON VEHICLE WEIGHT}

Automobile weight reduction achieved through use of FRP and aluminum components, or other means, translates directly into vehicle fuel savings. An estimate of the potential magnitude of these transportation energy savings $c$ an be derived from a U.S. Department of Transportation (DOT) correlation of fuel economy and vehicle weight.35,36 The correlation for a given year is based on test data collected for a large number of vehicle models in that year. The empirical. relation is:

$$
F E=A(W)^{-a}(H P / W)^{-b}
$$

where:

$$
\begin{aligned}
\mathrm{FE}= & \text { EPA composite fuel economy over a designated driving } \\
& \text { cycle (mpg), } \\
\mathrm{W}= & \text { vehicle inertia weight (dry weight plus passengers } \\
& \text { and fluids), } \\
\mathrm{HP}= & \text { rated engine horsepower, and } \\
\mathrm{A}, \mathrm{a}, \mathrm{b}= & \text { scaling coefficients that depend on engine character- } \\
& \text { istics. }
\end{aligned}
$$

The scaling coefficients differ for vehicles having gasoline and diesel engines. They also change from year to year as vehicle performance characteristics (other than weight) are improved. The values for 1979 vehicles with gasoline engines are: $A=.8680, a=0.863, b=0.284$. 


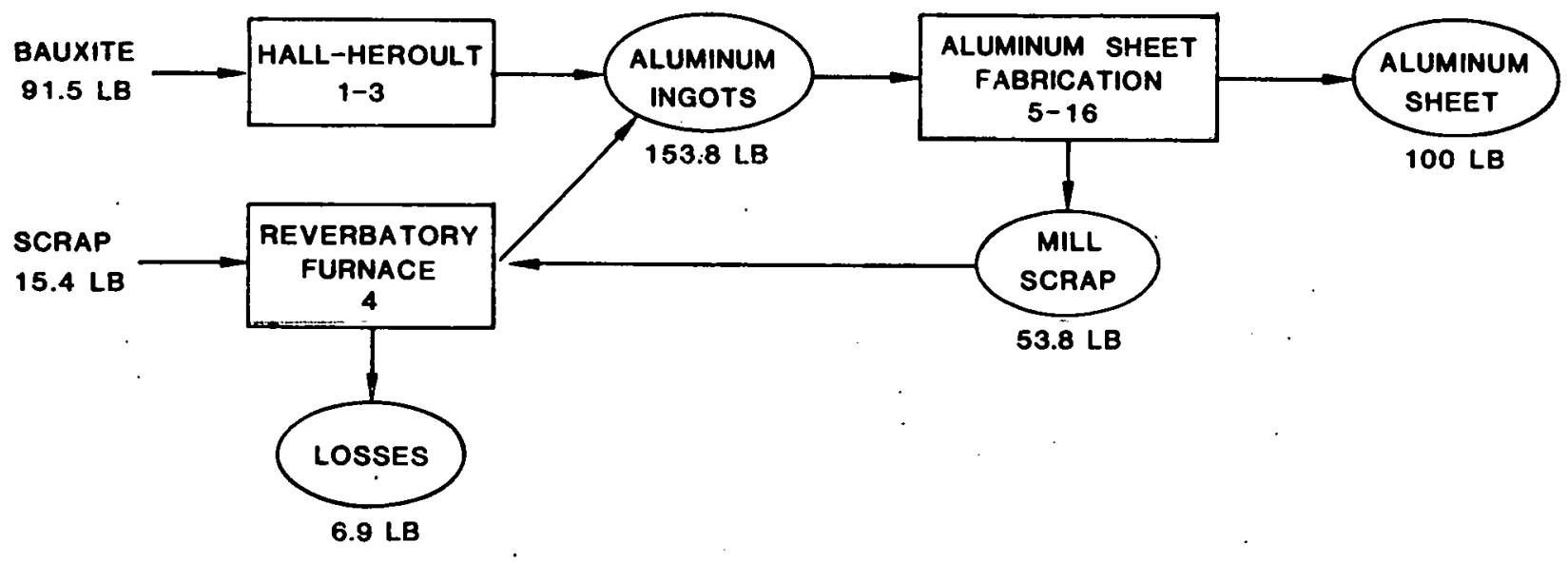

Fig. 4.5 Material Flows in Aluml num Sheet Manufacture

Table 4.8 Energy Consumption in Aluminum Sheet Manufacture, $1980^{\mathrm{a}}$

\begin{tabular}{lccc}
\hline \multicolumn{1}{c}{ Process Route } & $\begin{array}{c}\text { Sequence Energy } \\
\left(10^{3} \mathrm{Btu} / 1 \mathrm{~b}\right)\end{array}$ & $\begin{array}{c}\text { Participation } \\
(\%)\end{array}$ & $\begin{array}{c}\text { Aggregate Energy } \\
\left(10^{3} \mathrm{Btu} / 1 \mathrm{~b}\right)\end{array}$ \\
\hline Bayer/Hall-Heroult & 189.9 & 59.5 & 113.0 \\
Reverbatory furnace & 19.4 & 40.5 & 7.9 \\
Total & & 100.0 & 120.9 \\
\hline
\end{tabular}

aThis table assumes: (i) the materials flow sequence shown in Fig. 4.4, (2) an industry average of $115.8 \times 10^{3} \mathrm{Btu} / \mathrm{lb}$ in 1980 for aluminum ingot production via the Hall-Heroult process, 34 (3) $4.9 \times 10^{3} \mathrm{Btu} / 1 \mathrm{~b}$ for scrap-to-ingot via the reverbatory furnace, (4) $11.9 \times 10^{3} \mathrm{Btu} / \mathrm{b}$ for aluminum ingot to sheet, and (5) $34.12 \%$ thermal efficiency in electricity generation.

Equation 17 can be easily rearranged in terms of fuel consumption, FC, which is the reciprocal of fuel economy. Differentiating the equation then yields the change in fuel consumption with change in vehicle weight:

$$
\begin{aligned}
\lambda & \equiv \frac{\mathrm{d}(\mathrm{FC})}{\mathrm{dW}} \\
& \equiv \frac{\mathrm{a}}{\mathrm{A}} \mathrm{W}^{\mathrm{a}-1}\left(\frac{\mathrm{HP}}{\mathrm{W}}\right)^{\mathrm{b}}
\end{aligned}
$$

where the performance parameter (HP/W) is held constant. For a 3000-1b gasoline engine vehicle with a performance parameter of $0.03 \mathrm{hp} / \mathrm{lb}$ :

$$
\lambda=1.23 \times 10^{-5} \mathrm{gal} / \mathrm{mi} / \mathrm{lb}
$$

If the effect of weight reduction alone is to be evaluated, an adjustment must be made. The DOT data employed in developing Eq. 17 include the effect of 
Table 4.9 Embodied Energies of Steel, Fiber-Reinforced Plastics, and Aluminum Sheet $\left(10^{3} \mathrm{Btu} / \mathrm{lb}\right)$

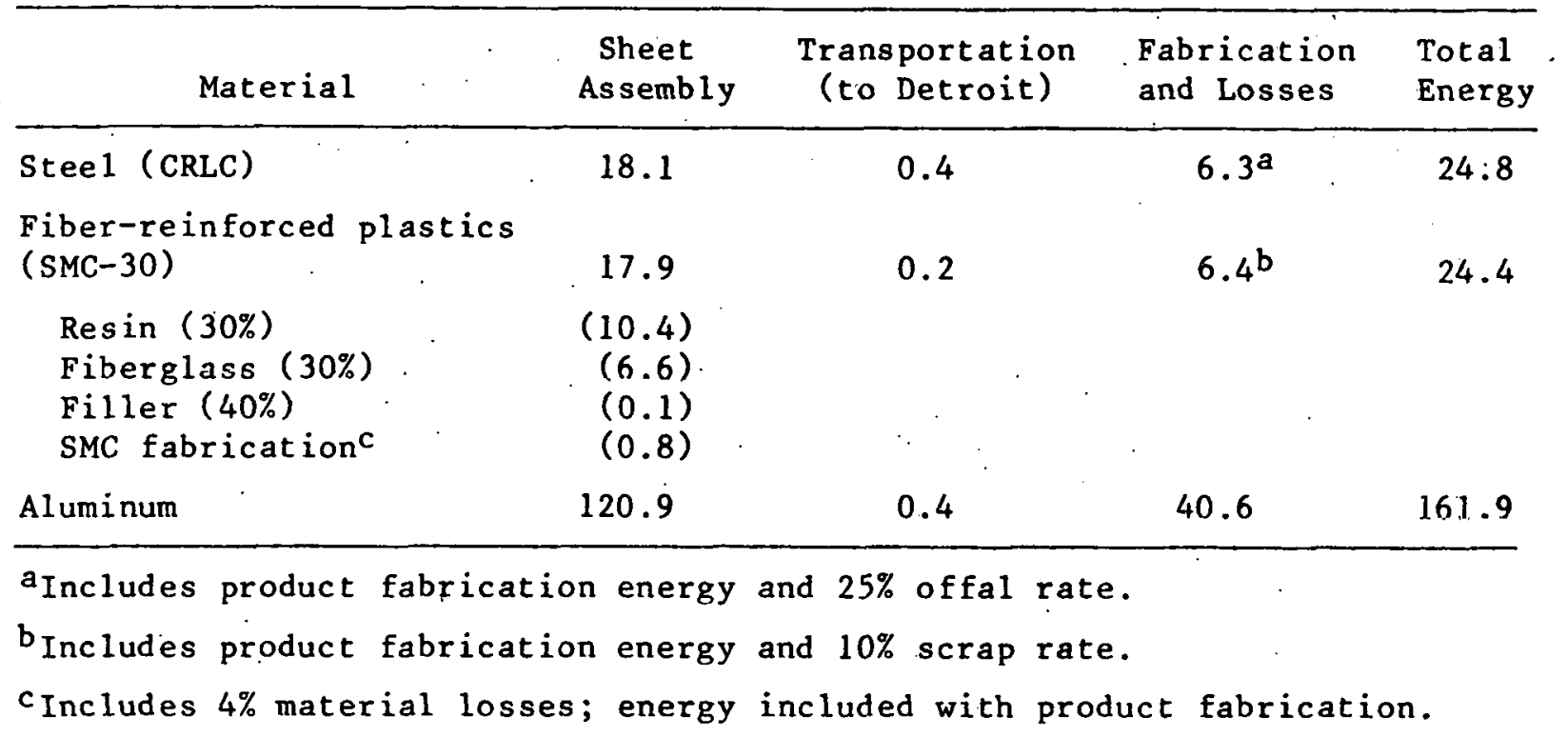

changes in aerodynamic drag as well as weight reduction. The share attributable to aerodynamic drag has been estimated at $20-40 \%$. A value of $24 \%$ is identified as the aerodynamic drag share of brake horsepower in Ref. 37. This value is assumed for the present computations and yields the following fuel consumption dependence on weight:

$$
\lambda_{W}=0.93 \times 10^{-5} \mathrm{gal} / \mathrm{mi} / 1 \mathrm{~b}
$$

This value is consistent with values estimated by auto manufacturers. $3,23,38$

The significance of $\lambda_{W}$ can be demonstrated by determining the reduction in fuel consumption to be attained by the vehicle weight reduction identified for 1977-1985 (see Table 4.1). Vehicle weight is projected to diminish by $1200 \mathrm{lb}$ over this period. Assuming a vehiclc life of $100,000 \mathrm{mi}$, each 1985 vehicle will consume an average of $1116 \mathrm{gal}$ less than the corresponding 1977 vehicle operating over the same distance.* If $9 \times 10^{6}$ domestic cars are sold each year and they each have a 10-yr average life, aggregate reduction in fuel consumption will reach $10.0 \times 10^{9}$ gal of gasoline per year when the entire vehicle fleet has achieved that weight reduction. This represents an $11 \%$ reduction in automotive fuel consumption relative to that consumed in 1979.39

\subsection{ENERGY IMPLICATIONS OF MATERIALS SUBSTITUTION}

Previous sections have provided the basis for assessing the energy implications of replacing a steel automobile body panel by one composed of FRP

*More exactly, Eq. 18 can be integrated with respect to weight between 3000-4200 1b, then corrected for aerodynamic drag. The result, $11201 \mathrm{~b}$, is nearly the same as that obtained by multiplying the weight change by $\lambda_{W}$. 
or of aluminum. The results of this assessment are presented in Table 4.10. As discussed in Sec. 4.2, a 1.0-1b. steel component can be replaced by a structurally equivalent $0.6-1 \mathrm{~b}$ FRP component or a $0.5-1 \mathrm{~b}$ aluminum component. The $0.4-1 b$ primary weight reduction achieved using the FRP component can be further translated into a $0.2-1 b$ secondary weight reduction. In other words, $1.5 \mathrm{lb}$ of primary and secondary steel $\mathrm{c}$ an be replaced by $0.6 \mathrm{lb}$ of FRP and 0.3 $1 b$ of secondary steel.* Likewise, the $0.5-1 b$ aluminum-related primary weight reduction permits an accompanying $0.25-1 \mathrm{~b}$ secondary weight reduction. Thus,

Table 4.10 Energy Reduction Potential of FiberReinforced Plastics and Aluminum Components (relative to a one-pound steel component)

\begin{tabular}{|c|c|c|}
\hline Variable & $F_{R P}{ }^{a}$ & Aluminum \\
\hline \multicolumn{3}{|l|}{ Reduction in weight ( $1 \mathrm{~b}$ ) } \\
\hline $\begin{array}{l}\text { Primary } \\
\text { Secondary }\end{array}$ & $\begin{array}{l}0.4 \\
0.2\end{array}$ & $\begin{array}{l}0.50 \\
0.25\end{array}$ \\
\hline Total & 0.6 & 0.75 \\
\hline \multicolumn{3}{|l|}{ Reduction in embodied energy $\left(10^{3} \mathrm{Btu}\right)$} \\
\hline $\begin{array}{l}\text { Component } \\
\text { Secondary }\end{array}$ & $\begin{array}{r}10.2 \\
5.0\end{array}$ & $\begin{array}{r}-56.2 \\
6.2\end{array}$ \\
\hline Total & 15.2 & -50.0 \\
\hline $\begin{array}{l}\text { Reduction in transportation energy } \\
\text { over } 100,000-\mathrm{mi} 1 \text { fetime }\left(10^{3} \mathrm{Btu}\right) \mathrm{c}\end{array}$ & 69.8 & 87.2 \\
\hline Total energy reduction $\left(10^{3} \mathrm{Btu}\right)$ & 85.0 & 37.2 \\
\hline \multicolumn{3}{|c|}{$\begin{array}{l}\text { aSheet molding compound containing } 30 \% \text { (by weight) } \\
\text { fiberglass. }\end{array}$} \\
\hline \multicolumn{3}{|c|}{$\begin{array}{l}\text { bsecondary components are asoumed to be composed of } \\
\text { steel. }\end{array}$} \\
\hline \multicolumn{3}{|c|}{$\begin{array}{l}\text { cTransportation energy requirements are calculated using } \\
\text { the weight reduction factor } 0.93 \times 10^{-5} \mathrm{gal} / \mathrm{mi} / \mathrm{lb} \text {. The } \\
\text { embodied energy of gasoline is estimated to be } 125 \mathrm{x} \\
10^{3} \mathrm{Btu} / \mathrm{gal} \text {. }\end{array}$} \\
\hline
\end{tabular}

*The basis for this calculation is $1.0 \mathrm{lb}$ of steel as primary weight, and 0.5 $1 \mathrm{~b}$ of steel as associated secondary weight. The secondary material is assumed $L U$ be steel for simplicity in estimating its energy intensity. In addition, cast aluminum, zinc, copper, lead, glass, rubber, plastics, and miscellaneous materials contribute to the secondary materials.mix. Since these other materials have greater energy intensities than steel, use of steel as a proxy underestimates the energy gains to be achieved in materials substitution. 
$1.5 \mathrm{lb}$ of primary and secondary steel can be replaced by $0.51 \mathrm{~b}$ of aluminum and $0.25 \cdot 1 \mathrm{~b}$ of secondary steel.

The embodied energies of the $1.0-1 b$ steel component, the 0.6-1b FRP component, and the $0.5-1 \mathrm{~b}$ aluminum component are calculated using the unit embodied energies of each material identified in Sec. 4.3. As noted, reductions in embodied energy achieved via the secondary weight reduction are computed assuming that steel is the secondary material." The FRP component is able to achieve a $15.2 \times 10^{3}$ Btu reduction in embodied energy. The sixfold higher unit embodied energy of the aluminum component leads to a $50.0 \times 10^{3}$ Btu increase in embodied energy in spite of the $50 \% 1$ ighter component weight.

Reductions in fuel consumption are the dominant effect stemming from the materials substitution. These are calculated for a vehicle life of $100,000 \mathrm{mi}$ using the fuel/weight factor of $0.93 \times 10^{-5} \mathrm{gal} / 1 \mathrm{~b} / \mathrm{mi}$ (Eq. 20 ). The embodied energy of gasoline is estimated to be $125 \times 10^{3} \mathrm{Btu} / \mathrm{gal}$. The FRP component achieves a $69.8 \times 10^{3}$ Btu improvement in fuel consumption relative to the steel component. When this is added to the improvement in embodied energy, a total energy difference of $85.0 \times 10^{3}$ Btu results. Aluminum achieves an even larger transportation energy savings of $87.2 \times 10^{3}$ Btu. This offsets the embodied energy penalty of aluminum so that total energy is reduced $37.2 \times 10^{3}$ Btu relative to steel.

Both FRP and aluminum provide significant opportunities for energy conservation in automobile manufacture and use. As HSS gain acceptance, however, the 10-20\% weight reduction they offer will offset aluminum's energy advantage and will substantially reduce that of FRP. (The total energy reduction achieved using HSS to reduce primary weight by $20 \%$ is $42.5 \times 10^{3}$ Btu.) The materials usage decision will then hinge on the considerations discussed in Sec. 4.1. The high cost of aluminum sheet is expected to critically restrict its use. Fiber-reinforced plastics usage will depend on the industry's ability to surmount the manufacturing difficulties discussed in Sec. 4.1.2. The market competition aspects of the potential energy savings appear to be sufficiently great for FRP to gain a significant market share:

\subsection{ENERGY RESOURCE CONSUMPTION}

An important aspect of steel, FRP, and aluminum competition in automotive applications is the type of energy resource consumed in their manufacture. Two aspects are of particular interest: (1) how much petroleum is used, because that energy resource is currently of great concern; and (2) how much electricity is used, because electricity can be generated by a variety of fuels or by hydropower and total fuel demand depends on the electricity source. The first issue is raised most frequently with regard to plastics, because hydrocarbons compose the body of these materials. The second issue is most relevant to aluminum because of its high energy requirements for electrolysis.

The embodied energies of manufacture were identified in Sec. 4.3 for each of the three materials: steel, $24.8 \times 10^{3} \mathrm{Btu} / 1 \mathrm{~b} ; \mathrm{FRP} ; 24.4 \times 10^{3}$ $\mathrm{Btu} / 1 \mathrm{~b}$; and aluminum, $161.9 \times 10^{3} \mathrm{Btu} / \mathrm{lb}$. In the case of steel and aluminum, the energy requirements arise from mining, metal sheet manufacture, sheet 
transport to Detroit, and product fabrication. In the case of FRP, they arise from feedstocks used in resin production; fuels required to manufacture resin, fiberglass, and filler, and to fabricate and mold SMC; and materials transport to Detroit. In order to translate the total embodied energy values into fuel requirements, the types of fuels employed in each industry must be identified. This has been done by DOE as part of their Industrial.Energy Efficiency Program.* The most recent results for the industries of interest are given in Table 4.11. The iron and steel industry depends mainly on coal and coke $(64 \%)$, the aluminum industry on electricity (68\%), and fiberglass manufacture on natural gas (75\%).

The fuel participations given in Table 4.11 for steel and aluminum can be directly employed to estimate fuel use in sheet processing, transportation, and product fabrication (see Table 4.12). For steel, the direct energy requirements are $21.44 \times 10^{3} \mathrm{Btu} / 1 \mathrm{~b}$ fuels and $1.14 \times 10^{3} \mathrm{Btu} / 1 \mathrm{~b}$ electricity, for a total of $22.58 \times 10^{3} \mathrm{Btu} / 1 \mathrm{~b}$. In comparison, $22.84 \times 10^{3} \mathrm{Btu} / 1 \mathrm{~b}$ fuels and $47.44 \times 10^{3} \mathrm{Btu} / 1 \mathrm{~b}$ electricity are employed in aluminum manufacture, for a total of $70.28 \times 10^{3} \mathrm{Btu} / \mathrm{lb}$. The electricity component of the energy requirement is allocated among fuels using the values given for electricity generation in Table 4.11 and assumes a thermal efficiency of $34.12 \%$. This thermal efficiency was applied to all electrical power, because nearly all U.S. hydroelectric sites have been developed and significant near-term expansion of nuclear capacity is unlikely. Hence, future electricity generating

Table 4.11 Fuel Participation by Industry, $1978(\%)$

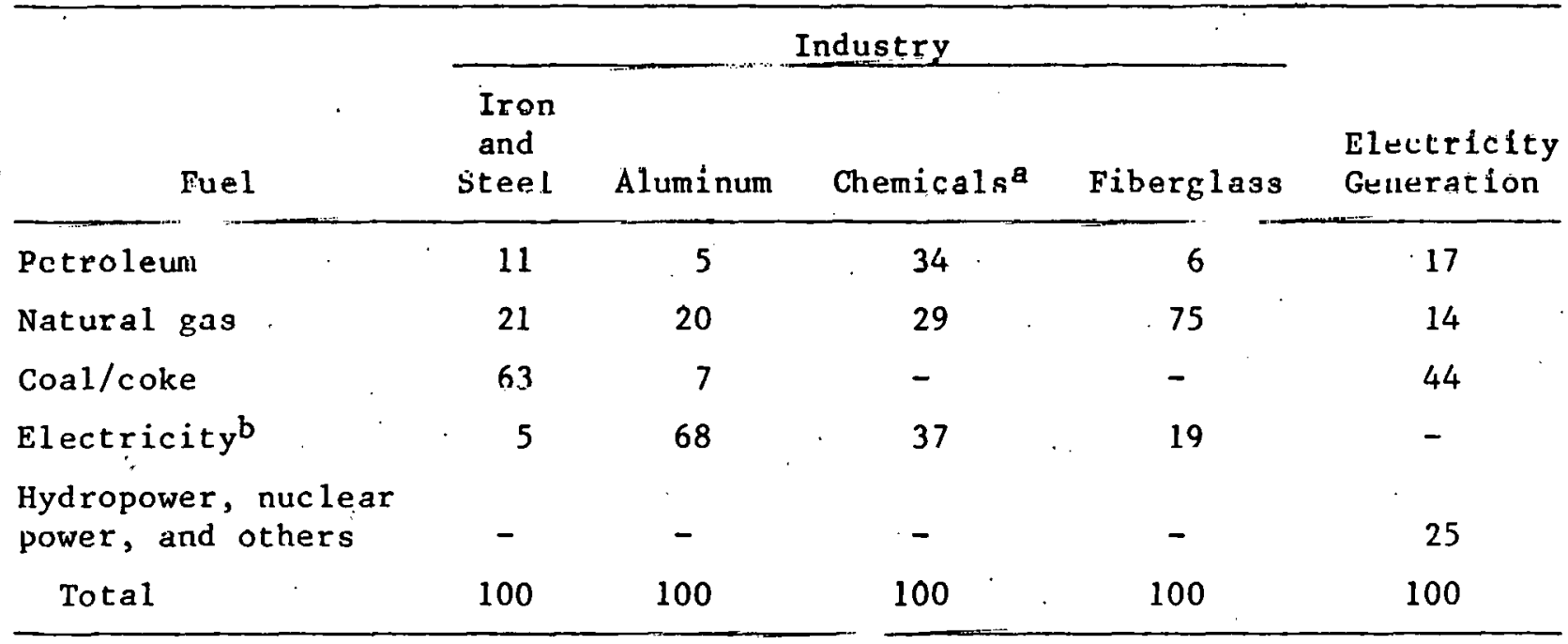

asteam usage in the chemical industry (4\%) has been allocated to petroleum ( $2 \%)$, natural gas $(1 \%)$, and coal/coke ( $1 \%) .40$

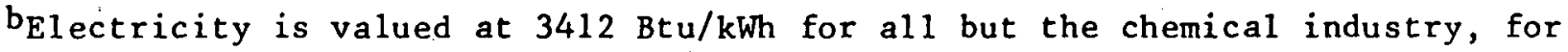
which it is valued at $10,000 \mathrm{Btu} / \mathrm{kWh}$.

Sources: Ref. 40 (industrial fuel allocations) and 41 (fuel use in electricity generation).

\footnotetext{
*Fuel use by industrial sector is also surveyed periodically as part of the Census of Manufactures.
} 
Table 4.12 Fuel Participation in Embodied Energy of Steel, Fiber-Reinforced Plastics, and Aluminum Components ( $10^{3} \mathrm{Btu} / \mathrm{lb}$ of component)

\begin{tabular}{|c|c|c|c|c|c|c|}
\hline Material & Petroleum & $\begin{array}{l}\text { Natural } \\
\text { Gas }\end{array}$ & $\begin{array}{l}\text { Coal/ } \\
\text { Coke }\end{array}$ & Electricity & $\begin{array}{c}\text { Hydro, Nuclear, } \\
\text { and other }\end{array}$ & Total \\
\hline \multicolumn{7}{|l|}{ Steel } \\
\hline Sheet processing & 2.42 & 4.62 & 13.87 & 1.10 & - & 22.01 \\
\hline Transportation : & 0.53 & - & - & - & - & 0.53 \\
\hline Fabrication & - & - & - & 0.04 & - & 0.04 \\
\hline Direct energy ${ }^{a}$ & 2.95 & 4.62 & 13.87 & 1.14 & - & 22.58 \\
\hline Electricity generation $b$ & 0.57 & 0.47 & 1.48 & $(1.14)$ & 0.84 & 2.22 \\
\hline Total fuels ${ }^{c}$ & 3.52 & 5.09 & 15.35 & $-\quad$. & 0.84 & 24.80 \\
\hline \multicolumn{7}{|l|}{ SMC-30 (FRP) } \\
\hline Resin & 7.69 & 1.85 & - & 0.85 & - & 10.30 \\
\hline Fiberglass & 0.04 & 5.20 & - & 0.83 & - & 6.07 \\
\hline Filler (calcium carbonate) & 0.11 & - & - & 0.02 & - & 0.13 \\
\hline Transportation & 0.24 & - & - & - & - & 0.24 \\
\hline Fabrication & - & 0.08 & - & 1.43 & - & 1.51 \\
\hline Direct energy & 8.08 & 7.13 & - & 3.13 & - & 18.34 \\
\hline Electricity generation & 1.51 & 1.27 & 4.06 & $(3.13)$ & 2.33 & 6.04 \\
\hline Total fuels & 9.59 & 8.40 & 4.06 & - & 2.33 & 24.38 \\
\hline \multicolumn{7}{|l|}{ Alumi num } \\
\hline Sheet processing & 3.49 & 13.94 & 4.88 & 47.40 & - & 69.71 \\
\hline Transportation & 0.53 & - & - & - & - & 0.53 \\
\hline Fabrication & - & - & - & 0.04 & - & 0.04 \\
\hline Direct energy & 4.02 & 13.94 & 4.88 & 47.44 & - & 70.28 \\
\hline Electricity generation & 23.64 & 19.47 & 61.18 & $(47.44)$ & 34.76 & 91.61 \\
\hline Total fuels & 27.66 & 33.41 & 66.06 & - & 34.76 & 161.89 \\
\hline
\end{tabular}

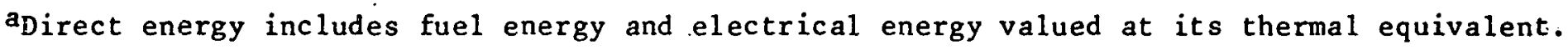

bFuel energy loss during electricity generation is calculated assuming $34.12 \%$ thermal efficiency and using the fuels participation given in Table 4.10.

${ }^{c}$ Total fuels includes fuel energy and electrical energy valued at its fuel equivalent (see footnote b). These are the values developed in Secs. 3 and 4 of this report. 
capacity will mainly be thermally based.. The total fuels requirement of aluminum manufacture is $6.5^{\circ}$ times that of steel, but the corresponding ratio for direct energy requirements is significantly less at 3.1 .

Using the average electricity generating facility mix, petroleum consumption by aluminum is nearly eight times that by steel. On the other hand, the large base-load demand of aluminum permits construction of dedicated coal-fired facilities. If all new aluminum capacity were based on coal-fired electricity, petroleum demand by aluminum in new facilicles would be only 4.02 $x 1 U^{3} \mathrm{Btu} / \mathrm{lb}$, while coal demand would increase to $143.9 \times 10^{3} \mathrm{Btu} / \mathrm{lb}$. If a large share of the electricity consumed in aluminum production were hydrobased, as has historically been the case, and the hydro is valued at its thermal equivalent, the total fuels requirement for aluminum decreases substantially. For example, $40 \%$ hydro would lead to a total fuels requirement of $125.2 \times 10^{3} \mathrm{Btu} / \mathrm{lb}$, which is $23 \%$ less than the value shown in Table 4.12 .

Identification of fuels consumption in FRP manufacture requires considering the participating constituents. Resin accounts for $30 \%$ of the FRP product being evaluated, which is SMC containing $30 \%$ fiberglass (SMC- 30 ) (see Sec. 3.4). Resin energy requirements are $22.16 \times 10^{3} \mathrm{Btu} / 1 \mathrm{~b}$ for feedstock and $12.47 \times 10^{3} \mathrm{Btu} / 1 \mathrm{~b}$ for process energy. Referring to $\mathrm{Fig} .3 .4$, a11 hydrocarbon feedstocks except ethane are based on petroleum. Altogether, the petroleum-based feedstocks -- gas oil, naphtha, and reformate -- account for $18.93 \times 10^{3} \mathrm{Btu} / \mathrm{lb}$. Ethane, a by-product of natural gas production, accounts for the other $3.23 \times 10^{3} \mathrm{Btu} / 1 \mathrm{~b}$ of feedstock energy. Process energy requirements for the resin can be allocated among fuels using the chemical industry values given in Table 4.10. Fiberglass, which accounts for $30 \%$ of the FRP, requires $0.3 \times 10^{3} \mathrm{Btu} / 1 \mathrm{~b}$ for raw materialo mining and $21.80 \times 10^{3} \mathrm{Btu} / \mathrm{bb}$ for manufacture. The mining energy io thouglit lu be composed of $33 \%$ petroleum (for diesel engines) and $67 \%$ electricity, and the manufacturing fuels participation is $15 \times 10^{3}$ Btu/lb natural gas and $6.8 \times 10^{3}$ Btu/lb electricity. 15 Filler energy requirements of $0.35 \times 10^{3}$ Btu/1b for mining, bencfieiatiul, and drying have betll esclmated as $67 \%$ petroleum and $33 \%$ electricity. Table 4.12 shows the fuel requirements for each FRP conetituent and the overall total. The $24.4 \times 10^{3}$ Btu/lb total fuel requirements are slightly less than those for steel and only one-sixth those far aluminum. Tetsuleum consumption in FRP manufacture is $9.59 \times 10^{3} \mathrm{Btu} / 1 \mathrm{~b}$, nearly three times that for steel.

The fuel requirements of the competing materials can bc placed ill an automotive cuulext by extending the previous analysis, which is summarized in Table 4.9. As discussed previously, on the average $1.01 \mathrm{~b}$ of steel in an automobile body panel can be replaced with equivalent structural effectiveness by $0.6 \mathrm{lb}$ of FRP or $0.5 \mathrm{lb}$ of aluminum. In addition, the primary weight reduction achieved $c$ an be further translated into a secondary weight reduction in engine, support structure, and drive train components. Potential secondary weight reduction was estimated to be $50 \%$ of the primary weight reduction: The comparative material weights are shown in the first colımn of Tablc 4.13. The first three ruws for each material in this table then identify the embodied energy requirements for each product (as given in Table 4.12) for the material weights given in the first column. Steel is assumed to be the secondary material in each instance. The lifetime transportation energy requirements for one pound of vehicle weight were identified earlier as $116 \times 10^{3} \mathrm{Btu} / \mathrm{b}$. Thus, the weight reductions achieved by FRP and aluminum represent significant petroleum savings over the vehicle 1 ifetime. 
Table 4.13 Life Cycle Fuels Participation in Structurally

Equivalent Steel, Fiber-Reinforced Plastics, and Aluminum Automobile Components

\begin{tabular}{|c|c|c|c|c|c|c|}
\hline Material & $\begin{array}{l}\text { We ight } \\
\text { (1b) }\end{array}$ & $\begin{array}{l}\text { Petroleum } \\
\left(10^{3} \text { Btu) }\right.\end{array}$ & $\begin{array}{c}\text { Natural } \\
\text { Gas } \\
\left(10^{3} \mathrm{Btu}\right)\end{array}$ & $\begin{array}{c}\text { Coall } \\
\text { Coke } \\
\left(10^{3} \text { Btu }\right)\end{array}$ & $\begin{array}{c}\text { Hydro, Nuclear, } \\
\text { and Other } \\
\left(10^{3} \text { Btu) }\right.\end{array}$ & $\begin{array}{c}\text { Total } \\
\left(10^{3} \text { Btu }\right)\end{array}$ \\
\hline \multicolumn{7}{|l|}{ Steel } \\
\hline $\begin{array}{l}\text { Primary } \\
\text { Secondary }\end{array}$ & $\begin{array}{l}1.0 \\
0.5\end{array}$ & $\begin{array}{l}3.52 \\
1.76\end{array}$ & $\begin{array}{l}5.09 \\
2.55\end{array}$ & $\begin{array}{r}15.35 \\
.7 .67\end{array}$ & $\begin{array}{l}0.84 \\
0.42\end{array}$ & $\begin{array}{l}24.80 \\
12.40\end{array}$ \\
\hline $\begin{array}{l}\text { Embodied } \\
\text { Transportation }\end{array}$ & $\overline{-}$ & $\begin{array}{r}5.28 \\
174.38\end{array}$ & $\begin{array}{l}7.64 \\
-\end{array}$ & $\begin{array}{c}23.02 \\
-\end{array}$ & 1.26 & $\begin{array}{r}37.20 \\
174.38\end{array}$ \\
\hline Total & 1.5 & 179.66 & 7.64 & 23.02 & 1.26 & 211.58 \\
\hline \multicolumn{7}{|l|}{ SMC-30 (FRP) } \\
\hline $\begin{array}{l}\text { Primary } \\
\text { Secondary }\end{array}$ & $\begin{array}{l}0.6 \\
0.3\end{array}$ & $\begin{array}{l}5.75 \\
1.06\end{array}$ & $\begin{array}{l}5.04 \\
1.53\end{array}$ & $\begin{array}{l}2.44 \\
4.60\end{array}$ & $\begin{array}{l}1.40 \\
0.25\end{array}$ & $\begin{array}{r}14.63 \\
7.44\end{array}$ \\
\hline $\begin{array}{l}\text { Embodied } \\
\text { Transportat ion }\end{array}$ & - & $\begin{array}{r}6.81 \\
104.63\end{array}$ & $\begin{array}{c}6.57 \\
-\end{array}$ & 7.04 & 1.65 & $\begin{array}{r}22.07 \\
104.63\end{array}$ \\
\hline Total & 0.9 & 111.44 & 6.57 & 7.04 & 1.65 & 126.70 \\
\hline \multicolumn{7}{|l|}{ Aluminum } \\
\hline $\begin{array}{l}\text { Primary } \\
\text { Secondary. }\end{array}$ & $\begin{array}{l}0.5 \\
0.25\end{array}$ & $\begin{array}{r}13.83 \\
0.88\end{array}$ & $\begin{array}{r}16.71 \\
1.2 .7\end{array}$ & $\begin{array}{r}33.03 \\
3.84\end{array}$ & $\begin{array}{r}17.38 \\
0.21\end{array}$ & $\begin{array}{r}80.95 \\
6.20\end{array}$ \\
\hline $\begin{array}{l}\text { Embodied } \\
\text { Transportat.ion .. }\end{array}$ & $\overline{-}$ & $\begin{array}{l}14.71 \\
87.19\end{array}$ & 17.98 & $\begin{array}{c}36.87 \\
-\end{array}$ & 17.59 & $\begin{array}{l}87.15 \\
87.19\end{array}$ \\
\hline Total & 0.75 & 101.90 & 17.98 & 36.87 & 17.59 & 174.34 \\
\hline
\end{tabular}

The lighter weight of the FRP component and its accompanying secondary weight reduction enables FRP to achieve lower embodied energy requirements and lower petroleum requirements than steel. In comparison, aluminum is less than either steel or FRP in petroleum consumption, and less than steel but greater than FRP in total energy requirements. In relative terms, the FRP component requires only $62 \%$ as much petroleum as the steel component, and $60 \%$ as much total fuel. Likewise, the aluminum component requires only $57 \%$ as much petroleum as the steel component, and the total fuel requirements of aluminum are $18 \%$ less than those for steel.

In summary, FRP can provide energy benefits from both points of view -- total energy and petroleum consumption. Aluminum provides a slightly greater reduction in petroleum consumption at a $38 \%$ increase in total energy relative to FRP. As noted previously, industry data indicate that nearly $40 \%$ of the electricity requirements of the aluminum industry are now based on hydroelectric power generation. If the thermal losses of this portion of electricity generation were excluded, the total fuel requirements of aluminum would be reduced to $118.6 \times 10^{3} \mathrm{Btu} / 1 \mathrm{~b}$, which makes them $6 \% 1 \mathrm{less}$ than those for FRP. 


\section{CONCLUSION}

\subsection{GENERAL FINDINGS}

Fiber-reinforced plastics can perform many of the structural functions of steel in automotive applications, but at a lighter weight. For this reason, FRP are a promising alternative in the ongoing effort in the United States to improve vehicle fuel oconomy by reducing vehicle weight. It is projected that average vehicle dry weight will be reduced $30 \%$ between 1977 and 1985 to meet 1985 CAFE requirements of $27.5 \mathrm{mph}$. Only about $18 \%$ of this weight reduction from $3750 \mathrm{lb}$ to $2600 \mathrm{lb}$ is expected to result from materials substitutions, because vehicle downsizing offers a more productive first alternative. After 1985, however, further decreases in vehicle weight are anticipated to result primarily from materials subslitut lons. Aluminum and FRP are the two matcrials expected to provide the stiffest compotition to steel. Steel manufacturess are responding by developing lightweight HSS that offer weight reductions that are slightly less than half those achievable with FRP or aluminum, but which maintain present production technology.

Fuel economy has been correlated with vehicle weight and aerodynamic drag for all U.S. automobile models over a period of years by DOT. For a gasoline vehicle weighing $3000 \mathrm{lb}$ and having a performance parameter of 0.03 $\mathrm{hp} / 1 \mathrm{~b}$, the effect of weight reduction (corrected for aerodynamic drag) is 9.3 x $10^{-6} \mathrm{gal} / \mathrm{mi} / 1 \mathrm{~b}$. Thus, assuming a vehicle lifetime of $100 \times 10^{3} \mathrm{mi}$, each pound of weight reduction saves $0.93 \mathrm{gal}$ of gasoline. In energy terms, this is equivalent to a savings of $116 \times 10^{3} \mathrm{Btu} / \mathrm{lb}$ of weight reduction.

The embodied energy, structural weight, and fuel economy (transporta$t$ ion energy) characteristics of steel, FRP, and aluminum were assessed to determine the overall energy saving achievable by materials oubstitution. In body panelo, a 1.0-1b steel component with an associated $0.51 \mathrm{~b}$ in secundary weight io equivalent to a 0.6-1b FRP component with an associaled 0.3-1b secondary weight or a $0 . b-1 b$ aluminum component with an associated $0.25-1 b$ secondary weight. (Because of its predominant usage, steel is assumed to be the secondary material in each case.) Table 5.1 summarizes the energy requirements of structurally equivalent automotive body panels. Fiberreinforced plastics offer the greatest improvements in both embodied and total

Table 5.1 Energy Requirements of Structurally Equivalent Automotive Body Panele, Inoluding Assuciared Second ary Weights $\left(10^{3}\right.$ Btu $)$

\begin{tabular}{lrrr}
\hline Energy Requirements & Steel & FRPa & Aluminum \\
\hline Life cycle transportation energy & 174.4 & 104.6 & 87.2 \\
Embodied energy & 37.2 & 22.1 & 87.2 \\
Total & 211.6 & 126.7 & 174.4 \\
\hline
\end{tabular}

asheet molding compound containing $30 \%$ (by weight) fiberglass. 
energy requirements. Aluminum, on the other hand, achieves the greatest savings in transportation energy, but this does not fully compensate for its large embodied energy requirements.

Table 5.2 summarizes the direct and tatal energy requirements for the three competing materials and identifies the petroleum requirements of each. This table is based on the average U.S. fuel usage of each industry and on current fuel requirements of electricity generation. If the electricity requirements of all new U.S. aluminum capacity were supplied by dedicated, base-load, coal-fired power plants, aluminum's petroleum consumption would be reduced to $4.0 \times 10^{3} \mathrm{Btu} / \mathrm{b}$, while its coal consumption would increase to $143.9 \times 10^{3} \mathrm{Btu} / 1 \mathrm{~b}$.

\subsection{RESEARCH AND DEVELOPMENT NEEDS}

Industry representatives indicated that the most significant constraints to greater use of FRP were (1) inadequate processing techniques (poor surface quality, low production rates, and undeveloped assembly techniques), (2) lack of a product characterization data base (uncertain energy absorption characteristics and inadequate knowledge of material properties), and (3) lack of recyclability (little progress is anticipated for the foreseeable future). Appropriate objectives of FRP research and development activity in these and other areas are summarized in Table 5.3.

Although some research and development effort is underway in each of these areas, it is of 1 imited scope. For the most part, the automotive industry is focused on attaining the 1985 CAFE standards via vehicle downsizing.* Extensive materials substitution will probably be delayed until the

Table 5.2 Summary of Fuel Requirements of Stee1, Fiber-Reinforced Plastics, and Aluminum Components ( $10^{3} \mathrm{Btu} / \mathrm{lb}$ of component)

\begin{tabular}{lrrr}
\hline Energy Requirements & Steel & FRPa & Aluminum \\
\hline Direct energy & 22.58 & 18.34 & 70.28 \\
Electricity generationb & 2.22 & 6.04 & 91.61 \\
Total & 24.80 & 24.38 & 161.89 \\
Petroleum only. & 3.52 & 9.59 & 27.66 \\
\hline
\end{tabular}

asheet molding compound containing $30 \%$ (by weight) fiberglase.

b Fuel energy loss during electricity generation, assuming $34.12 \%$ thermal efficiency.

*Market competition, rather than the CAFE standards, has now become the driving force for achieving improved fuel economy. 
Table 5.3 objectives for Fiber-Reinforced Plastics

Research and Development

Materials

Resins. Faster curing resins with greater mechanical strength are needed. Although. UPE resins cure in $2 \mathrm{~min}$, they are somewhat weak mechanically. Epoxy resins are mechanically strong but take 30-60 win to cure, even when curing agents and accelerators are used. Vinyl esters represent a compromise, having the curing behavior of: polyesters with mechanical properties intermediate between polyester and epoxy resins.

Reinforcements. Replacements for fiberglass that are cost effective and stronger would enable greater weight reductions through the use of FRP, While rarbon/graphitc fibers aite prumising, it is unlikely that their costs can be reduced below $\$ 6-10 / 1 b$ in the foreseeable future. Achievement of even these costs will require switching to a material like pitch for the precursor material. Because of cost considerations, hybrid systems composed of both fiberglass and carbon/graphite fibers are likely to be adopted. Metal whiskers offer greater weight reductions, but at a cost far too great for automotive applications.

Fillers. Lighter weight fillers would be desirable. Although microspheres are lightweight, they tend to degrade surface quality.

Processing Techniques

Surface Finish. External automobile body panels require class A surface quality. Difficulties with FRP as regards porosity and thesual shrinkage, especially near reinforcing ribs, must he overcolle. In-mold urethane coatings help to offect porosity effects, and thermoplastic additives counteract thermal shrinkage. Mixed glass lengths $c$ an be used to achieve good surface quality (short. fibers) and mechanical strength (long fibcrs). The shorter fibers also flow into the reinforcing ribs.

Production Rate. A further need is to achieve rapid wetting, with a switt increase in viscosity after wetting. Alternatives include cooling after wetting, evaporating a low-viscosity solvent, and inducing a chemical reaction. Silane coatings on the fibers $c$ an unhance wetting yuality; charge preheating can reduce in-mold time; and rotating molds can reduce press utilization time.

Reproducibility. More than 150 variables must be adjusted during the process sequence from resin formulation to product molding. Microprocessor control is a promising way of controlling SMC formulation variables, such as resin thickness, glass fiber dispersal, and carrier film tension.

Scrappage Reduction. Scrappage should be kept at $5 \%$ or less for economic competitiveness. This must be done for complex parts 
Table 5.3 (Cont'd)

over the entire production run, including initial process adjustments.

Bonding and. Joining Methods. Significant advances are needed in rapid-curing bonding agents; methods of bond clamping during cure so that the manufacturing process can continue; and quick, nondestructive testing methods.

Reinforced Thermoplastics. Reinforced thermoplastics offer shorter cycle times, easier automation, and less post-mold finishing. Data must be developed on the rheological behavior of this fiber/resin system and on the mobility of fibers during the molding process.

Product Characterization

Analytical Techniques. Finite element analysis, computer-aided design, computer graphics, and other techniques are needed to take advantage of the strongly anisotropic characteristics of FRP.

Testing Procedures. High-speed, nondestructive testing methods are necessary for all phases of FRP utilization. Tests are needed for bond integrity, mechanical strength as a function of orientation, performance in adverse environments, and reinforcement dispersion.

Design Engineering Data. Performance characteristics must be established for all types of service and failure conditions.

Fundamental Properties. The interfacial bond between resin and reinforcement needs to be fully characterized.

more cost effective downsizing opportunities are exploited. This lack of emphasis on materials substitution plus cash shortages resuleing from Detroit's recent market difficulties. have severely restricted research and development funds in the materials area. A number of industry representatives stated that support from a governmental agency like the U.S. Department of Energy (DOE) could be extremely helpful and that savings in total energy through use of FRP components in automotive applications might justify such governmental activity. The objective would be to develop the necessary engineering data and production expertise over the next few years so that FRP could participate fully in the materials tradeoff decisions to be made in the mid-1980s. The government could play two complementary roles: (1) financial support, possibly including tax incentives, for FRP-related research and development within the industrial and academic communities and (2) in-house development of basic engineering data.

Most funding for FRP development not related to the automotive industry is provided by the National Aeronautics and Space Aduinistration (N $\Lambda S \Lambda$ ). Research and development programs are conducted at NASA laboratories, 
and NASA supports contract research at universities, nonprofit research centers, and within industry. Because this effort is devoted to low-volume aerospace applications, the results usually do not apply to high-volume, costcompetitive automotive applications. One could foresee, therefore, an agency like DOE performing a funding role similar to that of NASA, but for automotive applications. While all areas of research could reasonably be supported, development of improved processing techniques should be emphasized.

Because no large-scale research center now exists for FRP materials, the second governmental role, that of establishing a significant in-house FRP engineering data base, could have significant benefits. Without such an effort, it is unlikely that sufficient data will be gathered, even over 5 yr, to support widespread use of FRP. For example, the necessary mechanical testing would require months to conduct, possibly involving up to $100 \times 10^{6}$ cycles. Such a coordinated testing program of anisulropic pky materials involving more than. 150 variables cannot be significaully compressed. Thio typo of reseaich is long term and of a fundamental nature -- not the type of problem best handled by the automotive industry, which of necessity emphasizes optimal solutions to short-term problems using existing resources. Also, the limited research funds of the automotive firms will likely be directed to a myriad of other problems, such as development of new engines. In summary, potential benefit in terms of national energy resources seems to support direct governmental activity in the conduct of FRP-related exploratory engineering design. 


\section{REFERENCES}

1. Facts and Figures of the Plastics Industry, The Society of the Plastics Industry, Inc., New York, N.Y. (1977).

2. Compton, W.D., Materials Substitution in the Automotive Industry, Proc. ASME Winter Meeting, San Francisco (Dec. 1978).

3. General Motors Corporation, personal communications (1980).

4. Facts and Figures of the Plastics Industry, The Society of the Plastics Industry, Inc., New York, N.Y. (1981).

5. Price Hikes Bottled Up, Plastics Technology, 26(7):131-139 (June 1980).

6. PP.G Industries, Inc., personal communications (1979-1980).

7. Milewski, J.V., Short-Fiber Reinforcements: Where the Action Is, Plastics Compounding, pp. 17-37 (Nov./Dec. 1979).

8. Murphy, T.A., General Motors Corporation, Face the Nation television program (May 4, 1980).

9. Beardmore, P., et al., Fiber-Reinforced Composites: Engineered Structural Materials, Science, 208:833-840. (May 23, 1980).

10. Filzers: A Bigger Bargain for Improving Resins, Modern Plastics, 57(4): 84-85. (April 1980).

11. Combining Reinforcements for More Balanced Cost/Performance, Plastics Design Forum, 4(3):92-104 (May/June 1979).

12. Blumenfeld, M., A Reference Notebook for Plastics, Part 4 -- Molding Methods, I/D Magazine, pp. 66-67 and 78 (March/April 1979).

13. Blumenfeld, M., A Reference Notebook for Plastics, Part 5 -- Injection Molding, I/D Magazine, RP. 62-6.3 (.Inly/Aug. 1979).

14. Gaines, L.L., and S.Y. Shen, Energy and Materials Flows in the Production of Olefins and Their Derivatives, Argonne National Laboratory Report ANL/CNSV-9 (Aug. 1980).

15. Energy/Material Flows Associated with Cyclic Petrochemicals, prepared by H.M. Mittelhauser Corporation for Argonne National Laboratory, ANL/CNSV-TM-56 (Oct. 1979).

16. Owens Corning Fiberglas, personal communications (1979-1980).

17. Kaiser, R., Commercial Potential for Metal Matrix Composites, presented at 2nd Conf. on Carbon Fiber-Reinforced Metal Matrix Composites, Monterey, Calif. (May 11, 1978). 
18. Motor Vehicle Facts, and Figures ' 80 , Motor Vehicle Manufacturers Assn. of the United States, Inc., Detroit (1980).

19. Thornton, P.H., Energy Absorption on Composite Structures, J. Composite Materials, 13:247-262 (July 1979).

20. Aluminum Co. of America Price Sheet (June 1980).

21. Mahoney, L.R., J. Braslaw, and J.J. Harwood, Effect of Changing Automobile Materials on the Junk Car of the Future, SAE Paper No. 790299 (1979).

22. Perry's Chemical Engineer's Handbook, 4th ed., R.H. Perry, C.H. Chilton, and S.D. Kirkpatrick, eds., McGraw Hill, New York, N.Y. (1963).

23. Harwood, J.J., Ford Motor Company, Detroit, Mich, personal communication (Aug. 1980).

24. Commercial Opportunities for Advanced Composites, American Society for Testing and Materials Publication STP 704, A.A. Watts, ed., Philadelphia (1980).

25. Chang, D.C., and J.W. Justusson, Structural Requirements in Material Substitution for Car-Weight Reduction, SAE Trans., 85:66-78 (1976).

26. Chang, D.C., and R.P. Khetan, Cost-Effective Selection of Fiber Systems for Automotive Structural Composites, Proc. Advances in Material Technology in America -- 1980, Vol. 1, Materials Recovery and Utilization, pp. 51-56, ASME, New York, N.Y. (1980).

27. Kusik, C.L., et al., Life Cyrle Finergy Requirements for Soloctad Sheet Materials Applicable to Manufacture of Automobile Components, prepared for the American Iron and Steel Institute by Arthur D. Little, Inc. (Aug. 1979).

28. Hall, E.H., et al., Evaluation of the Theoretical Potential for Energy Conservation in Seven Basic Industries, prepared for Battelle Columbus Laboratories, Columbus, Ohio (1975).

29. Fotential for Energy Conservation in the Steel Industry, prepared by Battelle Columbus Laboratories for the U.S. Federal Energy Administration, Columbus, Ohio (May 1975).

30. Darby, J.B., Jr., and R.M. Arons, Energy and Materials Flows in the Fabrication of Iron and Steel Semifinished Products, Argonne National Laboratory Report ANL/CNSV-8 (Aug. 1979).

31. Arons, R., and A. Wolsky, Energy and Materials Flows in the Fabrication of Aluminum Products, Argonne. National Laboratory Report ANL/CNSV-3 (Aug. 1978).

32. Schollmeyer, H.E., The Packaging Game: Chess without Checkmate, presented at International Packaging Week Conf., Washington, D.C. (Oct. 9, 1979). 
33. Mineral Commodity Summamies, U.S. Dept. of Interior, Bureau of Mines (1981).

34. Shen, S.Y., Energy and Materials Flows in the Production of Primary Aluminum, Argonne- National Laboratory Report ANL/CNSV-21 (Oct. 1981).

35. Kaiser, R., Automotive Uses of Advanced Composite Materials Progress Report, Sept. 30, 1977 to Dec. 30, 1978, prepared by Argos Associates, Inc., for U.S. Dept. of Transportation (1978).

36. Hsia,.H., Energy Technology Branch, Transportation Systems Center, Cambridge, Mass :, personal communication (March 1981).

37. Potential of Spark Ignition Engine Effect of Vehicle Design Variables on Top Speed, Performance, and Fuel Economy, U.S. Dept. of Transportation Report DOT-TSC-NHTSA-79-53 (March 1979).

38. Chrysler Corporation, personal communications (1980).

39. Anrual Report to Congress, Vol. I, U.S. Dept. of Energy, EIA Report (1978).

40. Annual Report, Industrial Energy Efficiency Program, July 1977 through December 1978, U.S. Dept. of Energy Report DOE/CS/0111 (Dec. 1979).

41. Energy Data Report: Preliminary Power Production Fuel Consumption, and Installed Capacity Data for 1979, U.S. Dept. of Energy Report DOE/EIA-0049(79) (May 1980). 
Internal

T.G. Alston

J.G. Asbury

L. Burris

M.G. Chasanov

R.R. Cirillo

E.J. Croke

$\mathrm{J}$. Dzingel

A.R. Evans

B.R.T. Frost

L.L. Gaines

R.F. Giese

W.j. Hallett

W. Harrison
$\mathrm{H}: \mathrm{N}$. Hersh

A.S. Kennedy

W. H. Klausmeier

A.B. Krisciunas

M.L. Kyle

K.S. Macal

M. Millar

P.A. Nelson

E.G. Pewitt

J.J. Roberts

R.E. Rowl and

N.A. Sather

S.Y. Shen
B. Sullivan

T. Surles

M.W. Tisue

W.J. Walsh

R.W. Weeks

R.M. Wolosewicz

A.M. Wolsky (172)

ANL Contract Copy

ANL Libraries (-3)

ANL Patent Department

TIS Files (6)

\section{External}

U.S. Department of Energy Technical Information Center, for distribution per UC-95f (246)

Manager, U.S. Department of Energy Chicago Operations Office (DOE-CH)

President, Argonne Universities Association

Energy and Environmental Systems Division Review Committee:

E.E. Angino, University of Kansas

H.J. Barnett, Washington University

E.N. Castle, Resources for the Future, Inc.

R.L. Clodius, National Association of State Universities and Land Grant. Colleges

B.A. Egan, Environmental Research and Technology, Inc.

N.C. Mullins, Indiana University

W.N. Poundstone, Consolidation Coal Co.

J.J. Stukel, University of Illinois

J.J. Wortman, North Carolina State University

W. Basham, National Highway Traffic Safety Administration, Washington, D.C.

A.L. Bastone, Owens Corning Fiberglas, Granville, Ohio

D.C. Cassidy, General Motors Corp., Warren, Mich.

J.A. Clum, University of Wisconsin, Madison

C.N. Cochran, Aluminum Company of America, Alcoa Center, Penn.

P. Dickensheets, General-Motors Corp., Warren, Mich.

J.N. Epe1, Budd Company, Troy, Mich.

R. Ferguson, Owens Corning Fiberglas, Granville, Ohio

J.H. Gibbons, Office of Technology Assessment, U.S. Congress

F. Glasgow, Chrysler Corp., Detroit; Mich.

R. Harmon, Alexandria, Va.

R. Harrison, PPG Industries, Inc., Pittsburgh, Penn.

J.J. Harwood, Ford Motor Company, Dearborn, Mich. (2)

H.S. Hsia, Department of Transportation, Cambridge, Mass.

R. Kaiser, Argos Associates, Inc., Winchester, Mass.

D.E. Kash, University of Oklahoma.

A. Kasper, Reynolds Metal's Company, Southfield, Mich. 
E. Kottcamp, Bethlehem Steel Corp., Bethlehem, Penn.

C.L. Kusik, Arthur D. Little, Inc., Cambridge, Mass.

J.S. McDermott, The Society of the Plastics Industry, Inc., New York, N.Y.

L. Mims, Illinois Institute of Natural Gas Resources, Chicago

H.W. Paxton, U.S. Steel Corp., Pittsburgh, Penn.

I.E. Poston, General Motors Corp., Warren, Mich.

A.D. Rosenstein, Chrysler Corp., Detroit, Mich.

A.S. Russe11, Aluminum Co. of America, Pittsburgh, Penn.

B.A. Sanders, General Motors Corp., Warren, Mich.

R.R. Schuck, Republic Steel Corp., Independence, Ohio

R.W. Schueller, PPG Industries, Inc., Troy, Mich."

M.K. Singh, Downers Grove, Ill.

N. Smith, Aluminum Co. of America, Southfield, Mich.

C.D. Snyder, Owens Corning Fiberglas, Granville, Ohio

H.L. Taylor, Inl and Steel Research Laboratories, East Chicago, Ind.

J.J. Tribendis, Aluminum Company of America, Alcoa Center, Penn.

T. Willson, American Iron and Steel Institute, Washington, D.C. 